\title{
Orientation of community-based tourism programs towards sustainable tourism criteria in a newly established democracy: The case of CBT Kochkor, Kyrgyz Republic
}

Trent F. Milam

West Virginia University

Follow this and additional works at: https://researchrepository.wvu.edu/etd

\footnotetext{
Recommended Citation

Milam, Trent F., "Orientation of community-based tourism programs towards sustainable tourism criteria in a newly established democracy: The case of CBT Kochkor, Kyrgyz Republic" (2009). Graduate Theses, Dissertations, and Problem Reports. 4501.

https://researchrepository.wvu.edu/etd/4501

This Thesis is protected by copyright and/or related rights. It has been brought to you by the The Research Repository @ WVU with permission from the rights-holder(s). You are free to use this Thesis in any way that is permitted by the copyright and related rights legislation that applies to your use. For other uses you must obtain permission from the rights-holder(s) directly, unless additional rights are indicated by a Creative Commons license in the record and/ or on the work itself. This Thesis has been accepted for inclusion in WVU Graduate Theses, Dissertations, and Problem Reports collection by an authorized administrator of The Research Repository @ WVU. For more information, please contact researchrepository@mail.wvu.edu.
} 
Orientation of Community-Based Tourism Programs

Towards Sustainable Tourism Criteria in a Newly Established Democracy:

The Case of CBT Kochkor, Kyrgyz Republic

Trent F. Milam

Thesis submitted to the

Davis College of Agriculture, Natural Resources and Design,

Division of Forestry and Natural Resources,

at

West Virginia University

In partial fulfillment of the requirements for the degree of

Master of Science

in

Recreation, Parks, and Tourism Resources

Chad D. Pierskalla, Ph.D., Committee Chair

David A. Smaldone, Ph.D.

David W. McGill, Ph.D.

Recreation, Parks, and Tourism Resources Program

Morgantown, West Virginia

2009

Keywords: Sustainable Tourism, Ecotourism, Sustainable Development, Social Capital, Less Developed Countries, Kyrgyzstan 


\section{Abstract \\ Orientation of Community-Based Tourism Programs \\ Towards Sustainable Tourism Criteria in a Newly Established Democracy: The Case of CBT Kochkor, Kyrgyz Republic}

Trent F. Milam

Due to its limited scale, sustainable tourism in less developed countries remains a difficult case to study. However, even though these operations are challenged in capacity and financial strength, their efforts and results are worth recognition and consideration. This study evaluates the sustainable tourism organization known as CBT Kochkor, a locally managed and staffed organization whose mission is to assist rural citizens in the post-Soviet country of Kyrgyzstan during its transition to a free market economy. Created under the tenets of sustainable tourism, CBT Kochkor provides income generation opportunities through community employment while minimally affecting the resource's natural environment and indigenous cultures. This study will evaluate CBT Kochkor through semi-structured open-ended interviews with CBT community members in the village of Kochkor, to develop an organizational history of CBT Kochkor and determine their progress towards their sustainable tourism goals. Based on the findings of this study, CBT Kochkor's status, in relation to binding and bridging social capital, is provided in light of current sustainable tourism criteria.

From these criteria, recommendations for program capacity development are provided in correlation to structural and ecological program development. Intended as a developmental resource for CBT Kochkor, this study will also provide researchers, rural communities, NGOs with an analytical tool for small-scale program assessment. Implications are also raised concerning the difficulties of evaluating a small-scale tourism due to small sample sizes. Because sustainable tourism in less developed countries rarely exists on a large scale, the theories utilized in this study require further application to small-scale sustainable tourism organizations in a variety of less developed countries. Questions that arose from this study in relation to further use of this model are 1) is measuring community participation a valid meter for the y-axis? 2) How accurate does the community participation model relate to the capacity elements of a tourism area lifecycle curve? 3) If an organization places off the curve in the results, are there better methods for CBT Kochkor to reorient itself? Based on the study's findings, the following areas merit further research: 1) the salience of this method for a larger study or with sustainable tourism organizations in other less developed countries, 2) methods to validate the accuracy of community participation levels, and 3) a contrast and comparison of ecotourism concepts between the West and the former Soviet Union. 
Table of Contents

Abstract

Table of Contents

List of Tables

iv

List of Figures

iv

Acknowledgements

V

Chapter One - Introduction

History and Background of the Problem

1

Kyrgyz Community Based Tourism Association

2

Research Questions

Delimitations

Limitations

Definition of Terms

Significance of Study

Chapter Two - Literature Review

Global Tourism and a Call for Change $\quad 8$

Sustainable Tourism $\quad 9$

Global Sustainable Tourism Criteria $\quad 11$

Social Capital $\quad 12$

Community Collaboration 14

Community Participation $\quad 18$

Tourism Area Cycle of Evolution $\quad 20$

$\begin{array}{ll}\text { Summary } & 22\end{array}$

Chapter Three - Methodology 23

$\begin{array}{ll}\text { Study Design } & 23\end{array}$

Sampling Method $\quad 24$

Instrument Design $\quad 26$

$\begin{array}{ll}\text { Data Treatment } & 26\end{array}$

$\begin{array}{ll}\text { Chapter Four - Findings } & 28\end{array}$

Demographics $\quad 29$

Results of Study 31

Chapter Five - Discussion, Recommendations, and Conclusion 46

$\begin{array}{ll}\text { Discussion } & 47\end{array}$

Current Position and Implications $\quad 54$

Recommendations $\quad 56$

$\begin{array}{ll}\text { Conclusion } & 59\end{array}$

$\begin{array}{ll}\text { References } & 60\end{array}$

$\begin{array}{ll}\text { Appendix } & 64\end{array}$ 


\section{List of Tables}

Table 2.1 Sustainable Tourism Definition / Convergence Position Correlations

Table 4.1 CBT Kochkor Participant Demographics

\section{List of Figures}

Figure 2.1 Convergence Position 11

Figure 2.2 Community Based Tourism Social Capital Assessment Model 14

$\begin{array}{lll}\text { Figure 2.3 Evolutionary Tourism Partnership Model } & 15\end{array}$

Figure 2.4 Ladder of Citizen Participation $\quad 19$

$\begin{array}{lll}\text { Figure 2.5 Tourism Area Lifecycle } & 21\end{array}$

$\begin{array}{lll}\text { Figure 3.1 Sampling Criteria Hierarchy } & 25\end{array}$

Figure 4.1 CBT Kochkor Organizational Structure $\quad 41$

Figure 5.1 Citizen Participation Mean Scores 55

Figure 5.2 Current position of CBT Kochkor in relation to tourism lifecycle curve 57 


\section{Acknowledgements}

I would like to first thank my wife for her incredible support during this entire process. You have been such a wonder and a blessing in my life. Chong rahkmat menin jol-dosum, siz daima jorukumdo jashiat! Next, I would like to thank Dr. Chad Pierskalla for providing me with the opportunity to contribute to the body of sustainable tourism research. Your attention to the smaller details allowed for a smooth and successful data collection in a very short amount of time. Also, a big thank you to my parents and in-laws who have given me so much encouragement over the years. I would also like to thank my thesis committee for your wonderful feedback and patience while this research developed over time. Finally, thank you to the CBT Kochkor community for your hospitality and eagerness to participate in this research. I would like to state that although this is a critical assessment of CBT Kochkor's performance and I may seem at times to pass harsh judgment on the organization, I would like to recognize that what CBT Kochkor has achieved was done so with scarce resources and extensive sacrifice of time and energy from its members. My purpose for this study was to provide CBT Kochkor with access to a professional program evaluation that commonly is not available to small-scale tourism organizations. Throughout the study, I have done my best to provide anonymity to all the participants by altering their names. 


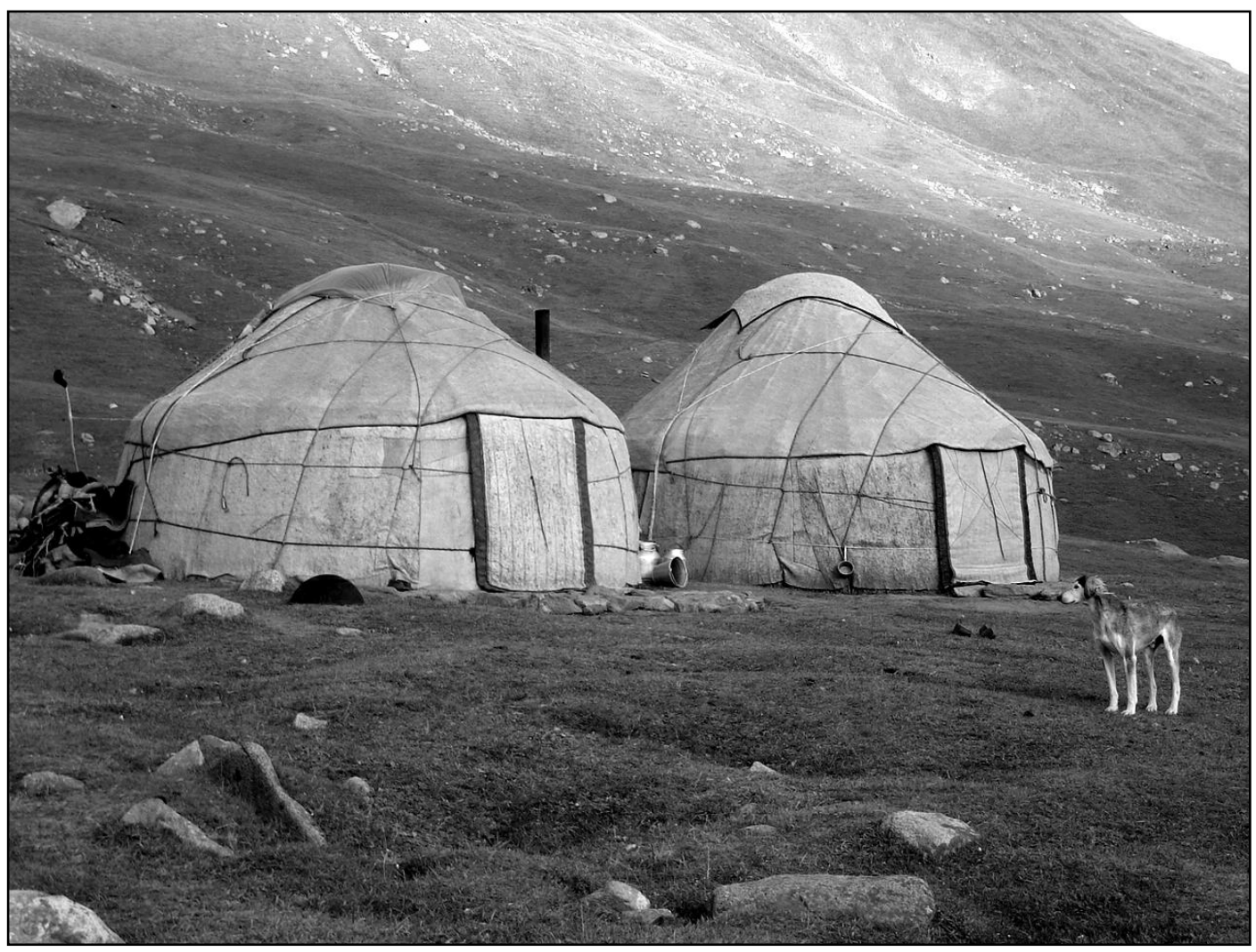

Yurt-stay at Kul Ukuk Lake, Kochkor Raion, Naryn Oblast, Kyrgyzstan 


\section{Chapter One}

\section{Introduction}

This research project will evaluate program orientation towards the sustainable tourism goals of the Kyrgyz community-based tourism organization CBT Kochkor and provide recommendations to continue its progress towards these goals. This line of inquiry started during my service in the Peace Corps from 2005 to 2007. During this time, I became friends with the CBT community as I utilized their services throughout my independent Peace Corps project work and my personal vacation time. CBT's mission is to assist rural citizens in the post-Soviet country of Kyrgyzstan during its transition to a free market economy (Helvetas Community Based Tourism Development Project, 2005).

Created under the tenets of sustainable tourism (The Global Development Research Center, 2008), CBT provides income generation opportunities through community employment while minimally affecting the natural environment and indigenous cultures. This research will evaluate CBT Kochkor to determine the program's progress towards their sustainable tourism goals via naturalistic inquiry, collection of qualitative data, and content analysis of the CBT community members' perceptions of program performance. Through semi-structured and open-ended interviews, inquiries were made into CBT Kochkor community members' experiences with their organization's development and how they perceive interactions between their community and CBT management. Comparison of these results to a modified tourism lifecycle (illustrated as a logistic curve) will be made to assist the organization's progress towards their sustainable tourism goals. 
History and Background of the Problem

Kyrgyzstan is the second smallest country in Central Asia and shares 533 miles of border with northwestern China. Located 1800 miles away from the former Soviet Union capitol, Moscow, this mountainous land has over 198,000 square kilometers, which is slightly larger than the state of South Dakota. As of 2006, Kyrgyzstan's population was approximately 5,213,898 with an average life expectancy of 69.12 years (Central Intelligence Agency, 2008) (Curtis, 2007). Despite its small size, Kyrgyzstan's ethnic make-up is extremely diverse, 65 percent of the population is Kyrgyz, 14 percent is Uzbek, and 13 percent Russian. The remaining 8 percent is comprised of a mixture of Tartar, Dungan, Uyghur, Ukrainian, German, and Tajik. Eighty percent of Kyrgyzstan's citizens are Sunni Muslim with the other 20 percent made up of Russian Orthodox and Protestant Christians (Curtis, 2007).

August $31^{\text {st }}, 1991$ marked a major event in the history of Kyrgyzstan. After unrest in various regions throughout the Soviet Union, a coup in Moscow against the regime of Mikhail Gorbachev failed. This move against the central government motivated the Kyrgyz power structure to declare independence from the U.S.S.R. Kyrgyzstan also saw during that time the election of the only president in the Central Asian region not backed by the communist party, a physicist named Askar Akayev (Central Intelligence Agency, 2008).

During the Soviet era, Kyrgyzstan's economy was centralized and dependent on other Soviet states for trade (Thompson \& Foster, 2003). After the collapse of the Soviet Union, due to a combination of remoteness, poor infrastructure and lack of resources, Kyrgyzstan's economy began to decline (Thompson, 2004). By 1993, the unemployment rate on the surface appeared to be at a favorable two percent, however more in-depth studies by the International Labor Organization (ILO) showed it to be closer to ten percent. Unfortunately, because neither reports 
were willing or able to take into account the significant numbers of employed state workers that did not receive pay, these numbers cannot show an accurate representation of Kyrgyzstan's depressed economy at that time (Namazie \& Sanfey, 1998). In the following years, later reports from the ILO show greater transparency from government unemployment reports showing unemployment rates up to seventy-seven percent (International Labor Organization, 2008).

As for President Akayev, soon it became evident that non-party affiliation did not guarantee honesty. Akayev, through policy changes, secured immunity from prosecution for himself and his family and increased the executive branch's power through suppression of opposition. After several years of questionable elections, in March 2005, massive groups of protesters from around the country converged on the capitol, causing Akayev to flee to Russia and into exile (Curtis, 2007).

The leader of the so-called 'Tulip Revolution', Kurmanbek Bakiyev, formed an interim government and served as president and prime minister until emergency elections later that July. Bakiyev ran for President and won, but was unable to gain parliamentary approval of his cabinet until five months later (Curtis, 2007). After several attempts to resolve a constitution, Bakiyev declared in 2007, that all previous versions of the Kyrgyz constitution were illegal and instituted a modified constitution from the Akayev era. He then dissolved parliament and called for an early election to reform the parliamentary structure (Central Intelligence Agency, 2008). The President's own party, the Ak-jol Party, questionably gained the majority and the U.S. State Department expressed deep concern about the conduct of the elections, citing several issues including widespread vote count irregularities and exaggerations in voter turnout (McCormack, 2007). Some of the current problems that Kyrgyzstan faces today are universal throughout the 
Commonwealth of Independent States, namely lack of political freedom, widespread corruption, and negative influences on democracy (Central Intelligence Agency, 2008).

Kyrgyz Community Based Tourism Association

Prior to CBT Kochkor's establishment, the village of Kochkor along with the whole of the Soviet Union was suffering from the effects of a complete economic collapse due to the disintegration of the Soviet government. CBT Kochkor began in 1997 as the Women Promotion Project with financial and managerial assistance from the Swiss international aid organization Helvetas, to familiarize rural women with free market economic principles. After three years of successful training and mixed results at creating start-up businesses, the project moved into its third phase and was renamed the Business Promotion Project and was restructured to build capacity for rural businesses. In 2003, the project was renamed again, this time as the Community Based Tourism Support Project. This occurred three years after having successfully establishing the first rural CBT office in the village of Kochkor (Raeva, 2008).

Today, there are eighteen other CBT offices located throughout Kyrgyzstan working towards their mission to, "contribute to the local economic development through increasing socially and economically sustainable tourism revenues while relying on stakeholder participation" (Kyrgyz Community Based Tourism Association, 2007). Although CBT has seen an increase in tourism service provisions from 2006 to 2007, the organization has concerns for its financial sustainability that could seriously affect its future success (Kyrgyz Community Based Tourism Association, 2008).

CBT's organizational design is to provide two primary services; outfitting and hospitality services for visitors to Kyrgyzstan and sustainable development opportunities for rural citizens in 
relation to tourism. Historically, non-governmental organizations (NGO) in Kyrgyzstan have not performed well. By 2000, fed by an influx of international aid, there were hundreds of NGOs mushrooming around the country. However, only 180 were officially registered and only five of those were fulfilling their mission statements. Due to lack of oversight, many of these NGOs received unmonitored funding. The result of this unregulated distribution was too little funding for too many organizations combined with no incentive for accountability (Connery, 2000).

\section{Research Questions}

This study will look for answers to the following questions:

- What is CBT Kochkor's citizen participation level between community members and CBT management?

- What is CBT Kochkor's stage of community partnership towards sustainable tourism goals?

- How do these social capital elements relate to contemporary sustainable tourism criteria?

\section{Delimitations}

This study was delimited to Kyrgyz Community Based Tourism Association member families, tourist guides, and taxi drivers available and willing to volunteer for interviews between the days of May $20^{\text {th }}$ to $30^{\text {th }}, 2009$. 


\section{Limitations}

This study was conducted with the CBT Kochkor community that is located in the regional center, various satellite villages, and yurts camps within the Kochkor raion of Naryn oblast, located in the central mountainous region of the country of Kyrgyzstan.

The following are the limitations that apply to this study:

1. The researcher will rely on a translator to communicate the instrument's questions to the participants and certain nuances of meaning might be lost in translation.

2. The political, environmental, social, and cultural conditions of the village of Kochkor and Kyrgyzstan overall are unique. The findings of this study will represent only one of eighteen Kyrgyz Community Based Tourism Association regional offices and may not be representative of the Association on a national level, or sustainable tourism organizations within the Central Asian region, or in other developing countries.

\section{Definitions of Terms}

aiyul ukmutu - The Kyrgyz word for village government or mayor.

jailoo - The Kyrgyz word for mountain pasture.

kymys - A traditional Kyrgyz drink made from the fermented milk of mares.

oblast - An administrative and territorial division in Russia, Ukraine, Belarus, and the former USSR, comparable to a U.S. state. 
raion - An administrative regional subdivision of post-Soviet states, a subdivision of an oblast or district of a city, comparable to a U.S. county or borough.

shyrdak - A colorful hand-made felt rug traditionally used to adorn yurts, but also found in village households. Usually comprised of a positive and negative color field with Kyrgyz symbols incorporated into the design.

som - The Kyrgyz monetary denomination, approximately 40 som equal 1 USD.

yurt - A portable circular domed structure covered with felt panels used as shelter by the nomadic peoples of Central Asia and Mongolia.

Significance of Study

This study's evaluation of CBT Kochkor's sustainable tourism goals orientation will contribute to the body of sustainable development and sustainable tourism research and lead to a formative evaluation that will assist CBT Kochkor in program advancement and capacity building. 


\section{Chapter Two}

\section{Literature Review}

This study will specifically evaluate the performance of the sustainable tourism organization, CBT Kochkor. Established twelve years ago in the post-Soviet country of Kyrgyzstan, this locally managed organization provides sustainable benefits for the village of Kochkor as it enters into a free market economy. Because the recently established and questionably democratic government of Kyrgyzstan is still in the flux of developing a constitution and forming supporting infrastructures, locally run (but internationally funded) NGOs have stepped up to provide the social and economic benefits required in Kyrgyz rural communities; such as adult education, income generation opportunities, and land-law development. However, this altruism is not without its own unique problems, namely corruption and misuse of funds (Connery, 2000).

Sustainable tourism development was one of the first forms of grassroots NGO activity seen in the village of Kochkor. Since 1997, CBT Kochkor has successfully navigated through the difficult waters of corruption that plague and bring down most Kyrgyz NGOs. As national tourism has grown in Kyrgyzstan, CBT Kochkor has been able to maintain and build capacity to serve both visitors to Kyrgyzstan and the members of CBT Kochkor.

\section{Global Tourism and a Call for Change}

Tourism is the largest business segment in the world with a claim to more than 230 million jobs, embodying $8.3 \%$ of worldwide employment. In 2007, global tourism and travel produced over 7 trillion USD and should increase to over 13 trillion in the next decade (World Travel and 
Tourism Council, 2007). Yet for all its financial good, in the early 80s, tourism along with other forms of unhindered development were found to be contributing to the diminishment of environmental and cultural resources around the world. In 1983, the Brundtland Commission called for a new method of development that would not merely act as damage control, but would anticipate and inhibit environmental damage by producing policies in a holistic manner without conceding the availability of future resources (United Nations World Commission on Environment and Development, 1987).

Nine years later, in response to the Brundtland Report, 172 world governments and over 2000 NGOs participated in the first Earth Summit in Rio de Janeiro, Brazil. After addressing the need for eco-efficiency involving present patterns of production, needs for alternative sources of energy and more public transportation, and the confirmation of a growing scarcity of clean water, the participating governments adopted Agenda 21 as a format to achieve world-wide sustainable development (United Nations, 1997). Backed by the strength of the Earth Summit and Agenda 21, in December 1992, the United Nations passed General Assembly Resolution A/RES/47/191, which established the Commission on Sustainable Development that would promote the principles of Agenda 21 by providing “access to and transfer of environmentally sound technologies and corresponding know-how" (United Nations, 2008).

\section{Sustainable Tourism}

Since the mid-70s, the definition of sustainable tourism has and still encounters much debate. It has been expressed simply as an ideal condition that all types of tourism should realize (Clarke, 1997; Weaver, 2005) and elaborately as a form of "responsible tourism that is both ecologically and culturally sensitive' (The Global Development Research Center, 2008). For the 
purposes of this paper, sustainable tourism will be defined, according to the World Tourism Organization (2004) concept, as being a type of tourism that:

1) Makes optimal use of environmental resources that constitute a key element in tourism development, maintaining essential ecological processes and helping to conserve natural heritage and biodiversity.

2) Respects the socio-cultural authenticity of host communities, conserves their living cultural heritage and traditional values, and contributes to inter-cultural understanding and tolerance.

3) Ensures viable, long-term, economic operations, while providing fairly distributed socio-economic benefits to all stakeholders; including stable employment, income-earning opportunities, social services to host communities, and poverty alleviation.

As concise as this definition may seem, its interpretation has significantly altered over time through debate and revision. Clarke (1997) chronologically categorized sustainable tourism's development into four sequential positions, Polar Opposites, Continuиm, Movement, and finally Convergence (Figure 2.1). The latter position states that the tourism provider subjectively defines sustainable tourism. In addition, sustainable tourism is a goal that all forms of tourism should strive for, rather than a label or certification possessed by an elite group. 


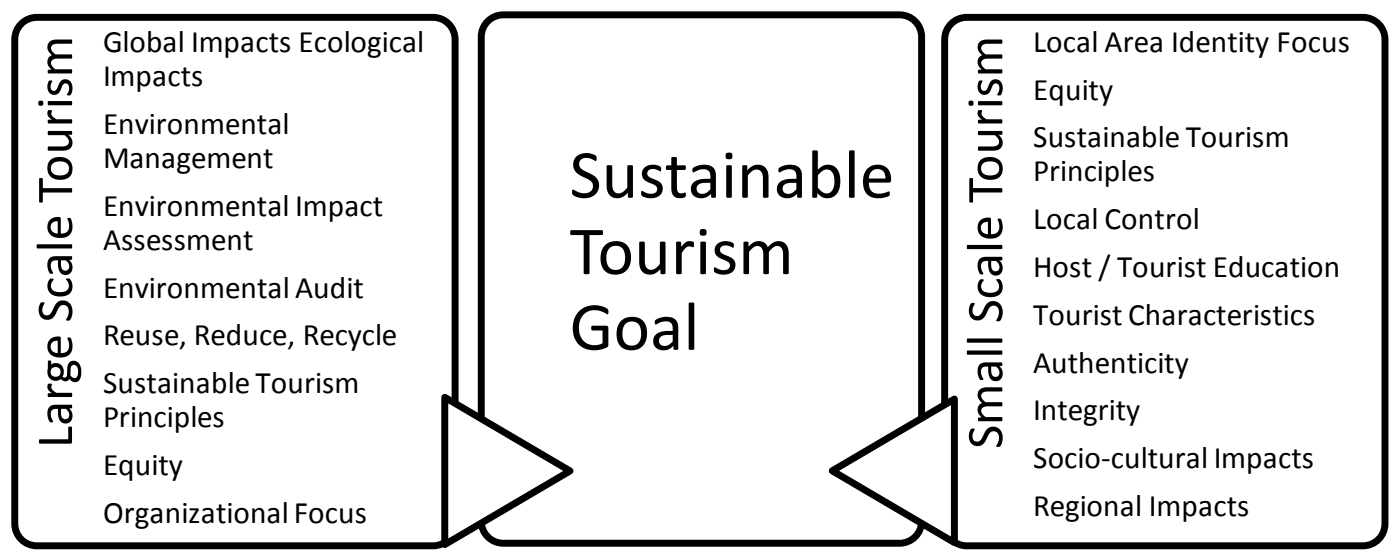

Figure 2.1 - Convergence Position (Clarke, 1997)

The Convergence position also provides size appropriate goal sets for large and small-scale tourism operations that can assist in sustainable tourism goal orientation. For small-scale tourism, this goal set's composition is based on more traditional concepts of sustainable development. When compared to this study's established sustainable tourism definition, eight out of the ten concepts directly relate. Grouped accordingly, these eight concepts fall under the themes of resource conservation, socio-cultural preservation, and fair economic development (Table 2.1).

Table 2.1

Sustainable Tourism Definition / Convergence Position Correlations

\begin{tabular}{|ccc|}
\hline Resource Conservation & Socio-cultural Preservation & Fair Economic Development \\
Regional Impacts & Local Area Identity Focus & Equity \\
& Host / Tourist Education & Integrity \\
& Authenticity & Local Control \\
& Socio-cultural impacts &
\end{tabular}




\section{Global Sustainable Tourism Criteria}

Conceived by the Partnership for Global Sustainable Tourism Criteria, a consortium of approximately forty-five organizations, the Global Sustainable Tourism Criteria is an international attempt to concede on the meaning and methods of sustainable tourism (Partnership for Global Sustainable Tourism Criteria, 2008). Developed and reviewed by consulting sustainable tourism industry experts and certification organizations, the intention of these criteria are to serve as guidelines for tourism and travel entities to become more sustainable, as a tool to assist travelers in choosing sustainable tourism services, and to act as a reference for media and institutions of higher education. The criteria outline four major themes for sustainable tourism; sustainable management, socio-economic benefits, cultural heritage preservation, and environmental conservation. Further detail is provided for each theme as recommendations and guidelines on how participating tourism entities can utilize these criteria to become more sustainable.

\section{Social Capital}

Capital is largely an economic theory that was first used as a sociological concept by Bourdieu (1986) to explain the economic, cultural, social and symbolic factors of a community that facilitate implementation or restriction of relative activities. Because of CBT Kochkor's role as a social organization in its community, the aspect of social capital shall be the focal point for this study, which Putnam (2000) defines as the "connections among individuals" and the "social networks and the norms of reciprocity and trustworthiness that arise from them". Concisely, social capital is that which allows a community to operate socially. Woolcock and Narayan (2000) further categorized these 
social networks and norms into four approaches, the communitarian, network, institutional and synergy approaches. The communitarian approach refers to social capital related to community organizations such as clubs, associations, or civic groups, of which CBT Kochkor is an example. For community program evaluations, social capital is particularly useful because of its ability to measure the scale that a community can collaborate and accomplish tasks. The sum of social capital available directly influences degrees of trust, reciprocity, economic and political access in a community (Buckland, 1998).

For a community to be able to access the necessary social capital for accomplishing tasks, these systems require a synergistic approach of collaboration between the community and institutions that directly affect it (Woolcock and Narayan, 2000). Okazaki (2008) determined that this mutual collaboration exists in forms of linking social capital and bridging social capital and related to the current standing of a community in respect to the tourism area life cycle (Figure 2.2). Bridging social capital are the descriptive elements that develop and transform over time and occur within the community to establish relationships between associated members. Linking social capital are the variables that influence levels of community participation and redistribution of power to the community from regional institutions and authorities (Macbeth et al., 2004; Okozaki, 2008). 


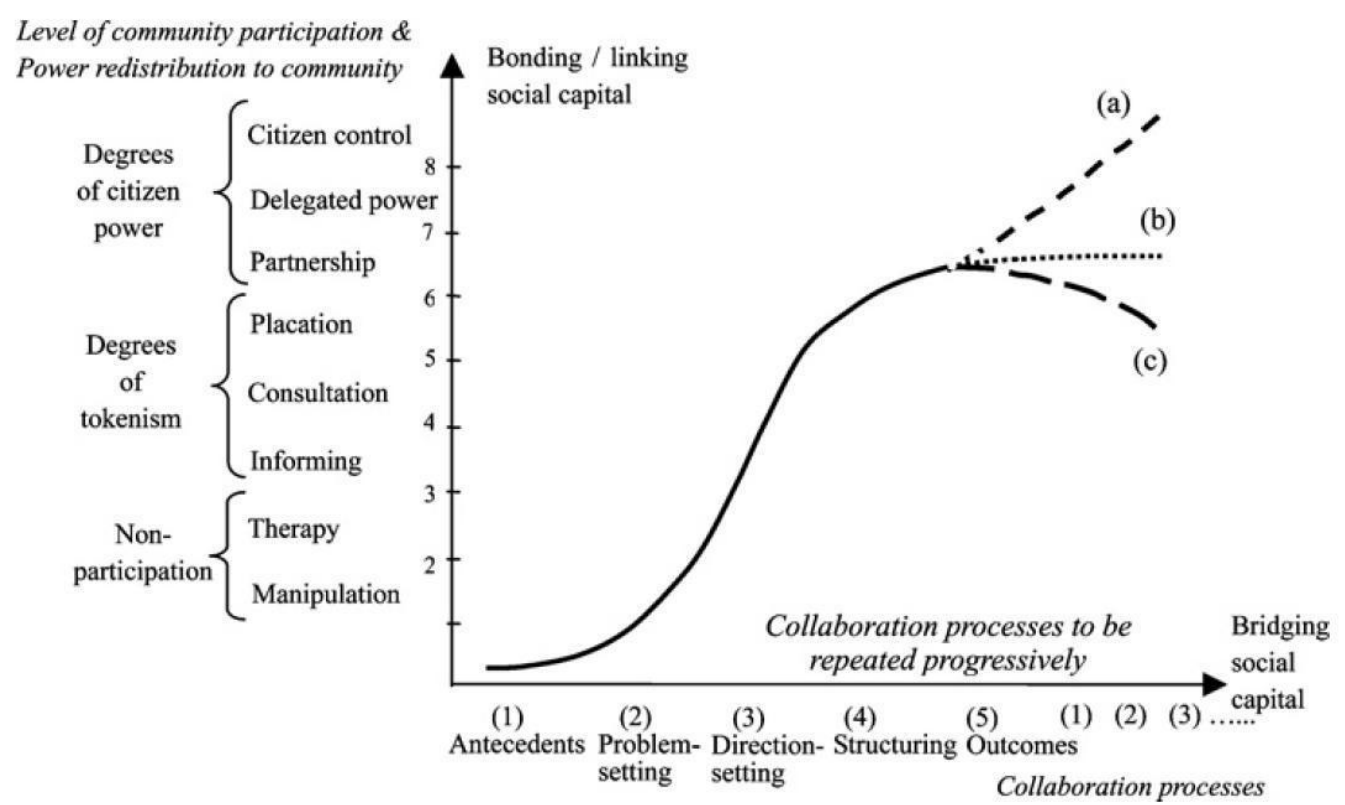

Figure 2.2 - Community Based Tourism Social Capital Assessment Model (Okozaki, 2008)

\section{Community Collaboration}

To provide needed empirical human dimensions research into the partnerships process, Selin and Chavez (1995) developed a domain level, process-oriented conceptual framework that examines partnerships as a management strategy and as a theoretical construct. This process, condensed into five dynamic stages, longitudinally represents the partnership life cycle and the conditions required for sustaining progress. These stages, begin with Antecedents, then ProblemSetting, Direction-Setting, Structuring, and finally Outcomes (Figure 2.3).

The Antecedents stage depicts the primary events, actors and motives that establish partnerships. Events that could bring about a partnership are mandates from power-holders or crises that highlight the need for partnerships. Actors that can influence the forming of partnerships could exist as; a broker that intervenes on behalf of stakeholders, or existing networks that provide stakeholders with natural organizational capacity building opportunities, 
and strong leadership from individuals who can act as catalysts. However, these events and actors require motivation to progress to further stages and can occur as a common vision of the outcomes of partnership or as incentives that motivate stakeholders into action.

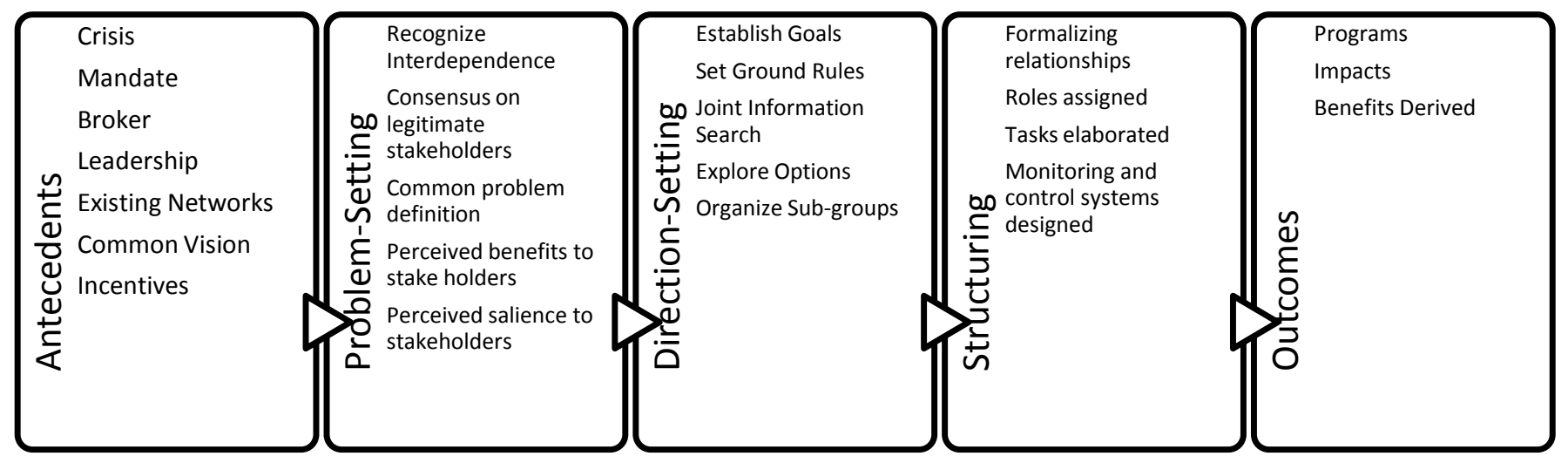

Figure 2.3 - Evolutionary Tourism Partnership Model (Selin \& Chavez, 1995)

During Problem-setting, who the stakeholders are and what is at stake is ascertained.

Through self-identification within the community or a realization of mutual relations within the problem framework, stakeholdership is established. Establishing exactly what is at stake for the community requires them to define the problem as a group, then each stakeholder needs to ask themselves how they will benefit from the partnership. If the benefits outweigh the cost, then the stakeholder will support the partnership into the next stage.

During the Direction-setting stage, there needs to be an investigation into the future of the partnership and its organizational structure. Then the partnership's structure grows through goal development, along with the creation of sub-groups representative to achieving those goals. Next, ground rules are agreed on to assist further progress. At this point, the partnership can systematically collect information about how to achieve desired outcomes and explore options to assist the partnership towards those outcomes. 
Once the partnership has begun to move towards those outcomes, the Structuring stage happens first with formalized relationships through regulatory frameworks that provide guidance for further collective actions. Second, internal regulatory systems are designed to monitor the partnership framework. Then, roles identified and assigned from the regulatory framework to achieve the desired outcomes to the members of the partnership. Then the tasks to further move the partnership towards the mission goals are elaborated.

In the final stage of Outcomes, those tasks evolve into programs created to provide alleviation or change the issues identified in the Antecedent and Problem-setting stage. These programs and partnership impacts undergo an evaluation to determine if perceived benefits have transpired. Although this model provides a clear outline of the common attributes of successful partnerships, it cannot dutifully represent the motivational forces of constant feedback and revisiting issues that cultivate them. Nor can it take into account the constraints of competition, bureaucratic inertia, and organizational fragmentation that can occur in partnerships.

Darrow and Vaske (1995) also summarize partnership criteria from the limited natural resource collaboration literature into three phases that are similar to Selin and Chavez's (1995) community collaboration model: 1) initiation, 2) planning, and 3) implementation/evaluation.

Like the Antecedents and Problem-setting stages proposed by Selin and Chavez (1995), the Initiation Phase originates from economic crises, mandates, or other motivators. Natural resource agencies seem to be more susceptible to the need for careful partner selection. After potential partners are identified and preliminary agreements are made, these agreements provide the opportunity to see how well these new partners can function as a group. 
The Planning Phase corresponds to the Direction-setting and Structuring stages of the Selin and Chavez (1995) model where more formal partnerships begin. In initial meetings, leadership roles are recognized and strategic plans are formed. For natural resource organizations, this stage is extremely convoluted because of the variety of financial, organizational, and legal arrangements involved with partnerships.

Darrow and Vaske (1995) also summarized partnership criteria from the limited natural resource collaboration literature into three phases that are similar to Selin and Chavez's community collaboration model: 1) initiation, 2) planning, and 3) implementation/evaluation. Like the Antecedents and Problem-setting stages proposed by Selin and Chavez (1995), the Initiation Phase originates from economic crises, mandates, or other motivators. Natural resource agencies seem to be more susceptible to the need for careful partner selection. After the field of potential partners are identified and preliminary agreements are made, these agreements then provide the opportunity to see how well these new partners can function as a group.

The Planning Phase corresponds to the Direction-setting and Structuring stages of the Selin and Chavez (1995) model where more formal partnerships begin. In initial meetings, leadership roles are recognized and strategic plans are formed. For natural resource organizations, this stage is extremely convoluted because of the variety of financial, organizational, and legal arrangements involved with partnerships.

While the Implementation phase of Darrow and Vaske's (1995) framework corresponds to the Outcomes stage of the Selin and Chavez (1995) model, the Evaluation Phase is not addressed. For this phase to succeed, ongoing evaluation and monitoring needs to be initially planned into the partnership along with marketing plans. As the partnership cycle concludes, the 
stakeholders can contemplate three things: 1) continuing the partnership, 2) extending the partnership to include new stakeholders, or 3) ceasing the partnership.

\section{Community Participation}

Contemporary concepts of community participation in policy and management arose from Arnstein's (1969) study of citizen reactions to the various Community Action Programs and Citizen Advisory Committees brought about by the Economic Opportunities Act of 1964. In this study, the relationships between "power-holders" and the "have-nots" are presented as eight rungs on a ladder of participation (Figure 2.4), with citizens taking greater control as they progressed up the rungs. To better illustrate the relationships between the rungs, they are grouped in three themes, from bottom to top, they are Non-participation, Tokenism, and Citizen Power.

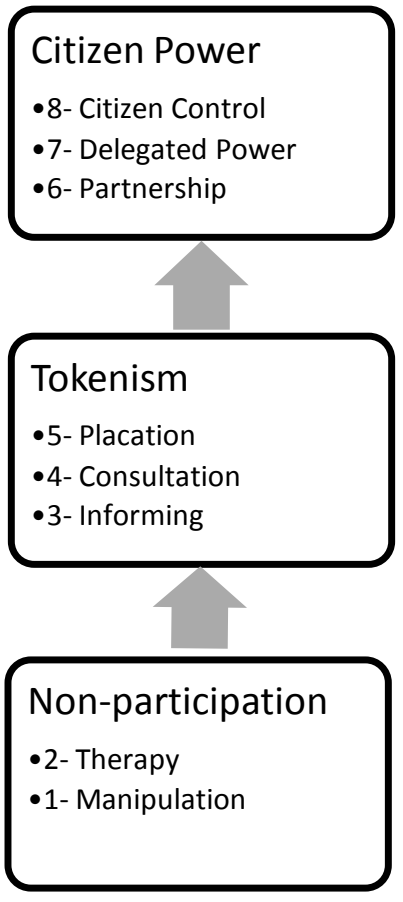

Figure 2.4 - Ladder of Citizen Participation (Arnstein, 1969) 
Non-participation, the lowest group, contains only two of the eight rungs; manipulation and therapy. The first rung, Manipulation, is the lowest level of community participation and exists when the power-holder altogether dictates to a community how they should support a program, without providing opportunities for input. Therapy, the next rung up, occurs when power-holders involve a community with a program only in order to alleviate issues instead of altering poorly functioning social structures.

Divided into three rungs, the middle group, Tokenism, contains Informing, Consultation, and Placation. The third rung, Informing, is where the power-holders inform the community of their rights and responsibilities, yet still are not provided with means of expressing opinions or influencing policy. The forth rung, Consultation, is where the community is sought after for opinions for polling reasons, but they are still not supported by policy at this point. The last rung of the Tokenism group, Placation, is the threshold of community empowerment. Backed by policy at this point; however, the power-holders retain decision-making.

Citizen Power, the highest group, also consists of three rungs Partnership, Delegated Power, and Citizen Control. At Partnership, the relationship between power-holders and the community more equally distributed in both policy and executive responsibilities. Delegated Power demonstrates negotiation between the community and power-holders as to who will control various program components. The final rung, Citizen Control, ideally has the community maintaining control virtually over all levels of program policy and management.

From the start, Arnstein states that in reality, the relationships and divisions between those who have and have-not are far more complex, diverse and numerous than illustrated in this abstraction. In addition, the ladder does not take into account such barriers as race or economic 
status. It exists, however, to provide a framework to evaluate and challenge the status-quo and move further towards citizen empowerment.

\section{Tourism Area Cycle of Evolution}

In response to early tourist motivation research that sought to categorize tourist experiences in static linear models, Butler (1980) developed a conceptual model of the tourism area lifecycle, based on the product life cycle model and incorporated capacity elements with a development continuum to measure the growth, maturity and decline of tourism destinations (Figure 2.5). Rebranding these traditional business concepts in a tourism framework, Butler presented the stages of a tourism destination's life as Exploration, Investigation, Development, Consolidation, Stagnation, and Rejuvenation / Plateau / Decline.

This S-curve begins with the exploration of a potential tourism destination as people who feel that they have found something special investigate this unknown area. As the word gets out, regional development occurs to increase visitor capacity. As the destination reaches it capacity for development, regional consolidation of the tourism industry settles in. Growth then stagnates and depending on the actions of the regional tourism industry it will either rejuvenate into a new growth cycle, plateau through inaction, or decline with neglect.

By combining linking and bridging social capital measurement, via Community Participation and Tourism Partnership models, with the Tourism Area Cycle of Evolution, Okazaki (2008) graphically represented the internal and external factors within a tourism organization that promote or inhibit its growth. Ideally as an organization progresses forward in tourism partnership and higher in community participation, their progress would track along the tourism lifecycle curve. However, no human structure is perfect and most organizations should typically 
place somewhere higher or lower off the curve. By plotting an organization with this model, it becomes easier to determine an organization's constraints and make recommendations for its progress.

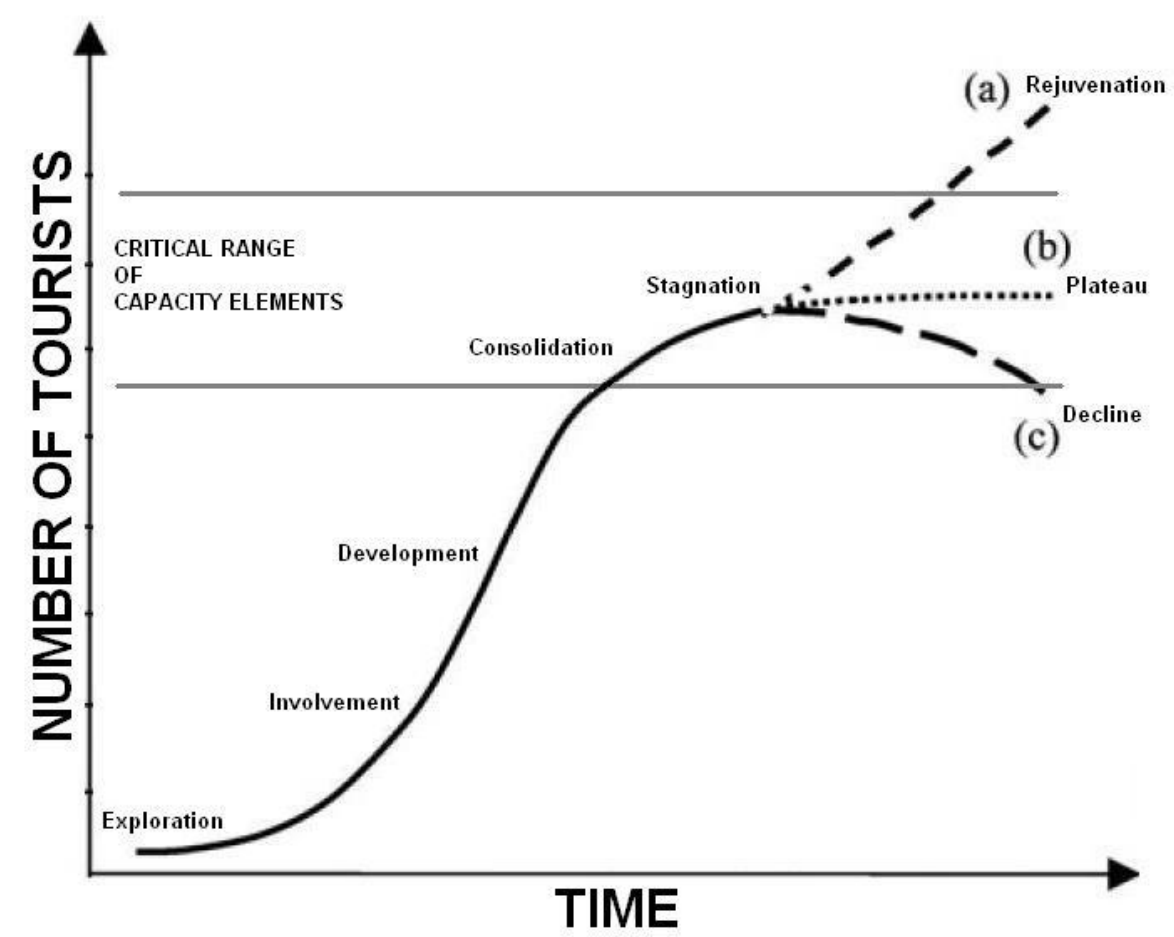

Figure 2.5 - Tourism Area Lifecycle (Butler, 1980)

\section{Summary}

Kyrgyzstan, a country new to democracy and the free market, is not as familiar with management experiences that we take for granted in the West. The history of NGOs in Kyrgyzstan creates a compelling case about how effective CBT is in fulfilling its mission of providing sustainable benefits to its members. This study will expand on the knowledge of sustainable development in less developed countries by evaluating an established, locally run sustainable tourism organization by determining their progress towards sustainable tourism goals 
through measuring their current levels of social capital in contrast to sustainable tourism criteria. By plotting the current state of CBT Kochkor, recommendations will be made to enable the organization's progress towards desired sustainable tourism outcomes. 


\section{Chapter Three}

\section{Methodology}

The CBT Kochkor member community is comprised of local management, home-stay and yurt-stay hosts, tour guides, and drivers. Together, under their management's guidance, they work together to provide visitors to Kochkor village the opportunity of a rural Kyrgyz cultural experience. Since CBT Kochkor was the first sustainable tourism project initiated in Kyrgyzstan, it is an ideal focus for a program evaluation of rural sustainable development.

\section{Study Design}

This study is a program evaluation that utilizes mixed research methods to determine current bridging and linking social capital levels within the sustainable tourism organization CBT Kochkor in the rural village of Kochkor, Kyrgyz Republic. The bridging social capital levels are measured by inquiring into the relationships between CBT community members and CBT management through a 5-point Likert scale that will measure levels of agreement towards statements of belief based on a modified ladder of community participation. Linking social capital levels are measured through semi-structured interviews with open-ended questions that develop a chronology that explores CBT Kochkor's progress through the stages of tourism partnership in relation to established sustainable tourism criteria. By measuring these social capital levels, the researcher establishes how CBT Kochkor's current state relates to the tourism lifecycle curve. By plotting this state, a formative evaluation can be developed that will provide recommendations for best practices that shall enable the organization's progress towards desired sustainable tourism outcomes. Data collection features document analysis, and semi-structured face-to-face interviews of key CBT personnel with open-ended questions. Validity of data 
through triangulation is provided by multiple data sources and perspectives, member checking, and peer review.

\section{Sampling Method}

To ensure authenticity of data, sample selection was criterion-based, conducted purposefully, and utilized an established sampling criteria hierarchy (Figure 3.1). The first selection criterion was membership status, where presently affiliated CBT members were identified from the CBT Kochkor employee population. The next criterion was length of service, due to the chronological nature of the study; the participants required knowledge of CBT Kochkor events since 2003, CBT's year of establishment. Considered next was the location of the participant. Currently affiliated CBT Kochkor community members were divided according to residence in Kochkor village (Central) or in one of the nearby satellite villages or jailoo yurt-stays (Rural). The last level of criteria was service position, divided into the three livelihoods of Host Family Head, Driver and Tour Guide. It was determined prior to data collection that all CBT drivers and tour guides were residing in Kochkor village.

To comprehend linking social capital levels, contributors related their personal experiences of CBT Kochkor. During the analysis, these chronologies were individually analyzed according to predetermined tourism participation and sustainable tourism criteria to establish their linking social capital levels along the tourism partnership continuum. 


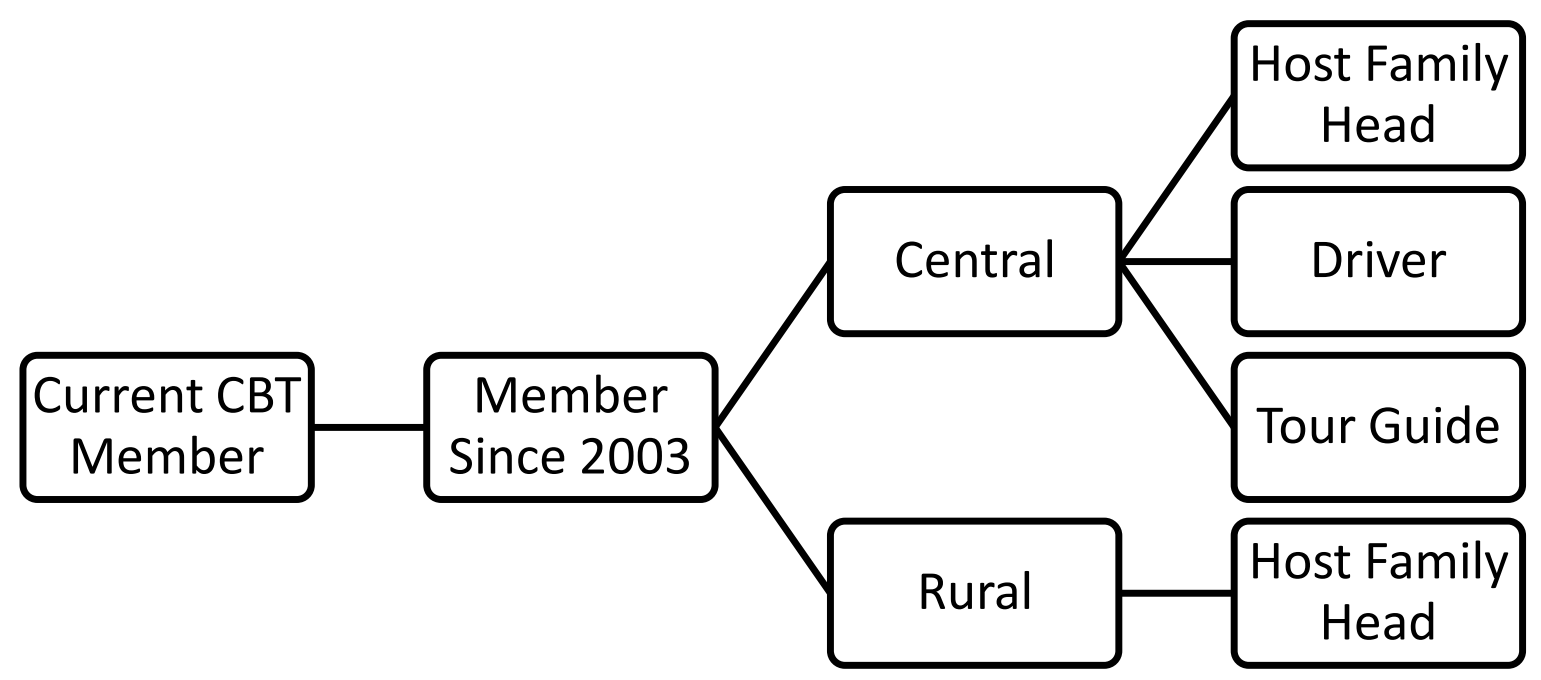

Figure 3.1 - Sampling Criteria Hierarchy

To determine bridging social capital levels, contributors were asked eight belief statement questions based on the community participation spectrum. Their responses were on a 5-point Likert scale that measures agreement levels, with one as strongly disagree and five as strongly agree. These scores determine the individual participant's current levels of bridging social capital towards CBT management in relation to policy creation and organizational management on a spectrum ranging from low to high community participation. Belief statement mean scores were used to determine the overall bridging social capital levels and to provide triangulation for the qualitative data. These social capital levels were plotted on the Community Based Tourism Social Capital Assessment model, and then compared to a modified tourism area life cycle curve. Then reviewing CBT Kochkor's current limitations in relation to their bridging (qualitative) and linking (quantitative) social capital levels, recommendations according to sustainable tourism 
criteria are provided to assist CBT Kochkor in progressing further along and up the life cycle curve.

\section{Instrument Design}

The instrument was designed to evaluate CBT Kochkor's progress towards Clarke's (1997) convergence position of sustainable tourism by utilizing mixed methods in measuring the organization's current bridging and linking social capital levels through a modified communitybased tourism social capital assessment model. The study protocol concentrates on tourism partnership and community participation in relation to the sustainable tourism criteria identified in the literature.

The first half of the protocol, tourism partnership, is broken down into the five stages of the Selin and Chavez (1995) tourism partnership model. Questions one and two of the instrument (Appendix A) encompass the first stage, Antecedents, by inquiring into the context of the crisis that led to the creation of CBT Kochkor by examining the crisis in general, the community leaders that were involved, any existing networks that were utilized, and any external brokers that might have been involved. Queries three through five reflect the second stage, Directionsetting, by focusing on themes of interdependence, stakeholder consensus, common definitions of problems, and perceived benefits and costs to stakeholders. Problem-setting, the third stage, is comprised of questions six through eight and direction setting, goal creation, sub-group creation, joint information search, and exploration of options themes. Stage four, Structuring, is the smallest stage with themes relating to roles and tasks assigned along with the creation of control and monitoring systems. The last stage, Outcomes, is formed by the results of the previous stages with themes concerning programs, benefits, and impacts. 


\section{Data Treatment}

Treated as unique cases, interviews were subjected to content analysis to establish common themes from the conversations and literature. Analysis of qualitative data was conducted by creating an organizational matrix that depicted each participants' responses to the survey questions on an ordinal scale ranging zero to three; with zero representing no answer, one representing a weak answer, two representing a median answer, and three representing a strong answer in respect to the question posed by the interviewer. The participants' response scores were then averaged and organized according to community collaboration themes. These theme scores were then averaged to identify which of the five stages of community collaboration were the weakest and strongest. At this point, the fourth stage of community collaboration was found to be the weakest. However, the third and fifth stages held almost equal standing as the strongest stages. This proved to be an issue as theoretically, only one stage could hold similar standing.

Once content analysis was completed, axial analysis of responses was conducted to identify deeper patterns, themes or relationships relative to the sub-themes identified in the literature. This stage of the analysis involved breaking the fifth stage of the community collaboration model into three sustainable tourism themes; economic development themes, cultural preservation themes, and ecological preservation themes. This spread the efficacy of stage five out enough to determine that CBT Kochkor's progress was less than previously determined.

Throughout the entire analysis, the researcher's personal experience and the reviewed literature provided context to assist interpretation of findings and hypothesis development. The interview data identified in relation to the theoretical frameworks were then presented as a historical timeline concentrating on the developmental process that established CBT Kochkor. The qualitative data were processed via SPSS to determine the mean, median, mode, and 
standard deviation. This information provides triangulation to the qualitative data and assist in plotting CBT Kochkor's bridging and binding social capital levels. 


\section{Chapter Four}

\section{Findings}

The findings of this mixed methods study are presented in two sections: (1) bridging social capital and (2) linking social capital of the sustainable tourism organization, CBT Kochkor. The first section on bridging social capital presents a qualitative timeline organized by the five stages of the Evolutionary Tourism Partnership model. To review, these five stages are Antecedents, Problem-setting, Direction-setting, Structuring, and Outcomes. Each stage represents a level of development achieved by a tourism partnership. Antecedents describe the context of the crisis that led to the tourism partnership. Problem-setting occurs when the partnership collaborates to further define issues. Direction-setting transpires with the initial establishment of the partnership's foundation. Structuring involves the partnership creating the formal relationships and infrastructure necessary for an organization to function. Lastly, Outcomes are the fruit of the partnership's labor as the result of programs, impacts, and benefits from the prior stages.

The bonding/linking social capital section are the quantitative results of degrees of agreement with eight belief statements that are structured according to the Ladder of Citizen Participation and presented as eight individual mean scores. The quantitative section is an exploratory measurement that provides triangulation for the qualitative data and all data will work in conjunction in the Community Based Tourism Social Capital Assessment model and determine CBT Kochkor's relation to a Tourism Area Lifecycle.

CBT Kochkor has functioned as the primary tourism provider in Naryn oblast for almost ten years. It has met many challenges since its creation; however, its progress has yet to be assessed by an independent party. As a sustainable tourism organization, its primary mission is to provide 
income-generating opportunities to its members, preserve the Kyrgyz culture, and preserve the ecosystems used for its tourism. The question remains, how well has CBT Kochkor performed its mission?

The purpose of this study is to evaluate CBT Kochkor's program orientation towards their sustainable tourism goals and provide recommendations how to continue its progress towards those goals. Through semi-structured, open-ended interviews, CBT Kochkor's member/management citizen participation levels and CBT Kochkor's stage of community partnership towards sustainable tourism goals were examined by collecting CBT members' personal histories of CBT Kochkor's development and inquiring into the relationships between community members and management. From these inquiries, the current state of CBT Kochkor along the Tourism Area Cycle of Evolution can be determined. It is anticipated that this program evaluation be utilized by the members and management of CBT Kyrgyzstan as a benchmark of progress to see how far CBT Kochkor has come, to understand where CBT Kochkor is in comparison to tourism area developmental theory, and to provide CBT Kochkor management with recommendations for program advancement and organizational capacity building.

\section{Demographics}

This study was conducted between the $20^{\text {th }}$ and the $27^{\text {th }}$ of May 2009, in Kochkor raion. Thirteen of the interviews occurred in Kochkor village, one was conducted in the nearby village of Kara-Suu, and one incomplete interview took place at Saralasaz jailoo (due to severe weather conditions, this interview was terminated early). All participants (Table 4.1) were active members in the community based tourism organization, CBT Kochkor. Twelve participants were 
current members of the General Meeting of CBT Kochkor; the three remaining participants were CBT Kochkor employees.

The study's fifteen participants consisted of home-stay and yurt-stay providers, vehicle drivers and tour guides residing in Kochkor village, the village of Kara Suu, and in the remote mountain pastures in northern Kochkor raion. Twenty-seven percent $(n=4)$ of the participants were male and the remaining 73 percent $(n=11)$ were female. All ten home-stay providers were female. The two yurt-stay providers were male and female. The tour guides and driver were all male. The male participants were 18, 25, and 50 years old and all the females were between 49 and 73 years old. Twenty percent $(n=3)$ of the participating CBT members had been working with the organization for less than eight years, 27 percent $(n=4)$ had been with CBT for eight years, and 53 percent $(n=8)$ of the participants had been with CBT for nine years.

\section{Table 4.1}

\section{CBT Kochkor Participant Demographics}

\begin{tabular}{cclcll}
\hline Participant & Age & Gender & Years with CBT & CBT Job & Regional Location \\
1 & 18 & Male & 5 & Guide & Central \\
2 & 47 & Male & 9 & Driver & Central \\
3 & 59 & Female & 8 & Home-stay & Central \\
4 & 25 & Male & 4 & Guide & Central \\
5 & 53 & Female & 9 & Yurt-stay & Rural \\
6 & 73 & Female & 9 & Home-stay & Central \\
7 & 48 & Female & 9 & Home-stay & Central \\
8 & 49 & Male & 8 & Yurt-stay & Rural \\
9 & 60 & Female & 9 & Home-stay & Central \\
10 & 59 & Female & 9 & Home-stay & Central \\
11 & 52 & Female & 9 & Home-stay & Central \\
12 & 65 & Female & 9 & Home-stay & Central \\
13 & 60 & Female & 7 & Home-stay & Central \\
14 & 62 & Female & 8 & Home-stay & Central \\
15 & 62 & Female & 8 & Home-stay & Central \\
\hline$n=15$ (Participant 8 's interview is incomplete due to bad weather in the mountains)
\end{tabular}


Stage One: Antecedents

To determine the context of the crisis that affected the village of Kochkor, participants were presented with questions that inquired into the critical events and actors that were involved with CBT Kochkor's establishment. The data forming this stage is comprised of responses to these inquiries along with personal communications with Helvetas staff members and CBT Kochkor management. Prior to CBT Kochkor's establishment, the village of Kochkor along with the whole of the Soviet Union was suffering from the effects of a complete economic collapse due to the disintegration of the Soviet government. Kyrgyzstan's economy was centralized and dependent on other Soviet states for trade during the Soviet era (Thompson and Foster, 2003). Due to geographic remoteness, poor infrastructure and lack of resources, Kyrgyzstan's economy began to fail after the Soviet Union's collapse (Thompson, 2004). Studies by the International Labor Organization (ILO) show that, in 1993, Kyrgyzstan's unemployment rate was near seventy seven percent (International Labor Organization, 2008). For the village of Kochkor, this involved the closure of all local factories and collective farms. Due to the remote nature of the village of Kochkor, the ubiquitous poor access to goods was particularly problematic for its residents. At one point, the regional government even instituted a voucher system for purchasing bread (Sultanova, 2009).

Another effect of the economic collapse was the lack of technological support for the country's infrastructure. Even at the end of the Soviet Union, Kyrgyzstan's infrastructure was already beginning to suffer. This lack of technical knowledge was also evident in the agricultural sector, as new crops were available but without the necessary information required to grow them (Jaanabekov, 2009). 
Change came to Kochkor through the intervention of international aid, specifically the Swiss development organization Helvetas, a politically and denominationally independent organization founded in 1955 for cooperative agricultural development. Currently, Helvetas is active in eighteen of the world's most impoverished countries within the regions of Africa, Cental Asia, and Latin America through information exchange and economic support (Helvetas, 2004). Helvetas sent two Swiss volunteers to Kochkor in 1995, Susanne and Walter Schläppi, as part of the Kyrgyz Swiss Agricultural Project. Although they were involved with various agricultural development projects in the Kochkor region, they were also concerned with the development of jailoo tourism. The Schläppis encouraged citizens of Kochkor to work together to provide tourism opportunities for international visitors (Shamenbekov, 2009).

At the start, Kochkor citizens' commonly thought these tourists were spies sent by Western governments or private businesses to collect information about former Soviet military installations or gold deposits; the Kyrgyz could not believe that these visitors were there only to experience Kyrgyz culture and nature. Five years later, jailoo tourism was one of the more successful Helvetas projects. It was able to withstand the high taxes and bureaucracy that plagued other rural private enterprises. Therefore, the resources of other less successful projects were incorporated as part of Helvetas' Business Promotion Project. In 2000, the project established its first official CBT group in Kochkor. Three years later, the Business Promotion Project was renamed the Community Based Tourism Support Project and focused to provide support for the newly registered Kyrgyz Community Based Tourism Association (Raeva, 2008). 
Stage Two: Problem-setting

For this stage of community participation inquires, questions concerning stakeholder interdependence, stakeholder consensus, common problem definition, and the benefits/costs of participation were presented to the participants. The idea for creating a community-run tourism organization did not come from a vacuum. Prior to CBT and even during the Soviet Union, Kochkor village was already an ideal stop for travelers from Europe, Japan, Mongolia, China and even America. Kochkor served as a natural gateway community for these travelers as they headed south towards popular destinations such as Song-Kul Lake, Tash Rabat caravanserai or the Torugat Pass into China.

The Helvetas volunteers living in Kochkor, who built on the pre-existing resources in Kochkor raion and Naryn oblast, monitored the development of CBT Kochkor. In Switzerland, agricultural tourism was already quite successful and the Schläppis attempted to connect this business model with Kochkor's resources. What encouraged all study participants the most to work together with each other was chiefly the opportunity to make money after several years of economic hardship. Twelve of the participants were pensioners and prior to working with CBT Kochkor only received 1500 som a month (Ozubekov, 2009). With this increase of income, they were better able to provide for their families (Question 5e).

Question $5 e$ - What sort of personal benefits did you see that encouraged you to continue cooperating?

"For example, if I make more money, I can help my family (Sultanov, 2009)."

"In the beginning, I simply provided horses to CBT. From this, I earned money and knew that it was a good job for me. (Temirova, 2009)."

"During our tourism season, we have a greater income generation. From this we can remodel our houses. This gives us a better quality of life and improves our tourism service quality. (Balabakchachiova, 2009)" 
"I felt that working with CBT would be an improvement than working with [other tourism groups]. I enjoy talking with tourists and the money too (Soyunagulova, 2009)."

Once the charter members of CBT Kochkor decided to work together, they began to look for new partners and predominantly relied on word of mouth advertising. Shepherds living at the pastures would see CBT member yurts with tourists coming to visit and paying to stay the night, friends and family who lived next to home-stays would see backpackers come to their door and stay for several nights. Those new partners who did decide to continue working with CBT went through a probationary period of tourism service training and evaluation that would last approximately one tourism season. Then during monthly General Meetings, the other CBT members would vote to see if the applicants could continue working with CBT. If approved by the majority vote, the applicants could continue to work with CBT Kochkor and could choose to become a paying member of the organization with the right to vote at monthly meetings.

Success, as one interviewee remarked, often depended on an individual's ability to work with a group, "The people who were successful were the members of the communist party. They knew how to work hard and were successful" (Soyunagulova, 2009).

From the beginning, CBT Kochkor's mission reflected the principles of sustainable tourism by concentrating on the development of economic, cultural and environmental benefits for the Kochkor tourism community and involving members in decision-making and providing access to resources (Kyrgyz Community Based Tourism Association, 2008). So that outside forces would not impose their values on an indigenous community, the charter members of the CBT Kochkor community were involved in the development of the organization's objectives. Due to the recent collapse of the Kyrgyz economy, financial issues were of the greatest concern. The members had to be able to make money soon and then sustain the business into the next year, which was 
difficult due to the lack of capital and a central office location. Helvetas helped CBT Kochkor with the initial financial problems by providing funding for rent and some basic office equipment.

After near eighty years of repression of their culture by the Soviets, the remembrance and continuation of Kyrgyz nomadic traditions was in a crisis. For the average Kyrgyz person, knowledge of Kyrgyz traditions, foods, crafts, and symbols had slowly eroded away and were known by few. When tourists asked the early members of CBT Kochkor about their traditions, they often were not able to provide any answers. Helvetas provided an immediate solution to this issue by providing cultural retraining seminars taught by Kyrgyz nationals who were able to relate their traditions (Question 7 a [ii]).

Question 7 a [ii] - How did your community decide what services to provide tourists?

"The members of Altyn Kol and Shepherd's Life went to seminars provided by Helvetas. One woman, Karen, taught these seminars for two years. They were about tourism and how to prepare Kyrgyz and Russian cuisine for tourists. During the seminars, we learned how Kochkor had a future in tourism. This future was our motivation (Soyunagulova, 2009)."

"These people provided many seminars like how to work with tours and helped pay for our office for few years. They also provided training how to cook our national cuisine for tourists. The 2003, people came from Helvetas to ask what problems we had. The biggest problem was that we did not have our own office. Helvetas then helped us find an office and paid for it for five years. Also, in 2006, we had a festival at Song-Kol Lake to save it, and we do that every year (Balabakchachiova, 2009)."

"In Kyrgyzstan, the cultural problem was big because during the Soviet Union all cultural activity was discouraged. After the Soviet Union, most people didn't know about their own culture. So Helvetas organized culture seminars that were required for CBT members (Koichiova, 2009)."

One of the most evident effects of the collapse of the Soviet was the degeneration of infrastructure. In relation to the local ecology, this meant the complete absence of sanitation services. As the tourism trade grew in Kochkor, so did the problem of waste disposal. Although 
the Kyrgyz are masters of reusing and recycling materials, households still produced waste.

Every half a kilometer or so, a corner dump could be found on the side of a road in areas like local parks or defunct construction sites. The immediate actions that CBT Kochkor took against the waste problem were for members to individually take responsibility for their own property and police their land for garbage (Question $5 \mathrm{c}$ ).

Question 5c - How did these problems relate to preservation of Kochkor's ecology?

"In the beginning, we would care for our own land around our house. We would collect trash and burn it in our garden. But things like plastic bottles, we wouldn't burn them. Instead we would give them to people who could reuse them or sell them. We would also not throw away our animal manure, but make it into fire fuel. The smoke from this manure is useful for the health. It is good for the eyes and if you breathe it your liver is better (Kotorchiova, 2009)."

"During CBT's beginning, we would keep our personal land clean and also encourage our neighbors to keep their areas clean too (Balabakchachiova, 2009)."

Question 5d - How did these problems relate government?

"We would communicate with the government about cleaning the trash in Kochkor or provide trash cans, but the government would not listen. So, CBT would clean parts of the village (Balabakchachiova, 2009).”

Question $9 d(v)$ - How did the partnership change the ecology of Kochkor?

"It has not changed very much, except maybe the street cleaning. The trash has been such a big problem in the past and it will continue to be a big problem because of the increase of tourism (Balabakchachiova, 2009)."

As the CBT Kochkor members began to work together and experience the development of their organization, they began to perceive costs and benefits of being members of a community run tourism organization. The greatest benefit that the participants stated that they received from working with CBT Kochkor was employment opportunities. A secondary benefit of employment was an increase of household income. Through this enhanced income, CBT members were able to improve their quality of life in many ways, for instance, being able to afford home 
improvement materials or purchasing livestock that could be used as either liquid capital or for food. One study participant used this new income to purchase a vehicle so that he could work as a taxi driver during the off-season. Some of the other minor benefits received from being employed in a tourism organization were, for instance, having your family exposed to international cultures and languages (Aidoochuova, 2009), or access to educational opportunities through tourism and ecotourism seminars (Balabakchachiova, 2009).

Although most CBT members were unwilling or unable to provide information about the personal costs of participating in a community-run tourism organization, many of the participants interviewed remarked on management problems in CBT Kochkor's early history. In the beginning, CBT Kochkor had difficulties retaining management and since 2000 has had seven different managers (Orozobaeva, 2009). This retention issue was due to intense competition for the management position and it was not until 2007, with the hiring of the latest manager, that this competitive clash diminished (Jildizbetova, 2009).

\section{Stage Three: Direction-setting}

This stage of the interview, participants were questioned about CBT Kochkor's organizational goals, ground rules, and their ability to jointly search for information and explore options. Once CBT Kochkor was able to function on a day-to-day basis and make a profit, the organization sought to further itself by increasing its professional capacity. This occurred predominantly in the areas of office site establishment and expansion of services. As mentioned before, CBT Kochkor did not operate out of a physical office space at first. Helvetas assisted CBT Kochkor by assisting them with the rent for an office space until they were able to purchase their own office building. The other main area that CBT Kochkor sought to expand was the types 
and amounts of mountain tours they provided. To develop these services, CBT Kochkor sought assistance and information from international volunteers and interns from the United States Peace Corps and French tourism students (Balabakchachiova, 2009).

CBT Kochkor's mission statement is to advance economic, social and environmental benefits for its community by engaging its members in policy making and providing access to assets. Its official goal for meeting this mission is to provide development opportunities for its members to increase their income, and to strengthen and empower its members by creating a civil society and social partnerships oriented towards its economic, social, and environmental missions (KCBTA, 2008). However, when the participants were asked about their organization's goal, a variety of answers was provided. Overall, the primary goal perceived by the study's participants was to provide income-generating opportunities and improve the quality of life of its members. Yet, only two of the fifteen participants provided responses indicating the organization's social and environmental goals. From its inception, the establishment of ground rules for CBT Kochkor's operations has occurred more as an ad hoc generation of general guidelines. These guidelines were described as; being hospitable, punctual, keep your house clean, be responsible for your own work, and be friendly (Balabakchachiova, 2009; Shamenbekov, 2009; Soyunagulova, 2009; Temirova, 2009).

Over the past nine years, CBT Kochkor has sought to develop community partnerships mainly within Kochkor by interacting with the local and regional government. Several interview participants mentioned that CBT Kochkor has actively maintained accurate bookkeeping and always paid their taxes as a form of working with the local government. Also mentioned was that CBT Kochkor had petitioned the regional government to maintain various areas of the regional infrastructure that assist in promoting Kochkor raion as a tourism destination, primarily 
sanitation within Kochkor village and the repair of the bridge that leads to Saralasaz jailoo (Balabakchachiova, 2009). Nationally, CBT Kochkor participates in informational exchange seminars with other Kyrgyz community-based tourism organizations within and without the Kyrgyz Community-Based Tourism Association. These seminars involve management and key organizational members meeting with other groups and comparing management methods and tourism services (Kotorchiova, 2009).

Internally, CBT Kochkor has developed a management structure that seeks to balance the problematic qualities universal to sustainable tourism organizations, principally the tension between financial sustainability and resource sustainability (Weaver, 2005). Presiding over the entire organization is the General Meeting (Figure 4.1), an authority composed of members of the CBT Kochkor community who have paid their dues. The purpose of the General Meeting is to provide policy-generating opportunities for the active members of CBT Kochkor. One a month, they meet to discuss upcoming work and review the activities of CBT Kochkor in relation to its mission. From the General Meeting, a sub-group called the Auditing Commission exists to annually check on the entire organization's performance and provide feedback for the Kyrgyz Community-Based Tourism Association annual report. The next level of the hierarchy is the coordinator, which for the purpose of this research is referred to as the manager. The coordinator monitors the performance of six other subgroups; the coordinator assistant, the accountant, and the four committees in charge of quality control, ecological actions, marketing, and ethics (CBT Kochkor, 2007). 


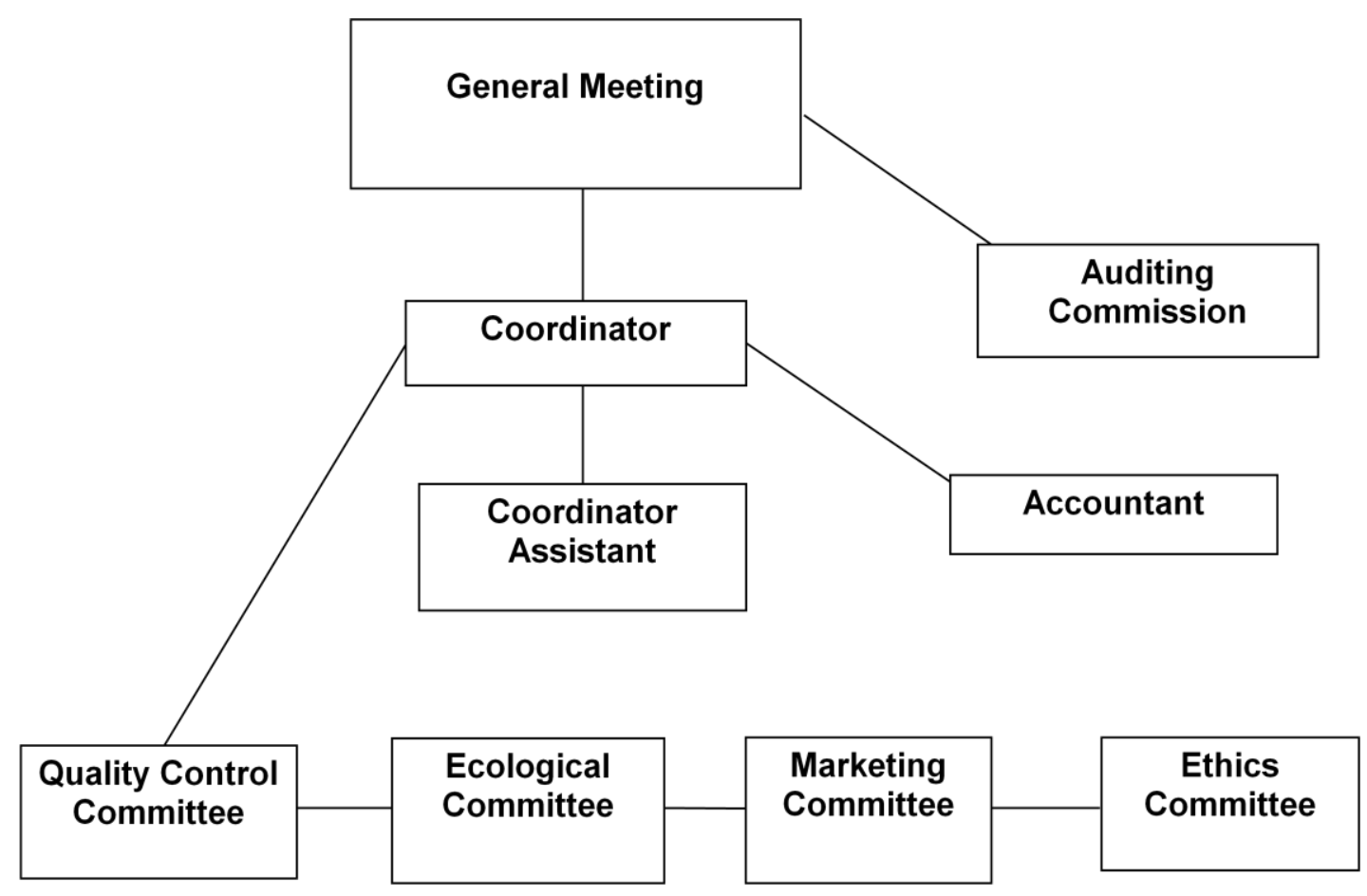

Figure 4.1 - CBT Kochkor Organizational Structure (CBT Kochkor, 2007)

Once CBT Kochkor instituted their organizational structure, the management and General Meeting members would meet monthly and present their issues, such as needing money to repair their tourism facilities or wanting to work in a different area of a jailoo. Once a year, during the General Meeting, a particular issue is identified for the organization to collectively work towards, the most recent example being a project to establish a permanent pit toilet near the CBT Kochkor yurts at Song-Kul Lake (Ozubekov, 2009). For project development and funding, the manager researches sources on the internet and develops a proposal for approval by the General Meeting (Balabakchachiova, 2009). 
Stage Four: Structuring

This stage provided the fewest themes for inquiries with questions only about roles/tasks assigned along with design of monitoring systems. The roles and tasks provided by the participants directly reflected CBT Kochkor's organizational structure. However, while inquiring about the monitoring systems associated with this phase, each participant provided a different response. When asked if CBT had a constitution that formalized the relationships within the organization, eight of the participants did not know if CBT Kochkor had a constitution at all. Additionally, five participants stated that CBT Kochkor did not have a constitution but rather a list of rules and one participant stated that the organization had no form of rules at all.

\section{Stage Five: Outcomes}

When inquiring on the subject of outcomes, several questions were presented referring to programs established, benefits derived, and impacts perceived. For each of these elements, responses have been broken down according to the sustainable economic development, cultural preservation, and ecological preservation principles of the CBT Kochkor mission. Concerning established programs, two participants were able to identify at least one active program, one economically oriented and the other cultural. The economic program identified was a savings fund used for CBT Kochkor media promotions. The cultural preservation program identified was created solely for planning and executing various cultural festivals in the region. No participants identified a CBT Kochkor program that involved ecological preservation. The remaining twelve participants were unable to identify any current programs implemented by CBT Kochkor. 
Pertaining to benefits, there were many more responses provided by the study participants. Eight of the participants identified personal economic benefits that resulted from collaborating with CBT Kochkor (Question 5 e).

Question 5e - What sort of personal benefits did you see that encouraged you to continue cooperating [with CBT Kochkor]?

"During tourism season, I receive a good income. I use this money to clothe my grandchildren and maybe send them to university one day (Sultanova, 2009)."

"For example, if I make more money, I can help my family (Sultanov, 2009)."

"During our tourism season, we have a greater income generation. From this we can remodel our houses. This gives us a better quality of life and improves our tourism service quality. Last year, people came from Talas [oblast] and Osh [oblast] to teach us about how to design our houses to be good for the ecology. It was good information and I remodeled my house to be green. I now have a green [housing] certificate from CBT (Balabakchachiova, 2009).”

"I felt that working with CBT would be an improvement than working with [other jailoo tourism groups]. I enjoy talking with tourists and the money too (Soyunagulova, 2009)."

"I've received a good supplement to my pension. You see, after I retired, I did not want to stop working. I wanted to remain active. Thankfully, this work is unique and interesting (Shamshyova, 2009)."

Question $9 b$ - What benefits were resulted from the partnership [between CBT and its workers]?

"CBT members can remodel their houses from the money they get from working (Koichiova, 2009)."

"Two or three years ago, our guest houses were not so good. Because of the money, they have made they can now repair their houses. Drivers can also now afford European cars instead of old Soviet cars (Sultanov, 2009).”

"Every year CBT is growing because of tourism increasing. Our service providers then earn more and more money. They then use this money to improve their houses (Temirova, 2009)."

"In 2008, we had a great tourism season that contributed to a new fund to build a conference hall (Balabakchachiova, 2009)."

"CBT members have received individual results. I personally have received a good profit over the past two years (Soyunagulova, 2009)."

"We have been able to own our office space instead of renting it. Also, now the coordinator has a salary and we can pay office workers a salary too (Jildizbetova, 2009)." 
However, only one participant identified a cultural benefit from collaborating with CBT Kochkor, the opportunity to relearn their culture from the enactment of traditional activities such as yurt installation, making felt carpets, and equestrian games. Concerning ecological benefits, the results were the same as the established programs, no participants were able to refer to any ecological benefits and four study participants were unable to identify any overall benefits at all.

Of the outcomes, perceived impacts were the element that the study participants most responded. Three participants perceived economic impacts of CBT Kochkor's efforts while noting an improvement in personal quality of life and quality of life throughout Kochkor village. None of the participants identified any perceived cultural impacts, yet four participants perceived ecological impacts from CBT Kochkor's work with motivating the village government to restart Kochkor sanitation. Seven of the participants stated that CBT Kochkor did not affect the Kochkor region at all.

\section{Community Participation}

The interview concluded with responses to a series of belief statements that measured the study participants' perceptions of CBT Kochkor community participation in policy-creation and management. The relationships studied were between CBT Kochkor community members and CBT Kochkor management in relation to Arnstein's Ladder of Citizen Participation. The questionnaire was designed so that if the participant had a higher level of agreement in one area of the ladder that the other areas of the ladder would in turn reflect lowers scores. The data were analyzed using SPSS (a software package used in the social sciences) to determine descriptive statistics and the resulting scores function as an evaluative framework that provides triangulation for the qualitative data. 
Respondents were asked to report how strongly they agree with 8 different belief statements that represent different rugs on Arnstein's Ladder of Citizen Participation (Table 4.2). Responses were measured on a 5-point Likert-type scale ranging from 1=strongly disagree to $5=$ strongly agree. The first, second, and third belief statements that were examined relate to the upper-most level of the ladder, Citizen Power. Of the 8 belief statements examined, respondents most strongly agreed with statement 1 , 'I believe that the CBT Kochkor community controls the making and management of CBT Kochkor policies'. The mean score for responses to belief statement 1 , the top rung of the citizen participation ladder, is 4.07 (median=4.00, $n=14$ ). The mean score for responses to both statements 2 and 3 is 4.00 (median=4.00, $n=14)$. The mean response score for statements 4, 5, and 6 known as Tokenism on the Citizen Participation Ladder, respectively scored 3.85 (median=4.00, $n=14), 1.93$ (median=4.00, $n=14)$, and 1.86 (median=2.00, $\mathrm{n}=14$ ). At the bottom lies the section known as Non-Participation, which consists of statements 7 and 8 . The mean score for responses to question 7 is 1.93 (median=2.00, $\mathrm{n}=14$ ). Lastly, respondents most strongly disagreed with statement 8, 'I believe that CBT Kochkor management does not give the CBT Kochkor community a choice in supporting its programs' (mean=1.79, median=2.00, $\mathrm{n}=14)$. 
Table 4.2

\section{Community Participation}

Relationships between CBT Kochkor management and community members.

$S_{1}$ - I believe that the CBT Kochkor community controls the making and management of CBT Kochkor policies.

\begin{tabular}{|c|c|c|c|c|}
\hline$n$ & Mean & Median & Mode & std \\
14 & 4.07 & 4.00 & 4.00 & 1.00 \\
& & & & \\
14 & 4.00 & 4.00 & 4.00 & 0.88 \\
& & & & \\
14 & 4.00 & 4.00 & 4.00 & 0.68
\end{tabular}

$\mathrm{S}_{2}$ - I believe that the CBT Kochkor community has control over the management of CBT Kochkor policies. However, the CBT Kochkor management controls the creation of CBT Kochkor policies.

$\mathrm{S}_{3}$ - I believe CBT Kochkor management and the CBT Kochkor community negotiate in the creation and management of CBT Kochkor policies.

$\mathrm{S}_{4}$ - I believe that CBT Kochkor's design allows for equal sharing of power between CBT Kochkor management and the CBT Kochkor community.

\begin{tabular}{lllll}
14 & 3.85 & 4.00 & 4.00 & 1.17 \\
14 & 1.93 & 2.00 & 2.00 & 0.83 \\
& & & & \\
14 & 1.86 & 2.00 & 2.00 & 0.77 \\
14 & 1.93 & 2.00 & 2.00 & 0.62 \\
14 & 1.79 & 2.00 & 2.00 & 0.43 \\
\hline
\end{tabular}

$\mathrm{S}_{5}$ - I believe that CBT Kochkor management does not listen to CBT Kochkor community's opinions.

$\mathrm{S}_{6}$ - I believe that CBT Kochkor management does not allow the CBT Kochkor community the opportunity to change CBT Kochkor policies.

Scale: $1=$ Strongly Disagree, 2= Disagree, $3=$ Neither Agree or Disagree, $4=$ Agree, $5=$ Strongly Agree

$\mathrm{S}_{7}$ - I believe that CBT Kochkor management does not try to amend the problems affecting the CBT Kochkor community.

$\mathrm{S}_{8}$ - I believe that CBT Kochkor management does not give the CBT Kochkor community a choice in supporting its programs. 


\section{Chapter Five}

\section{Discussion, Recommendations, and Conclusion}

In this chapter, the CBT Kochkor's relationship to the social capital theoretical frameworks of community collaboration participation will be discussed. The community collaboration framework utilizes the Selin and Chavez (1995) Tourism Participation model as a developmental timeline of CBT Kochkor while proceeding through each stage of the model. For each stage, CBT Kochkor's key strengths and issues will be addressed according to their relevant themes and sustainable tourism criteria. Darrow and Vaske (1995) determined that the Selin and Chavez (1995) framework needed further extension to incorporate yet another stage after Outcomes, a sixth stage where the tourism community evaluated their progress towards their own self defined goals. The intention of this study is to provide CBT Kochkor with that evaluation.

The community participation framework utilizes the Arnstein's ladder of citizen participation. The study findings reflecting the perceptions of the CBT Kochkor members' relationships with management and CBT Kochkor social capital levels will be discussed with the aid of a modified product lifecycle curve. That is, both the qualitative and quantitative research findings will be synthesized by plotting the results on a graph and identifying the datum point along a modified product lifecycle curve that best represents CBT Kochkor's current situation and its progress towards achieving its sustainable tourism goals. Then CBT Kochkor's status as a sustainable tourism operation will be discussed with the purpose of providing recommendations for increasing organizational capacity. 


\section{Community Collaboration}

Stage One: Antecedents

The antecedent stage of a community participation model is essentially the history of the organization in context to the events that transpired to create it (Selin and Chavez, 1995). Such events commonly occur as a crisis response, in this case the fall of the Soviet Union. A government mandate and/or third party broker then instigates how to respond. The instigators then utilize common visions, incentives, and existing networks to motivate this response.

The key events initiated in CBT Kochkor's creation are comparable to the crisis and broker elements in the first stage of the Selin and Chavez (1995) model. The crisis in this case was not only the disintegration of the Soviet economy throughout the former U.S.S.R., but specifically, for Kochkor, the collapse of the regional governing infrastructure and industrial base. In four years, Kochkor saw the closing of local factories, farms, and offices. Those that did not fold operated with an unpaid skeleton crew.

"The main problem was that there was no work. For example, from 1974 to 1991, there was a beer factory in Kochkor and it shipped beer all over Naryn oblast and even to the town of Balykchi in Issyk Kul oblast. It made two types of beer, Jigylovski and Rijsky beer. The equipment that made the beer came from Czechoslovakia. But, when the Soviet Union stopped, the head of the factory died about the same time, the factory was closed and everything was sold off (Jildizbetova, 2009)."

The broker identified in CBT Kochkor's history was the Swiss organization Helvetas.

Starting as a general agricultural development program, by 2000, Helvetas focused its business development efforts in Kochkor solely with CBT Kochkor. Over the years, they financially assisted CBT Kochkor by providing for office rent and equipment. Helvetas also provided for CBT Kochkor's necessary organizational needs through seminars that trained members how to work with tourists. As of 2009, according to its mission, Helvetas has begun to withdraw 
assistance from CBT Kochkor so that they will be locally run and completely independent of aid (Orozobaeva, 2009).

Stage Two: Problem Setting

During this stage of the model, the stakeholders begin to realize the depth and scope of the situation and understand that to succeed a collective effort is required. For the members of CBT Kochkor, such a group effort came naturally because of their experiences working on collective farms and in factories during the Soviet Union. The key motivator that encouraged them to work together was the opportunity to move out of the financial distress that plagued their nation and finally improve their lives and finances.

"Hmm. How should I say this? When it comes to work, money decides everything. The main benefit [from working with CBT Kochkor] was receiving more money from working with CBT. This helped my family very much (Jildizbetova, 2009).”

Stage Three: Direction Setting

Common indicators for this stage are an appreciation of common purpose, mutual exploration of possibilities, establishing goals, setting ground rules, and organizing into administrative sub-groups. CBT Kochkor's progress along the Tourism Participation model is strongest in this stage, with key strengths lying in the areas of Joint Information Search, Established Goals, and Organizing Sub-groups. Joint Information Search occurred in the form of CBT Kochkor's monthly General Meeting. During these monthly meetings, the members of CBT Kochkor discuss and share useful information for strengthening the organization (Shamenbekov, 2009). The element of Established Goals defined in the CBT Kochkor mission statement is the 
eradication of poverty through economic growth and the preservation of Kyrgyz culture and the natural environment (CBT Kochkor, 2007). The final salient element of CBT Kochkor in the Direction-setting stage, Organizing Sub-groups, exists in the form of their well-defined hierarchy. Chief in the hierarchy is the General Meeting, operated by the members of CBT Kochkor who have paid their annual membership fees. Created as a means of overseeing operations of the organization, the General Meeting monitors management's performance and the service quality of all CBT operations in Kochkor. Lower in the hierarchy, CBT Kochkor management (referred to as the coordinator) monitors the performance of office staff and the sustainable operation committees (CBT Kochkor, 2007).

However, despite CBT Kochkor's well-developed hierarchy, the creation and dissemination of the organization's ground rules remains a key issue and the Direction-setting stage. When inquired about any possible ground rules for CBT Kochkor, the participants of the study provided a variety of responses that focused strictly on their behavior during interactions with tourists and overall service quality instead of organizational ground rules that related to its hierarchal structure.

"Members must be punctual and responsible (Temirova, 2009)."

"Our most important rule is to be hospitable and friendly. We always restate this during every monthly meeting (Balabakchachiova, 2009).”

"Our rules are; keep houses clean, be hospitable, and maintain CBT economy (Soyunagulova, 2009).”

"The members decided to learn more about our culture so that they could communicate to tourists about our culture. They also said that we must be open to other cultures and be hospitable. For the past two years at Song-Kul, we have had some celebrations to clean up the lake and show Kyrgyz traditions such as our horse games (Shamenbekov, 2009).”

"During a meeting we made one rule that we must show our traditional customs. As a group we confirmed this (Jaanabekov, 2009)." 
Stage Four: Structuring

Relationships are formalized in this stage, tasks for those relationships are elaborated, and then monitoring/control systems are created in the form of regulatory frameworks. For the Structuring stage, CBT Kochkor's performs well in its official associations between members and management. Because of its hierarchical structure and limited service roles of management, tour guiding, driving, and hospitality provider, everyone in CBT Kochkor fits in somewhere with a specific purpose. The responsibilities of maintaining and improving CBT Kochkor are also well distributed. Over its nine-year history, various duties were performed by CBT members whose skills matched the organization's needs. For example, currently one participant was an engineer during the Soviet Union and works as the construction supervisor for building the new CBT Kochkor meeting hall (Jaanabekov, 2009).

However, the greatest weakness in this stage is the lack of access to CBT Kochkor's constitution. At most, the participants for this study were able to state that CBT Kochkor had a list of rules that the members were supposed to follow. Nevertheless, when pressed further about what these rules were, none of the study participants could provide a sufficient response. One participant thought that she had a list of rules that described what she was required to do when working with tourists, but when the interviewer eventually looked at it, all she had was a pamphlet in English for tourists visiting Kochkor with recommendations on how to be an 'ecotrekker'. 
Stage Five: Outcomes

This final stage of the Selin and Chavez (1995) model depicts the results of all the prior stages. These results occur in the forms of Impacts, Benefits, and Programs. For the purpose of this study, the researcher has defined these outcomes in the following ways; programs being current actions performed by the organization intended for its improvement, impacts being results of actions performed by the organization that have affected the community as a whole, and benefits being results of actions performed by the organization that have affected individuals. Each of these outcomes will be discussed according to the sustainable development themes found in the CBT Kochkor mission statement and sustainable tourism criteria.

All fourteen participants identified CBT Kochkor's strongest outcomes as economic benefits, economic impacts, and economic programs. As the main perceived impact created by CBT Kochkor's presence, the economic effects from the increase of capital in Kochkor after years of poverty was mentioned by all participants, either in the form of increase of income or access to employment. This increase was due to the direct economic benefits received by CBT Kochkor members. Twelve of the fourteen participants were retirees and prior to working with CBT Kochkor only received income from a monthly pension check that was 1500 som ( 37 USD) (Ozubekov, 2009). As for economic programs, from the start CBT Kochkor has implemented a savings fund intended for developing the organization. Its first significant use was in 2007, when a fire destroyed all CBT Kochkor's furniture and office equipment. Because of the saving's fund, the organization was not only able to repair the damage, but were also able to upgrade the office to be more energy efficient through insulation and then modernize the office equipment with new phones, faxes and computers (Balabakchachiova, 2009). 
CBT Kochkor's relationship with the village's ecology has been positive but limited. Only two ecological programs have been initiated, one located within Kochkor and the other at SongKul Lake. During their preliminary training, the charter members of CBT Kochkor received training that encouraged them to keep their own property clean and encourage their neighbors to do likewise (Kotorchiova, 2009). As these members began to see the impacts of the defunct sanitation system resulting in ever-growing piles of garbage on their streets, they engaged the village government to start collecting garbage again. The government initially failed to respond to their request, so the CBT members who lived in Kochkor began to police the trash in their own neighborhoods (Temirova, 2009).

In 2008, CBT Kochkor received grant funding to finance monthly garbage collection at public dumpsites around Kochkor village and truck the waste to the old garbage dump used during the period of Soviet government (Shamenbekov, 2009). At Song-Kul Lake, CBT Kochkor, in tandem with other Kyrgyz tourism organizations, holds an annual outing called “Cleanup Song-Kul Lake”. This event, held on Earth Day, involves CBT members, and any interested tourists, cleaning the pastures and beaches used for jailoo tourism (Orozobaeva, 2009). Occasionally, if funding permits, the festivities will include a small-scale development project such as building pit toilets or a well (Ozubekov, 2009). However, although these efforts are well executed, their immediate impacts are localized to Kochkor village and Song-Kul Lake, which are only two of seven areas utilized by CBT Kochkor's tours (Kyrgyz Community Based Tourism Association, 2006).

As for critical issues concerning CBT Kochkor's outcomes, a lack of social and ecological impacts, benefits, and programs stand out as key areas that the organization can improve upon. Several participants stated during the study, working for CBT Kochkor has provided them with 
an opportunity to honor their cultural heritage during festivals and cultural demonstrations. However, there have been no significant or developed social benefits or programs provided to CBT Kochkor members. Current efforts to preserve Kyrgyz culture only exist as demonstrative exhibitions for the advantage of tourism. No efforts are being made to catalog or educate future generations about Kyrgyz traditions.

\section{Community Participation}

In regards to Community Participation, the CBT Kochkor member community's relationship with their managerial structure just barely reached the highest rung of Citizen Control on Arnstein's Ladder of Citizen Participation with a mean score of 4.07 (Figure 5.3). The organization would have scored higher if not for one of the fourteen participants strongly disagreeing with the first question concerning the degree of citizen control within CBT Kochkor. Nevertheless, the high levels of agreement for questions one through three indicate that the positive relationship between CBT Kochkor community and management exists in the Citizen Power stage. This placement on the Community Participation Ladder is due to Helvetas' intention for CBT Kochkor to be a self-sufficient entity with policy and managerial control placed in the hands of Kyrgyz citizens from the beginning. The strength of these relationships relates to Arnstein's (1969) statement that the 'have-not' citizens in developing areas can induce significant social change to ensure that they benefit from the incoming affluence of development aid. However, Aref and Redzuan (2009) determined that community participation levels for tourism creation in developing areas tends to be low. 


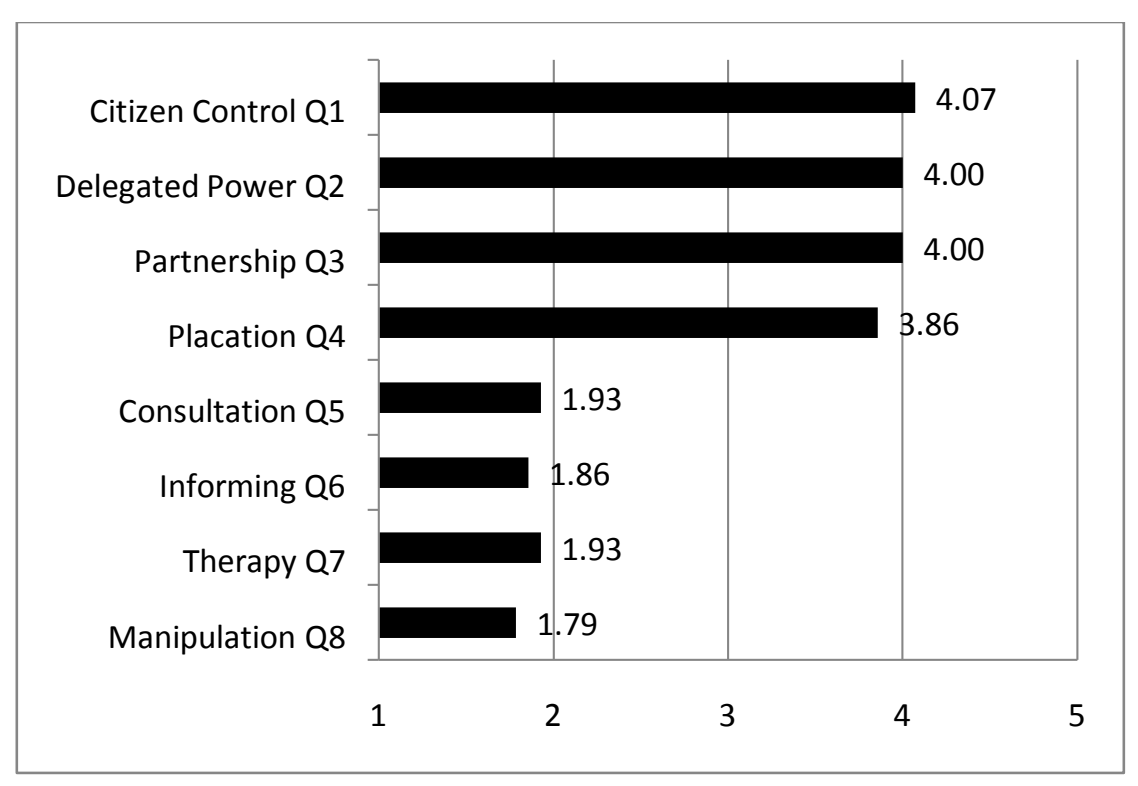

Figure 5.1 - Citizen Participation Mean Scores

\section{Current Position and Implications}

Ascertained from the model used for this study (Figure 5.2), CBT Kochkor's current position is determined by intersecting the degree of community participation with the current stage of the organization's community collaboration. As indicated by the acquired mean scores, this organization placed near the highest level on the $y$-axis due to citizen control incorporated into CBT Kochkor's organizational structure. Determined from the qualitative findings from the interviews obtained, CBT Kochkor's placement on the Community Collaboration axis is fully in the third stage, Direction-setting. In relation to its management/community relationships, the intersection of these two lines position CBT Kochkor significantly over the tourism lifecycle curve. However, pertaining to its development in the community collaboration process, CBT Kochkor is considerably behind the curve. 
This position places CBT Kochkor in a critical moment of its lifecycle, in accordance with Butler's (1980) theory. If CBT does not attempt to rejuvenate its organizational structure and sustainable tourism programs, it will continue into stagnation and decline. If CBT Kochkor were to strengthen open access to its current constitution among its members and diversify its programs to fully reflect sustainable tourism development (specifically in the areas of cultural and ecological preservation), then sufficient momentum could be attained to propel itself along the community collaboration model and reestablish itself accurately on the tourism lifecycle curve.

This research also raises implications of the difficulties of evaluating a small-scale tourism due to small sample sizes. Because sustainable tourism in less developed countries rarely exists on a large scale, the theories utilized in this study require further application to small-scale sustainable tourism organizations in a variety of less developed countries. Questions that arose from this study in relation to further use of this model are 1) is measuring community participation a valid meter for the y-axis? 2) How accurate does the community participation model relate to the capacity elements of a tourism area lifecycle curve? 3) If an organization places off the curve in the results, are there better methods for CBT Kochkor to reorient itself? Based on the study's findings, the following areas merit further research: 1) the salience of this method for a larger study or with sustainable tourism organizations in other less developed countries, 2) methods to validate the accuracy of community participation levels, and 3) a contrast and comparison of ecotourism concepts between the West and the former Soviet Union. 


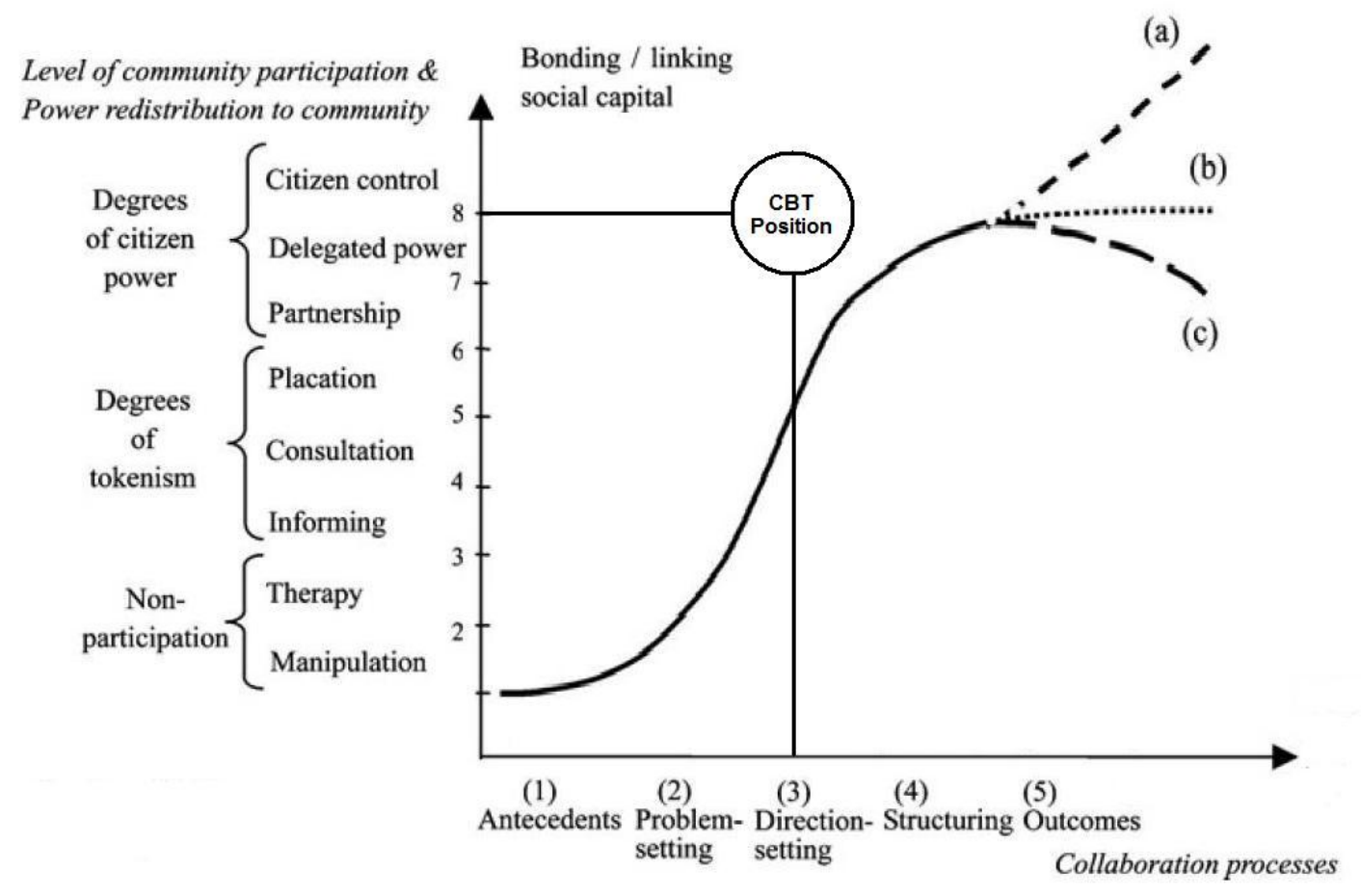

Figure 5.2 - Current position of CBT Kochkor in relation to tourism lifecycle curve

\section{Recommendations}

For CBT Kochkor to effectively and promptly reorient itself to the tourism lifecycle curve and avoid the risk of premature organizational decline, it needs to address the deficiency of an available constitution for its members and the saliency of its programs towards sustainable tourism criteria. In this section, recommendations to assuage these issues will be provided according to industry standard criteria, namely an accessible constitution and ecological preservation programs. 


\section{Constitutional Access and Development}

Of all the elements provided by the Selin and Chavez (1995) Tourism Community Participation model, CBT Kochkor's greatest deficiency lies in the lack of a publicly accessible code of conduct or constitution created by the CBT members. According to sustainable tourism criteria, such a document should be developed by, with consent, and in collaboration with the CBT community. This constitution, which is an extension of the socio-cultural development of sustainable tourism, would outline the rights and responsibilities of the organization's members and management. Within these rights and responsibilities, certain additions would need to be included for the organization to meet the international criteria. These criteria relate to international labor laws that prohibit the exploitation of children for labor, ensure fair hiring practices for women and local minorities, guarantee a living wage, and pledge to protect water sources, energy access or the sanitation of neighboring communities (Partnership for Global Sustainable Tourism Criteria, 2008).

For CBT Kochkor to develop such a document would not require any drastic changes within the organization, their well-established General Meeting, hierarchal structure, current hiring practices already reflect sustainable socio-cultural development. The purpose of providing the organization with an accessible constitution or by-laws is to allow for greater internal stability by protecting the rights of all CBT members and greater recognition by external agencies of CBT Kochkor's status as a sustainable development organization (Wolf, 1999; Hummel, 1996). Also, if CBT Kochkor's constitution were more widely available, the opportunity for community members to be more engaged with policy making would increase and the validity of CBT Kochkor's community participation social capital would be strengthened. 


\section{Ecological Programs}

Although CBT Kochkor does have ecological programs designed to combat local sanitation issues, they are still preliminary and extremely localized to the streets that homestays reside and the jailoos that the yurtstays utilize. To acquire effective and positive results towards the region's ecological resources, CBT Kochkor needs to expand the organization's knowledge and efforts regarding ecotourism development. The Partnership for Global Sustainable Tourism Criteria (2008) concedes that an effective environmental conservation program entails several factors that might not even be necessary in Kyrgyzstan, for example, the issue of solid waste disposal. Although waste management training has been provided to CBT Kochkor members, the implementation of these skills has been voluntary and executed on a small scale by individual members. This individualized recycling program, however, was merely an extension of a Kyrgyz cultural trait. The Kyrgyz, because of their nomadic heritage, were expert recyclers and until the Russians came to their country, did not even have a word for trash. Because of their limited resources, the Kyrgyz people already reused, reduced, and recycled everything from manure to plastic bottles.

For CBT Kochkor to make a positive ecological impact, their environmental preservation efforts should be concentrated in two areas and in accordance with sustainable tourism criteria. The first concentration should come as the active preservation of the ecological resources used for CBT Kochkor tourism and the second concentration should be in providing continuing education opportunities for their members about ecological conservation techniques. In relation to sustainable tourism criteria, the preservation of ecological resources would necessitate CBT Kochkor to identify at-risk flora, fauna, or even an entire ecosystem that would be the focus of 
their conservation efforts. Then, per ecological conservation education, CBT Kochkor members who actively utilize ecological resources could receive training in the following areas; Leave No Trace principles (Leave No Trace, 2008), ecosystem preservation techniques such as flora and fauna habitat protection, and ecological interpretation techniques.

\section{Conclusion}

In conclusion, CBT Kochkor's position within the social capital frameworks of the Selin and Chavez (1995) Tourism Community Participation model and Arnstein's Ladder of Citizen Participation, in relation to the Tourism Lifecycle Curve, is significantly ahead of the curve in management/membership relations yet substantially behind the curve in organizational structure and sustainable tourism outcomes. By renewing the organization's efforts towards constitutional accessibility and establishment of ecological programs, CBT Kochkor can maintain its salient management/member relations and fully meet its mission statement to provide sustainable economic, socio-cultural, and environmental benefits to its members and the region of Kochkor. 


\section{References}

Aidoochuova, M. (2009, 5 26). Personal communication.

Aref, F., \& Redzuan, M. (2009). Assessing the Level of Community Participation as a Component of Community Capacity Building for Tourism Development. European Journal of Social Sciences, 68-75. Arnstein, S. (1969). A Ladder of Citizen Participation. Journal of the American Institute of Planners, 216-224.

Balabakchachiova, J. (2009, 5 22). Personal communication.

Bourdieu, P. (1986). Forms of Capital. In J. Richardson, Handbook of Theory and Research for the Sociology of Education (pp. 241-58). New York: Greenwood.

Buckland, J. (1998). Social Capital and Sustainability of NGO Intermediated Development Projects in Bangladesh. Oxford University Press and Community Development Journal , 236-248.

Butler, R. (1980). The Concept of a Tourism Area Cycle of Evolution: Implications for Management of Resources. Canadian Geographer, 5-12.

CBT Kochkor. (2007). CBT Kochkor Summary of Mission and Services. Kochkor, Naryn, Kyrgyzstan.

Central Intelligence Agency. (2008, 9 4). CIA- The World Factbook- Kyrgyzstan. Retrieved 9 18, 2008, from CIA- The World Factbook: https://www.cia.gov/library/publications/the-worldfactbook/geos/kg.html

Clarke, J. (1997). A Framework of Approaches to Sustainable Tourism. Journal of Sustainable Tourism, 224-233.

Connery, J. (2000). Caught Between a Dictatorship and a Democracy: Civil Society, Religion and Development in Kyrgyzstan. The Fletcher Journal of Development Studies .

Curtis, G. (2007). A Country Study: Kyrgyzstan. Washington, DC: Library of Congress.

Darrow, C., \& Vaske, J. (1995). Partnerships in Natural Resource Agencies: A Conceptual Framework. Proceedings of the Second Symposium on Social Aspects and Recreational Research (pp. 87-88). San Diego: Diane Publishing Company.

Helvetas Community Based Tourism Development Project. (2005). Development of Rural Areas of Kyrgyzstan through Community Based Tourism Development. Retrieved 10 19, 2008, from Publications of the Aga Khan Development Network:

http://www.akdn.org/publications/2005_akf_mountains_presentation14_english.pdf 
Helvetas. (2004). Helvetas - Schweizer Gesellschaft für internationale Zusammenarbeit. Retrieved 1013 , 2009, from http://www.helvetas.org/wEnglish/about_us/index.asp?navid=2

Hummel, J. (1996). Starting and Running a Nonprofit Organization. Minneapolis: University of Minnesota Press.

International Labor Organization. (2008, 11). LABORSTA Internet: 3A (yearly data). Retrieved 11 10, 2008, from LABORSTA Internet: http://laborsta.ilo.org/

Jaanabekov, S. (2009, 5 20). Personal communication.

Jildizbetova, N. (2009, 5 26). Personal communication.

Koichiova, B. (2009, 5 23). Personal communication.

Kotorchiova, A. (2009, 5 23). Personal communication.

Kyrgyz Community Based Tourism Association. (2007). Community Based Tourism Development in Kyrgyzstan. Bishkek, Kyrgyzstan.

Kyrgyz Community Based Tourism Association. (2006, 8). Guidebook 2006. Retrieved 9 18, 2008, from CBT Kyrgyzstan: http://www.cbtkyrgyzstan.kg/images/stories/files/Guidebook_2006.pdf

Kyrgyz Community Based Tourism Association. (2008). Yearly Report 2007. Bishkek: Kyrgyz Community Based Tourism Association.

Leave No Trace. (2008). Leave No Trace Principles. Retrieved 11 7, 2009, from Leave No Trace: http://www.lnt.org/programs/principles.php

Macbeth, J., Carson, D., \& Northcote, J. (2004). Social Capital, Tourism and Regional Development: SPCC as a Basis for Innovation and Sustainability. Current Issues in Tourism, 502-522.

McCormack, S. (2007, 12 20). The Kyrgyz Republic's December 16 Parliamentary Elections. Retrieved 11 8, 2008, from U.S. Department of State: http://www.state.gov/r/pa/prs/ps/2007/dec/97906.htm

Namazie, C., \& Sanfey, P. (1998). Happiness in Transition. Department of Economics, University of Kent.

Okozaki, E. (2008). A Community Based Tourism Model: Its Conception and Use. Journal of Sustainable Tourism, 511-529.

Orozobaeva, A. (2009, 5 27). Personal communication.

Ozubekov, M. (2009, 5 25). Personal communication. 
Partnership for Global Sustainable Tourism Criteria. (2008). Global Sustainable Tourism Criteria. Retrieved 9 29, 2009, from Partnership for Global Sustainable Tourism Criteria:

http://sustainabletourismcriteria.org/index.php?option=com_content\&task=view\&id=58\&Itemid=188

Putnam, R. (2000). Bowling Alone: The Collapse and Revival of American Community. New York:

Simon \& Schuster.

Raeva, D. (2008, 8 18). Personal communication.

Selin, S., \& Chavez, D. (1995). Developing an Evolutionary Tourism Partnership Model. Annals of

Tourism Research, 844-856.

Shamenbekov, S. (2009, 5 20). Personal communication.

Shamshyova, N. (2009, 5 25). Personal Communication.

Soyunagulova, J. (2009, 5 22). Personal communication.

Sultanov, B. (2009, 5 25). Personal Communication.

Sultanova, A. (2009, 5 25). Personal communication.

Temirova, G. (2009, 5 24). Personal communication.

The Global Development Research Center. (2008, 10 4). The Sustainable Tourism Gateway. Retrieved 11 13, 2008, from The WWW Virtual Library on Urban Environmental Management:

http://www.gdrc.org/uem/eco-tour/st-whatis.html

Thompson, K. (2004). Post-colonial Politics and Resurgent Heritage: The Development of Kyrgyzstan's Heritage Tourism Product. Current Issues in Tourism , 370-382.

Thompson, K., \& Foster, N. (2003). Ecotourism Development and Government Policy in Kyrgyzstan. In D. Fennel, \& R. Dowling, Ecotourism Planning and Policy (pp. 169-186). Wallingford: CABI Publishing.

United Nations. (2008). A/RES/47/191 Resolution Adopted by the General Assembly. Retrieved 11 13, 2008, from UN Documentation Center: http://www.un.org/documents/ga/res/47/ares47-191.htm

United Nations. (1997, 5 23). Earth Summit. Retrieved 11 23, 2008, from About the United Nations: http://www.un.org/geninfo/bp/enviro.html

United Nations World Commission on Environment and Development. (1987). The Report of the Brundtland Commission, Our Common Future. Oxford: Oxford University Press.

Weaver, D. (2005). Sustainable tourism. Butterworth-Heinemann. 
Wolf, T. (1999). Managing a nonprofit organization in the twenty-first century. New York: Free Press. Woolcock, M., \& Narayan, D. (2000). Social capital: Implications for development theory, research, and policy. World Bank Research Observer, 225-49.

World Tourism Organization. (2004). Sustainable Development of Tourism. Retrieved 11 13, 2008, from The World Trade Organization: http://www.unwto.org/frameset/frame_sustainable.html World Travel and Tourism Council. (2007). World Travel and Tourism Council: Progress and Priorities 2007-08. Retrieved 11 13, 2008, from World Travel and Tourism Council Annual Reports:

http://wttc.travel/download.php?file=http://www.wttc.org/bin/pdf/original_pdf_file/finpp_2007.pdf 


\section{Appendix A - Interview Protocol}

Thank you for agreeing to participate in this study. Because of your experience as a (STATE

COMMUNITY ROLE) for CBT, your history with CBT is very valuable. Any personal information you share is voluntary and will not be shared with anyone else. Any information you give me, I will only be use it to help me understand your story. If you do not wish to answer a question I ask, you do not have to answer. Also, you can stop the interview if you feel uncomfortable from the questions. Shall we begin?

Please tell me about yourself. (Field note: record gender)

- What is your full name?

- How old are you?

- How many family members live in your house?

- How many years have you worked with CBT?

- Besides working for CBT as a (STATE COMMUNITY ROLE), what else do you do for money?

- What was your work before working for CBT?

- (If participant was out of secondary school by 1991, i.e. 34 years or older) What was your work before the end of the Soviet Union?

Now, I would like to ask you questions about your history with CBT.

1. Please tell me what was happening in your community before CBT Kochkor was made.

a) What problems were there in your community? Were there economic problems? Were there social problems?

b) During that time, what was your government doing about the problem?

2. Who helped make CBT?

a) Who were the leaders that created CBT?

b) What were their roles?

c) Tell me how the people you have named are connected with each other.

d) Were any outside groups involved?

3. What motivated your community to work together and make CBT? 
4. After your community began to work together, how did they find new partners in Kochkor rayon?

a) What did your community look for when choosing new partners for CBT Kochkor?

b) How did they decide that these people should be allowed to join CBT?

5. After new partners had been chosen, how did your community identify their problems?

a) How did these problems relate to economic development in Kochkor village?

b) How did these problems relate to the preservation of the Kyrgyz cultural?

c) How did these problems relate to preservation of Kochkor's ecology?

d) How did these problems relate government?

e) What sort of personal benefits did you see that encouraged you to continue cooperating?

f) What sort of personal price did you see that discouraged you from cooperating?

6. After your community decided who the partners were and what the problems were, what did they do that grew the partnership?

a) What were their goals?

b) What rules did they create to guide further actions?

c) How did they develop more partnerships in your community?

d) What sort of groups did they make to confront their problems?

7. What did your community do to learn more about achieving their goals?

a) How did they acquire information to progress towards their goals?

i. Were there tourists already visiting Kochkor at that time?

ii. How did your community decide what services to provide tourists?

b) How did they explore possible alternatives to achieve their goals?

8. After your community had decided how to complete their goals, how did the continue to improve CBT?

a) What roles were given to people?

i. Were these roles given to citizens of Kochkor? 
b) What sorts of tasks were given to these people?

c) Was a constitution or charter made for CBT?

d) Was there any sort of system made that would examine your community's growth towards their goals?

9. Once your community organized and began to do their tasks, what happened because of their actions?

a) What programs were made to lighten the problems identified?

b) What benefits were resulted from the partnership?

c) Were these benefits equal to what was expected?

d) What sort of impacts occurred from the partnership?

i. How did the partnership effect involvement in or access to democracy in your community?

ii. How did the partnership effect honesty in your community?

iii. How did the partnership effect cultural exchanges between your community and the tourists?

iv. How did the partnership effect the overall community of Kochkor? (Not the CBT community)

v. How did the partnership effect the ecology of Kochkor? 
The last questions I will ask you are about how you see the relationships between the CBT management and the CBT Kochkor community. I will read a statement and then ask you say your amount of agreement to the statement from one to five, one means very much disagree, two means disagree, three means neither agree nor disagree, four means agree, and five means agree very much. Please give your answer as a number.

\begin{tabular}{|c|c|c|c|c|c|}
\hline & $\begin{array}{l}\quad 1 \\
\text { Strongly } \\
\text { Disagree }\end{array}$ & $\begin{array}{c}2 \\
\text { Disagree }\end{array}$ & $\begin{array}{c}3 \\
\text { Neither } \\
\text { Agree or } \\
\text { Disagree }\end{array}$ & $\begin{array}{c}4 \\
\text { Agree }\end{array}$ & $\begin{array}{l}5 \\
\text { Strongly } \\
\text { Agree }\end{array}$ \\
\hline \multicolumn{6}{|l|}{$\begin{array}{l}\text { I believe that the CBT Kochkor community } \\
\text { controls the making and management of CBT } \\
\text { Kochkor policies. }\end{array}$} \\
\hline \multicolumn{6}{|l|}{$\begin{array}{l}\text { I believe that the CBT Kochkor community has } \\
\text { control over the management of CBT Kochkor } \\
\text { policies. However, the CBT Kochkor } \\
\text { management controls the creation of CBT } \\
\text { Kochkor policies. }\end{array}$} \\
\hline \multicolumn{6}{|l|}{$\begin{array}{l}\text { I believe CBT Kochkor management and the } \\
\text { CBT Kochkor community negotiate in the } \\
\text { creation and management of CBT Kochkor } \\
\text { policies. }\end{array}$} \\
\hline \multicolumn{6}{|l|}{$\begin{array}{l}\text { I believe that CBT Kochkor's design allows for } \\
\text { equal sharing of power between CBT Kochkor } \\
\text { management and the CBT Kochkor community. }\end{array}$} \\
\hline \multicolumn{6}{|l|}{$\begin{array}{l}\text { I believe that CBT Kochkor management does } \\
\text { not listen to CBT Kochkor community's } \\
\text { opinions. }\end{array}$} \\
\hline \multicolumn{6}{|l|}{$\begin{array}{l}\text { I believe that CBT Kochkor management does } \\
\text { not allow the CBT Kochkor community the } \\
\text { opportunity to change CBT Kochkor policies. }\end{array}$} \\
\hline \multicolumn{6}{|l|}{$\begin{array}{l}\text { I believe that CBT Kochkor management does } \\
\text { not try to amend the problems affecting the CBT } \\
\text { Kochkor community. }\end{array}$} \\
\hline $\begin{array}{l}\text { I believe that CBT Kochkor management does } \\
\text { not give the CBT Kochkor community a choice } \\
\text { in supporting its programs. }\end{array}$ & & & & & \\
\hline
\end{tabular}

Thank you so much for your time. This has been a very interesting and informative experience to talk with you. I would like to ask you one more question. Were there any questions that you were hoping for me to ask that I didn't ask you? 


\section{Appendix B - Interview Protocol / Community Participation Relationships}

\begin{tabular}{|c|c|}
\hline \multicolumn{2}{|l|}{ Stage One: Antecedents } \\
\hline Question & Theme \\
\hline $\begin{array}{l}1 \text { Please tell me what was } \\
\text { happening in your community } \\
\text { before CBT Kochkor was made. }\end{array}$ & Crisis \\
\hline $\begin{array}{l}\text { 1a What problems were there in } \\
\text { your community? }\end{array}$ & Crisis \\
\hline 1a Were there economic problems? & Crisis \\
\hline 1a Were there social problems? & Crisis \\
\hline $\begin{array}{l}\text { 1b During that time, what was your } \\
\text { government doing about the } \\
\text { problem? }\end{array}$ & Crisis \\
\hline 2 Who helped make CBT? & Leaders \\
\hline $\begin{array}{l}\text { 2a From those people you named, } \\
\text { who were the leaders? }\end{array}$ & Leaders \\
\hline 2b What were their roles? & Leaders \\
\hline $\begin{array}{l}\text { 2c Tell me how the people you } \\
\text { have named are connected with } \\
\text { each other. }\end{array}$ & Existing networks \\
\hline $\begin{array}{l}\text { 2d Were any outside groups } \\
\text { involved? }\end{array}$ & Broker \\
\hline
\end{tabular}

\begin{tabular}{|l|l|}
\hline \multicolumn{2}{|l|}{ Stage Two: Problem Setting } \\
\hline Question & Theme \\
\hline $\begin{array}{l}\text { 3 What motivated your community } \\
\text { to work together and make CBT? }\end{array}$ & Recognize interdependence \\
\hline $\begin{array}{l}\text { 4 After your community began to } \\
\text { work together, how did they find } \\
\text { new partners in Kochkor rayon? }\end{array}$ & $\begin{array}{l}\text { Consensus of legitimate } \\
\text { stakeholders }\end{array}$ \\
\hline $\begin{array}{l}\text { 4a What did your community look } \\
\text { for when choosing new partners for } \\
\text { CBT Kochkor? }\end{array}$ & $\begin{array}{l}\text { Consensus of legitimate } \\
\text { stakeholders }\end{array}$ \\
\hline $\begin{array}{l}\text { 4b How did they decide that these } \\
\text { people should be allowed to join }\end{array}$ & $\begin{array}{l}\text { Consensus of legitimate } \\
\text { stakeholders }\end{array}$ \\
\hline
\end{tabular}




\begin{tabular}{|l|l|}
\hline CBT? & \\
\hline $\begin{array}{l}\text { 5 After new partners had been } \\
\text { chosen, how did your community } \\
\text { identify their problems? }\end{array}$ & Common problem definition \\
\hline $\begin{array}{l}\text { 5a How did these problems relate } \\
\text { to economic development in } \\
\text { Kochkor village? }\end{array}$ & Common problem definition \\
\hline $\begin{array}{l}\text { 5b How did these problems relate } \\
\text { to the preservation of the Kyrgyz } \\
\text { culture? }\end{array}$ & Common problem definition \\
\hline $\begin{array}{l}\text { 5c How did these problems relate } \\
\text { to preservation of Kochkor's } \\
\text { ecology? }\end{array}$ & Common problem definition \\
\hline $\begin{array}{l}\text { 5d How did these problems relate } \\
\text { government? }\end{array}$ & Common problem definition \\
\hline $\begin{array}{l}\text { 5e What sort of personal benefits } \\
\text { did you see that encouraged you to } \\
\text { continue cooperating? }\end{array}$ & Perceived benefits to stakeholders \\
\hline $\begin{array}{l}\text { 5f What sort of personal price did } \\
\text { you see that discouraged you from } \\
\text { cooperating? }\end{array}$ & Perceived price to stakeholders \\
\hline
\end{tabular}

\begin{tabular}{|l|l|}
\hline \multicolumn{2}{|l|}{ Stage Three: Direction Setting } \\
\hline $\begin{array}{l}\text { 6 After your community decided } \\
\text { who the partners were and what the } \\
\text { problems were, what did they do } \\
\text { that grew the partnership? }\end{array}$ & General Direction Setting \\
\hline 6a What were their goals? & Establish Goals \\
\hline $\begin{array}{l}\text { 6b What rules did they create to } \\
\text { guide further actions? }\end{array}$ & Set Ground Rules \\
\hline $\begin{array}{l}\text { 6c How did they develop more } \\
\text { partnerships in your community? }\end{array}$ & Organize Sub-groups \\
\hline $\begin{array}{l}\text { 6d What sort of groups did they } \\
\text { make to confront their problems? }\end{array}$ & Organize Sub-groups \\
\hline $\begin{array}{l}\text { 7 What did your community do to } \\
\text { learn more about achieving their } \\
\text { goals? }\end{array}$ & Joint Information Search \\
\hline $\begin{array}{l}\text { 7a How did they acquire } \\
\text { information to progress towards }\end{array}$ & Joint Information Search \\
\hline
\end{tabular}




\begin{tabular}{|l|l|}
\hline their goals? & \\
\hline $\begin{array}{l}\text { 7ai Were there tourists already } \\
\text { visiting Kochkor at that time? }\end{array}$ & Joint Information Search \\
\hline $\begin{array}{l}\text { 7aii How did your community } \\
\text { decide what services to provide } \\
\text { tourists? }\end{array}$ & Joint Information Search \\
\hline $\begin{array}{l}\text { 7b How did they explore possible } \\
\text { alternatives to achieve their goals? }\end{array}$ & Explore Options \\
\hline $\begin{array}{l}\text { 8 After your community had } \\
\text { decided how to complete their } \\
\text { goals, how did they continue to } \\
\text { improve CBT? }\end{array}$ & Explore Options \\
\hline
\end{tabular}

\begin{tabular}{|c|c|}
\hline \multicolumn{2}{|l|}{ Stage Four: Structuring } \\
\hline Question & Theme \\
\hline $\begin{array}{l}\text { 8a What roles were given to } \\
\text { people? }\end{array}$ & Roles assigned \\
\hline $\begin{array}{l}\text { 8ai Were these roles given to } \\
\text { citizens of Kochkor? }\end{array}$ & Roles assigned \\
\hline $\begin{array}{l}\text { 8b What sorts of tasks were given } \\
\text { to these people? }\end{array}$ & Tasks elaborated \\
\hline $\begin{array}{l}\text { 8c Was a constitution made for } \\
\text { CBT? }\end{array}$ & $\begin{array}{l}\text { Monitoring and control systems } \\
\text { designed }\end{array}$ \\
\hline $\begin{array}{l}\text { 8d Was there any sort of system } \\
\text { made that would examine your } \\
\text { community's growth towards their } \\
\text { goals? }\end{array}$ & $\begin{array}{l}\text { Monitoring and control systems } \\
\text { designed }\end{array}$ \\
\hline
\end{tabular}

\begin{tabular}{|l|l|}
\hline Outcomes \\
\hline Question & Theme \\
\hline $\begin{array}{l}\text { 9 Once your community organized } \\
\text { and began to do their tasks, what } \\
\text { happened because of their actions? }\end{array}$ & Impacts \\
\hline $\begin{array}{l}\text { 9a What programs were made to } \\
\text { lighten the problems identified? }\end{array}$ & Programs \\
\hline $\begin{array}{l}\text { 9b What benefits were resulted } \\
\text { from the partnership? }\end{array}$ & Benefits derived \\
\hline
\end{tabular}




\begin{tabular}{|l|l|}
\hline $\begin{array}{l}\text { 9c Were these benefits equal to } \\
\text { what was expected? }\end{array}$ & Benefits derived \\
\hline $\begin{array}{l}\text { 9d What sort of impacts occurred } \\
\text { from the partnership? }\end{array}$ & Impacts \\
\hline $\begin{array}{l}\text { 9di How did the partnership change } \\
\text { involvement with or access to } \\
\text { democracy in your community? }\end{array}$ & Impacts \\
\hline $\begin{array}{l}\text { 9dii How did the partnership } \\
\text { change honesty in your } \\
\text { community? }\end{array}$ & Impacts \\
\hline $\begin{array}{l}\text { 9diii How did the partnership } \\
\text { change cultural exchanges between } \\
\text { your community and the tourists? }\end{array}$ & Impacts \\
\hline $\begin{array}{l}\text { 9div How did the partnership } \\
\text { change the overall community of } \\
\text { Kochkor? (Not the CBT } \\
\text { community) }\end{array}$ & Impacts \\
\hline $\begin{array}{l}\text { 9dv How did the partnership } \\
\text { change the ecology of Kochkor? }\end{array}$ & Impacts \\
\hline
\end{tabular}




\section{Appendix C - Participating Households in Kochkor}

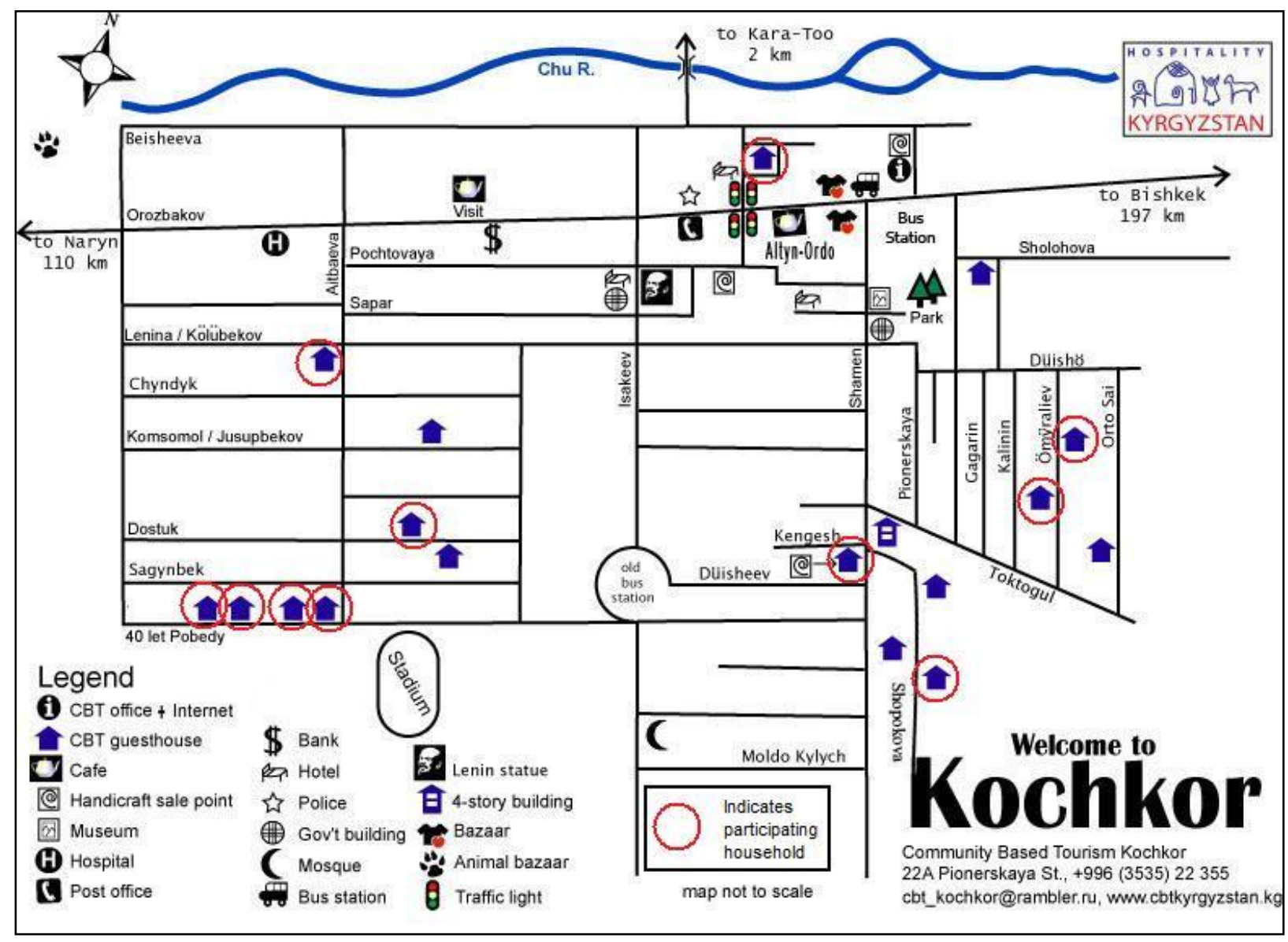

Participating households indicated by circle. 
Appendix D - Images of Kochkor, Kyrgyzstan

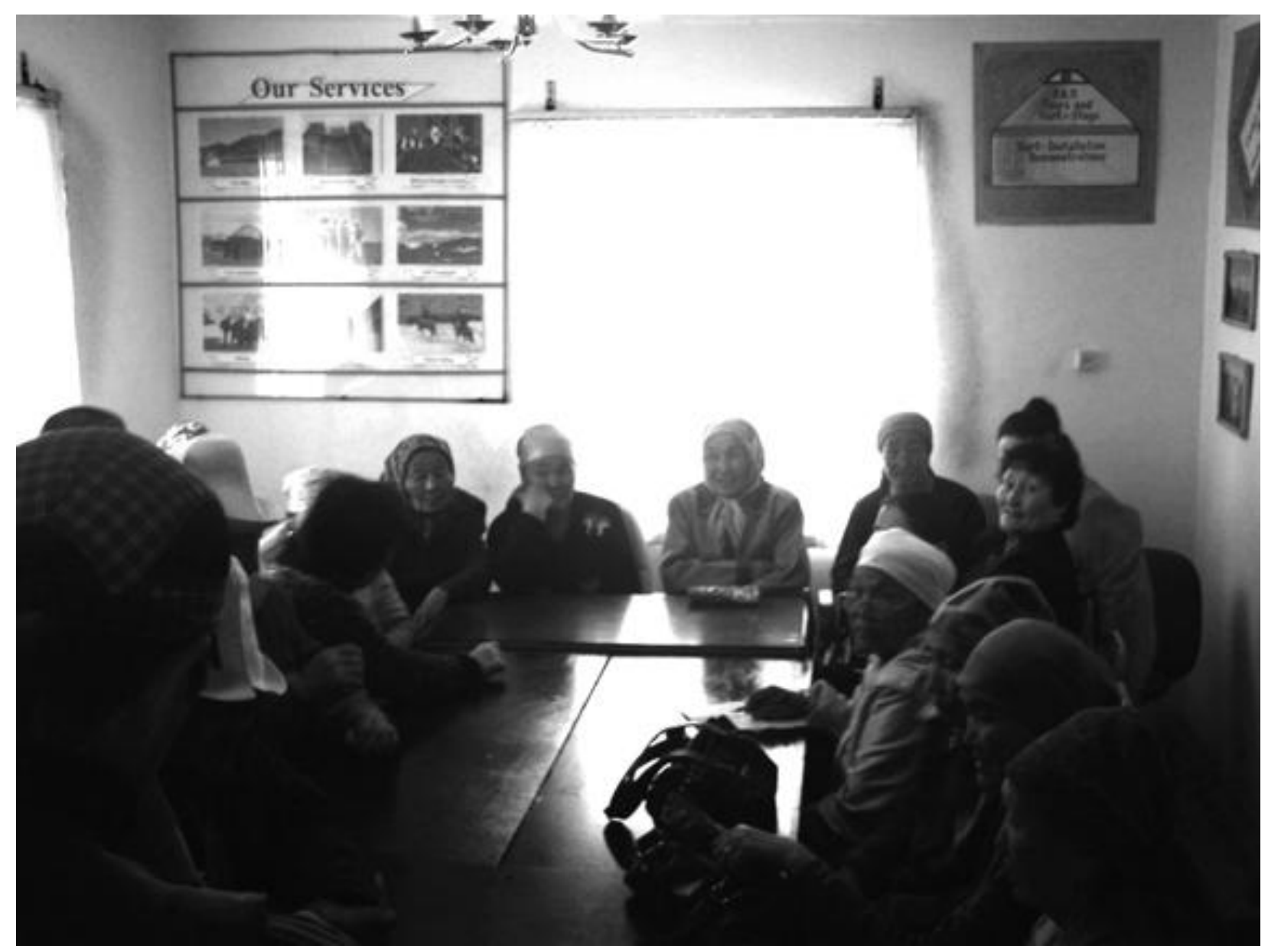

Photo 1 - General Meeting of CBT Kochkor members 


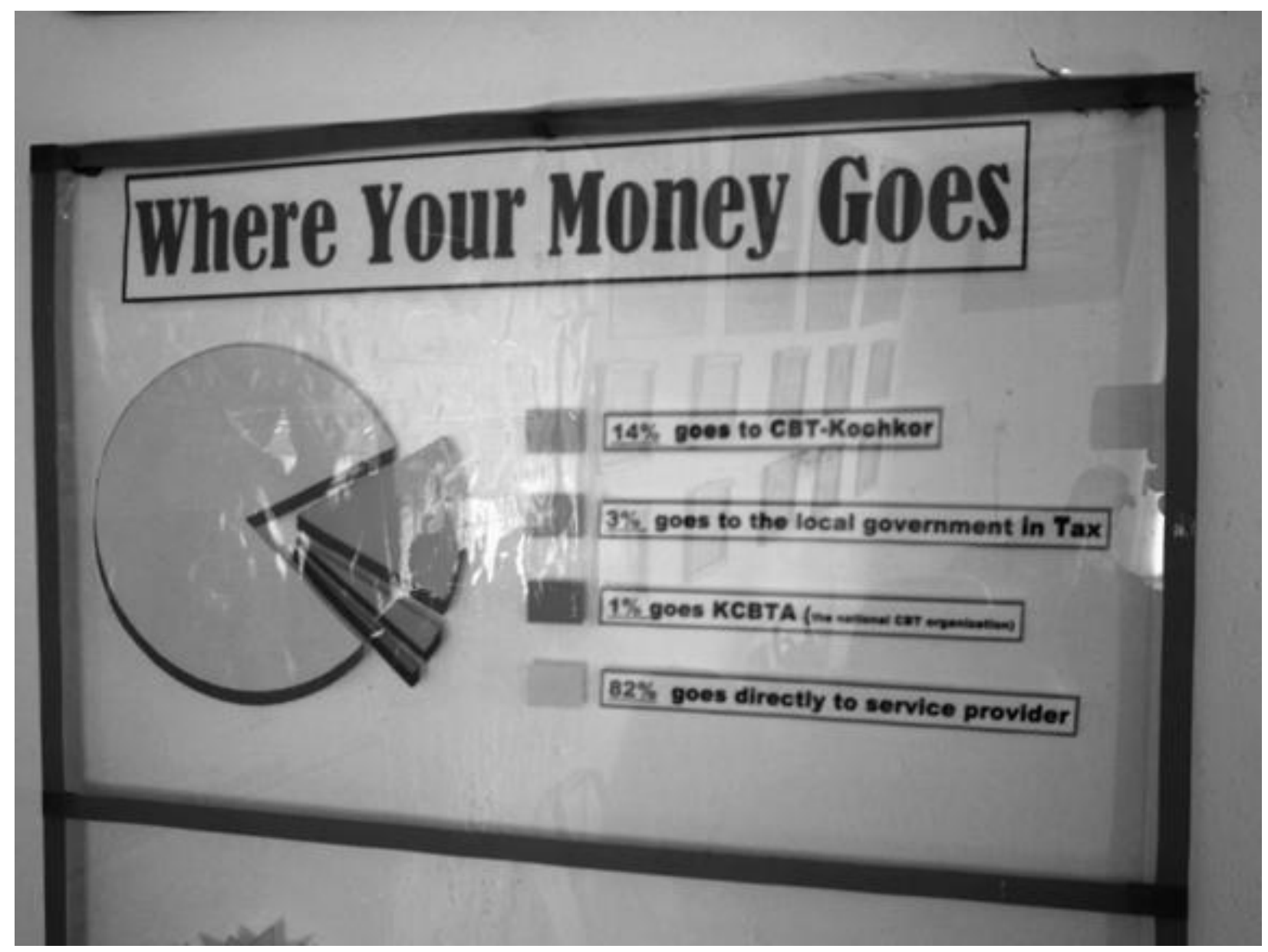

Photo 2 - Sustainable tourism information in CBT Kochkor office 


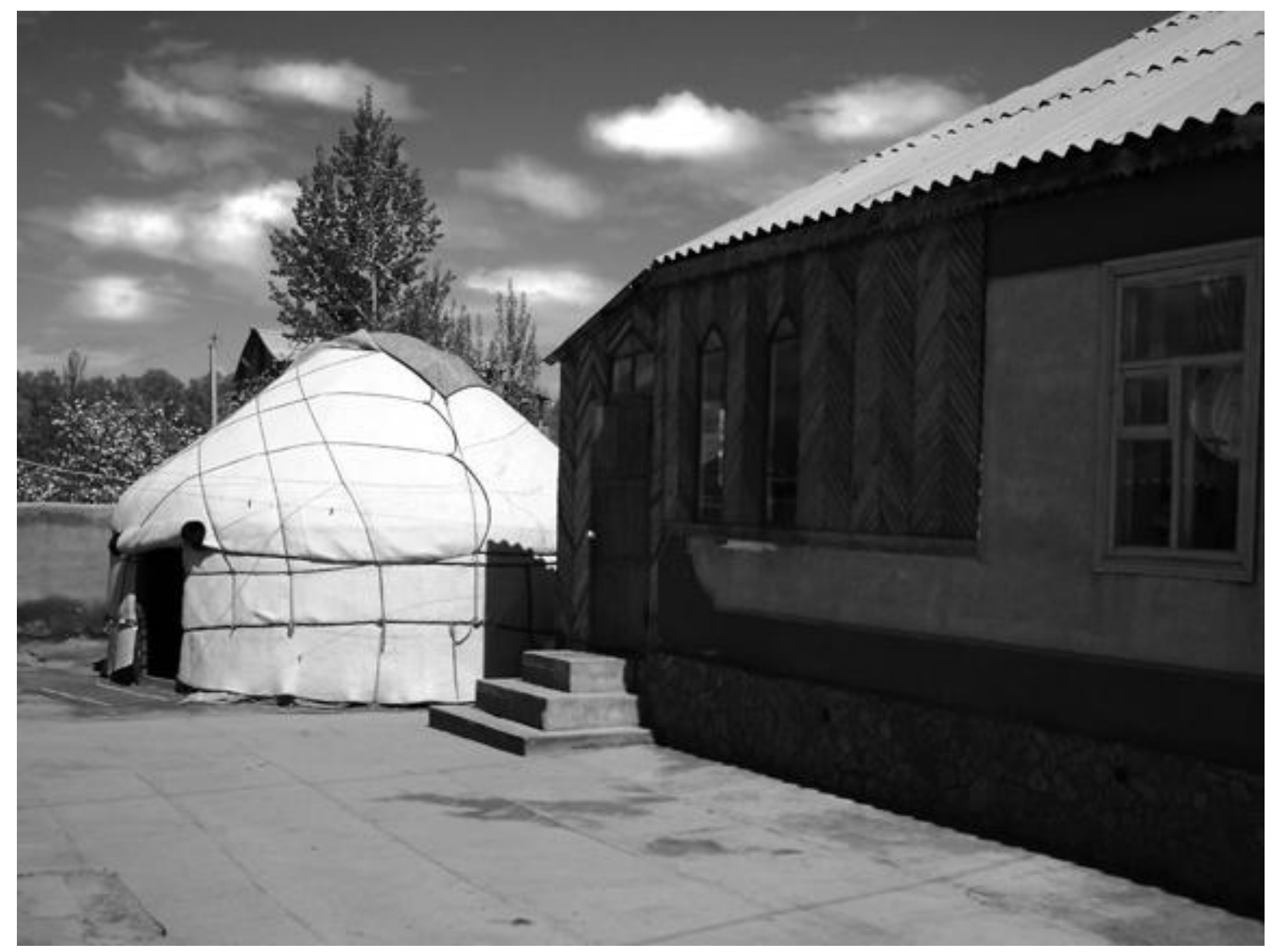

Photo 3 - CBT Kochkor homestay 


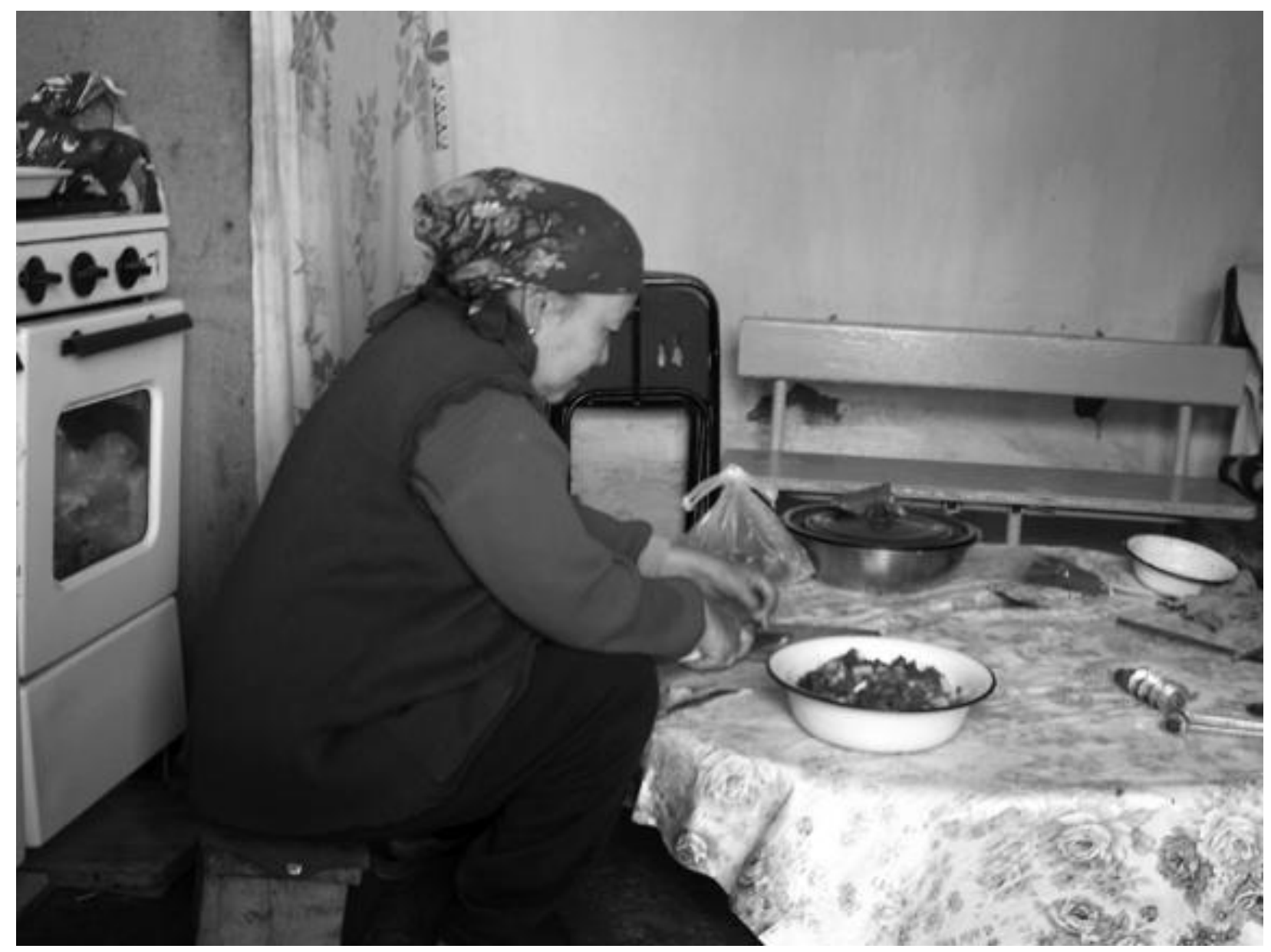

Photo 4 - CBT Kochkor homestay provider preparing evening meal 


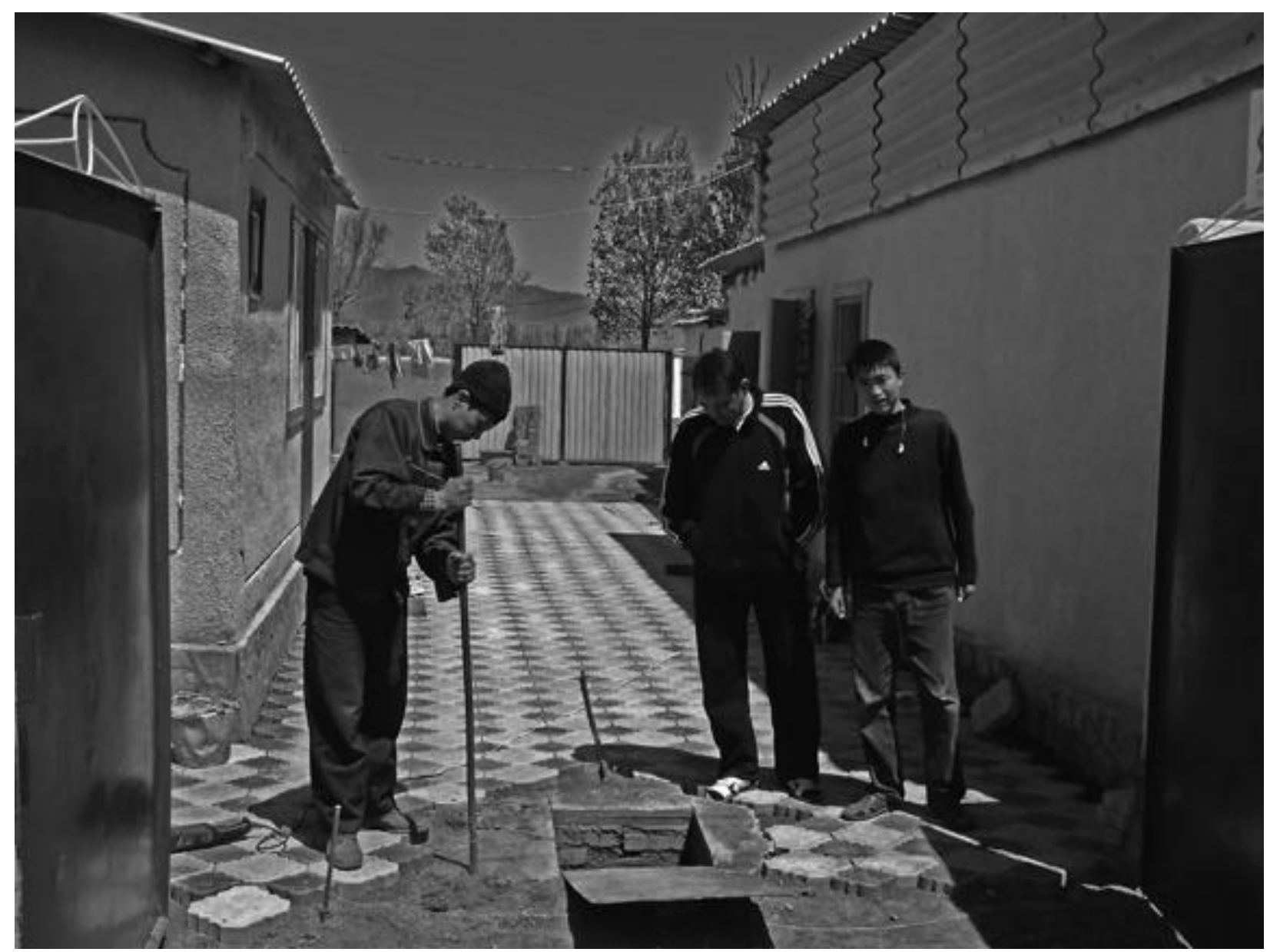

Photo 5 - Home improvements at a CBT Kochkor homestay 


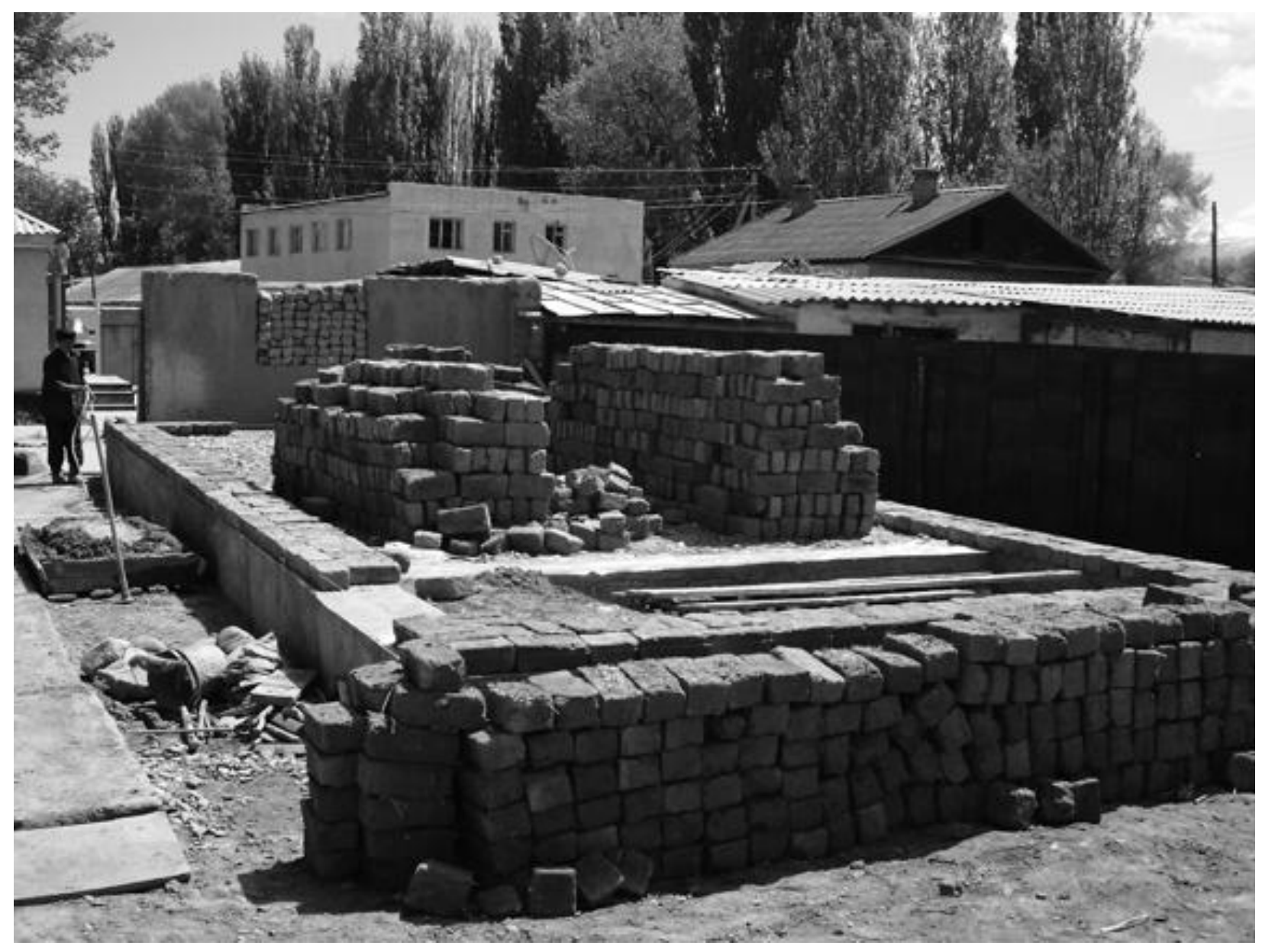

Photo 6 - CBT Kochkor meeting hall construction 


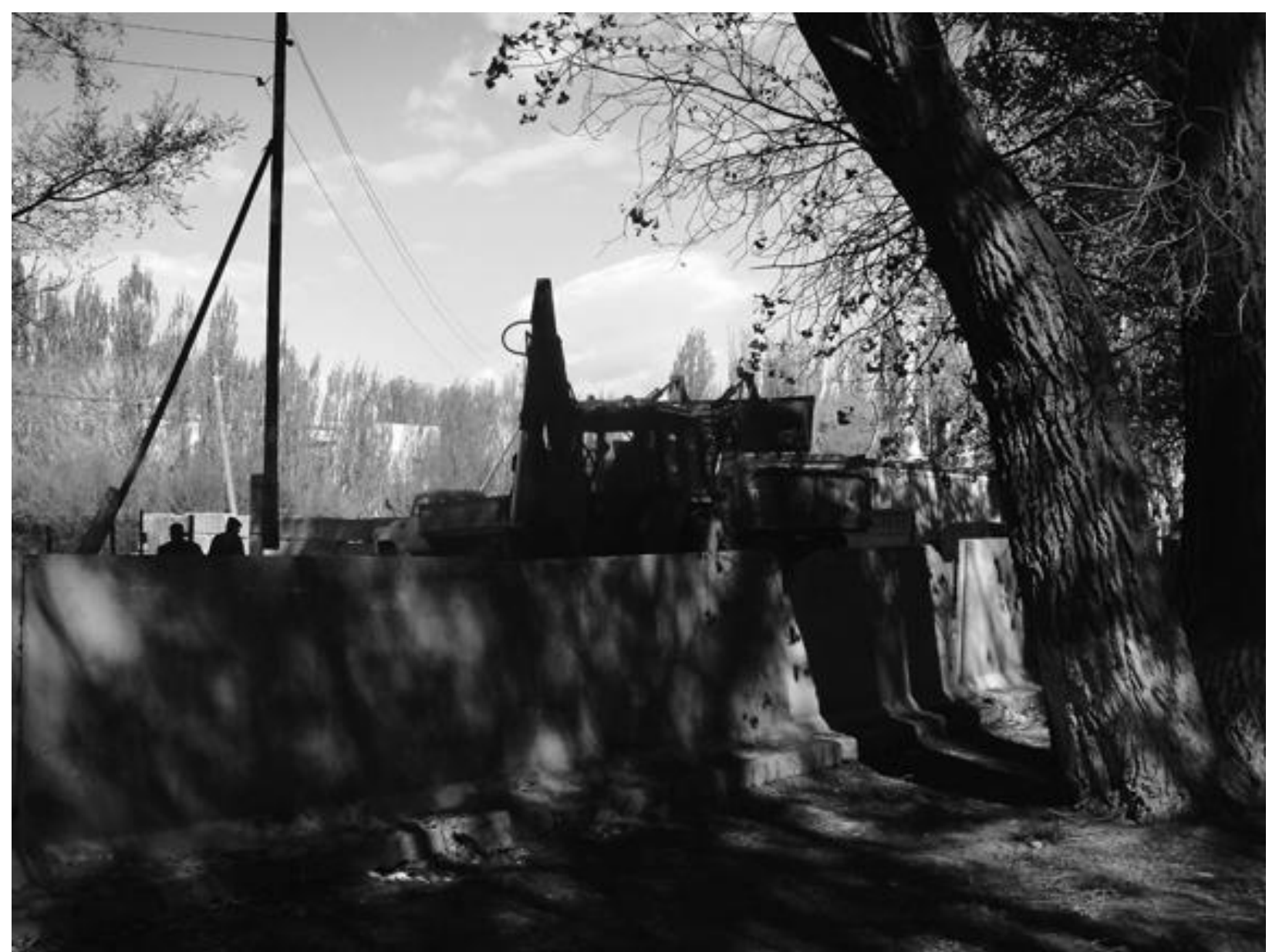

Photo 7 - Sanitation workers in Kochkor 


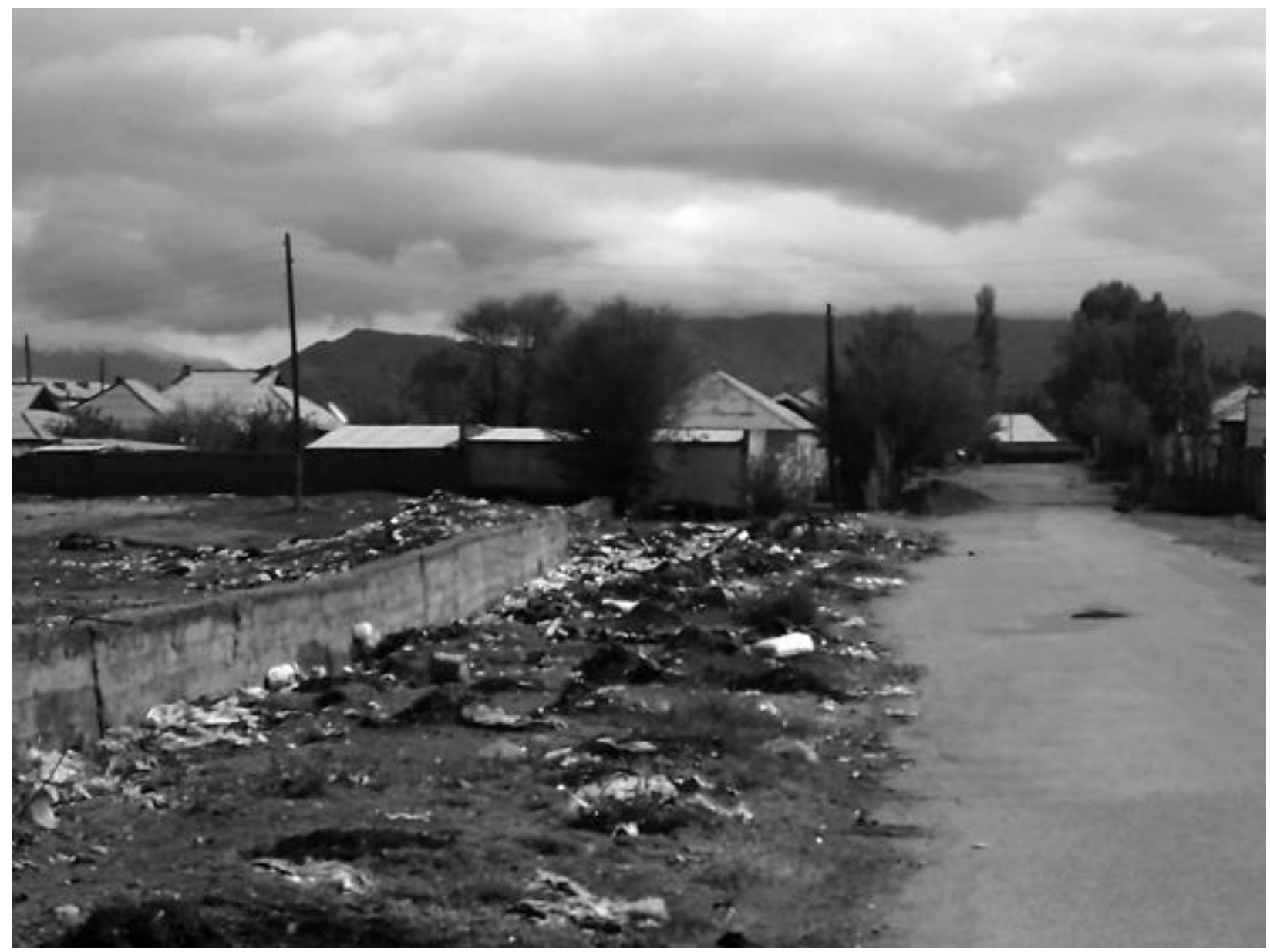

Photo 8 - Dump-site on street in Kochkor 


\section{Appendix E - Global Sustainable Tourism Criteria}

Preamble

Sustainable tourism is on the rise: consumer demand is growing, travel industry suppliers are developing new green programs, and governments are creating new policies to encourage sustainable practices in tourism. But what does "sustainable tourism" really mean? How can it be measured and credibly demonstrated, in order to build consumer confidence, promote efficiency, and fight false claims?

The Global Sustainable Tourism Criteria are an effort to come to a common understanding of sustainable tourism, and will be the minimum that any tourism business should aspire to reach. They are organized around four main themes: effective sustainability planning; maximizing social and economic benefits for the local community; enhancing cultural heritage; and reducing negative impacts to the environment. Although the criteria are initially intended for use by the accommodation and tour operation sectors, they have applicability to the entire tourism industry.

The criteria are part of the response of the tourism community to the global challenges of the United Nations' Millennium Development Goals. Poverty alleviation and environmental sustainability - including climate change - are the main cross-cutting issues that are addressed through the criteria.

Beginning in 2007, a coalition of 27 organizations - the Partnership for Global Sustainable Tourism Criteria - came together to develop the criteria. Since then, they have reached out to close to 100,000 tourism stakeholders, analyzed more than 4,500 criteria from more than 60 existing certification and other voluntary sets of criteria, and received comments from over 1500 individuals. The Sustainable Tourism Criteria have been developed in accordance with the ISEAL Code of Best Practice, and as such will undergo consultation and receive input every two years until feedback is no longer provided or unique.

Some of the expected uses of the criteria include the following:

* Serve as basic guidelines for businesses of all sizes to become more sustainable, and help businesses choose sustainable tourism programs that fulfill these global criteria; 
* . Serve as guidance for travel agencies in choosing suppliers and sustainable tourism programs;

* Help consumers identify sound sustainable tourism programs and businesses;

* Serve as a common denominator for information media to recognize sustainable tourism providers;

* Help certification and other voluntary programs ensure that their standards meet a broadlyaccepted baseline;

* Offer governmental, non-governmental, and private sector programs a starting point for developing sustainable tourism requirements; and

* Serve as basic guidelines for education and training bodies, such as hotel schools and universities.

The criteria indicate what should be done, not how to do it or whether the goal has been achieved. This role is fulfilled by performance indicators, associated educational materials, and access to tools for implementation, all of which are an indispensable complement to the Global Sustainable Tourism Criteria.

The Partnership conceives the Global Sustainable Tourism Criteria as the beginning of a process to make sustainability the standard practice in all forms of tourism.

\section{Global Sustainable Tourism Criteria}

A. Demonstrate effective sustainable management.

* A.1. The company has implemented a long-term sustainability management system that is suitable to its reality and scale, and that considers environmental, sociocultural, quality, health, and safety issues.

* A.2. The company is in compliance with all relevant international or local legislation and regulations (including, among others, health, safety, labor, and environmental aspects).

* A.3. All personnel receive periodic training regarding their role in the management of environmental, socio-cultural, health, and safety practices.

* A.4. Customer satisfaction is measured and corrective action taken where appropriate. 
* A.5. Promotional materials are accurate and complete and do not promise more than can be delivered by the business.

* A.6. Design and construction of buildings and infrastructure:

o A.6.1. comply with local zoning and protected or heritage area requirements;

o A.6.2. respect the natural or cultural heritage surroundings in siting, design, impact assessment, and land rights and acquisition;

o A.6.3 use locally appropriate principles of sustainable construction;

o A.6.4 provide access for persons with special needs.

* A.7. Information about and interpretation of the natural surroundings, local culture, and cultural heritage is provided to customers, as well as explaining appropriate behavior while visiting natural areas, living cultures, and cultural heritage sites.

B. Maximize social and economic benefits to the local community and minimize negative impacts.

* B.1. The company actively supports initiatives for social and infrastructure community development including, among others, education, health, and sanitation.

* B.2. Local residents are employed, including in management positions. Training is offered as necessary.

* B.3. Local and fair-trade services and goods are purchased by the business, where available.

* B.4. The company offers the means for local small entrepreneurs to develop and sell sustainable products that are based on the area's nature, history, and culture (including food and drink, crafts, performance arts, agricultural products, etc.).

* B.5. A code of conduct for activities in indigenous and local communities has been developed, with the consent of and in collaboration with the community.

* B.6. The company has implemented a policy against commercial exploitation, particularly of children and adolescents, including sexual exploitation. 
* B.7. The company is equitable in hiring women and local minorities, including in management positions, while restraining child labor.

* B.8. The international or national legal protection of employees is respected, and employees are paid a living wage.

* B.9. The activities of the company do not jeopardize the provision of basic services, such as water, energy, or sanitation, to neighboring communities.

C. Maximize benefits to cultural heritage and minimize negative impacts.

* C.1. The company follows established guidelines or a code of behavior for visits to culturally or historically sensitive sites, in order to minimize visitor impact and maximize enjoyment.

* C.2. Historical and archeological artifacts are not sold, traded, or displayed, except as permitted by law.

* C.3. The business contributes to the protection of local historical, archeological, culturally, and spiritually important properties and sites, and does not impede access to them by local residents.

* C.4 The business uses elements of local art, architecture, or cultural heritage in its operations, design, decoration, food, or shops; while respecting the intellectual property rights of local communities.

D. Maximize benefits to the environment and minimize negative impacts.

* D.1. Conserving resources

o D.1.1. Purchasing policy favors environmentally friendly products for building materials, capital goods, food, and consumables.

o D.1.2. The purchase of disposable and consumable goods is measured, and the business actively seeks ways to reduce their use.

o D.1.3. Energy consumption should be measured, sources indicated, and measures to decrease overall consumption should be adopted, while encouraging the use of renewable energy. 
o D.1.4. Water consumption should be measured, sources indicated, and measures to decrease overall consumption should be adopted.

* D.2. Reducing pollution

o D.2.1. Greenhouse gas emissions from all sources controlled by the business are measured, and procedures are implemented to reduce and offset them as a way to achieve climate neutrality.

o D.2.2. Wastewater, including gray water, is treated effectively and reused where possible.

o D.2.3. A solid waste management plan is implemented, with quantitative goals to minimize waste that is not reused or recycled.

o D.2.4. The use of harmful substances, including pesticides, paints, swimming pool disinfectants, and cleaning materials, is minimized; substituted, when available, by innocuous products; and all chemical use is properly managed.

o D.2.5. The business implements practices to reduce pollution from noise, light, runoff, erosion, ozone-depleting compounds, and air and soil contaminants.

* D.3. Conserving biodiversity, ecosystems, and landscapes

o D.3.1. Wildlife species are only harvested from the wild, consumed, displayed, sold, or internationally traded, as part of a regulated activity that ensures that their utilization is sustainable.

o D.3.2. No captive wildlife is held, except for properly regulated activities, and living specimens of protected wildlife species are only kept by those authorized and suitably equipped to house and care for them.

o D.3.3. The business uses native species for landscaping and restoration, and takes measures to avoid the introduction of invasive alien species.

o D.3.4. The business contributes to the support of biodiversity conservation, including supporting natural protected areas and areas of high biodiversity value. 
o D.3.5. Interactions with wildlife must not produce adverse effects on the viability of populations in the wild; and any disturbance of natural ecosystems is minimized, rehabilitated, and there is a compensatory contribution to conservation management.

(Partnership for Global Sustainable Tourism Criteria, 2008) 


\section{Appendix F - Interview Excerpts}

\section{$\underline{\text { Stage } 1 \text { - Antecedents }}$}

Question 1-Please tell me what was happening in your community before CBT Kochkor was made.

"At that time... sometimes the government would send us to work in the fields or factories. During my free time, I would make shyrdaks."

"During the Soviet Union, many people worked for the government and received a salary from the government. Life was very simple then. After independence, people began to work independently in their own businesses."

"During the Soviet Union, life was good and equal. After Soviet Union, only people who could afford to own businesses had a better life. However, those who could not had the same life as before."

"Four or five years ago, there weren't many tourists. But, when they did come to Kochkor, people would invite them to drink tea or kymys. Now there are more tourists and the village is growing."

"As I said, during the Soviet Union, I received a pension. After it was finished, I began to raise cattle. During the Soviet Union, life was good. Even after it was finished, life was good because the government gave the land back to the people. Except for us, we to an extra pension instead."

"We had very high unemployment and there was no salary for government workers after the end of Soviet Union."

"During 1992 and 1993, life was difficult for people, but because I worked for the government, I was able to continue working and life for my family was okay."

"Oh, it was very bad during that time. Many people would walk around drunk. People would also break into your home. I lost three sheep to thieves during that time."

"During the Soviet Union, everyone had jobs. But, once [the Soviet Union] was finished, there was no work and many people didn't receive pay, even those people who worked with the government."

Question 1a - What problems were there in your community?

"The children were affected most by the end of the Soviet Union. During the Soviet Union, the government would pay for the children's university education. Now, the government does not pay." 
"One of the problems after the Soviet Union was that we had almost no access to clothes or other goods."

"There were many problems, and the government didn't help the people or teach them how to adapt or pay the workers and teachers."

"In 2006, there was a big earthquake."

"The only work available was raising animals for the government; even then the government rarely paid us. Also, we did not receive a pension. Many people did not have flour or wheat and no money. After Soviet Union, farmers did not know how to grow crops other than what they already knew how to grow. So, they could not grow the new types of crops that were available."

"During the Soviet Union everything was OK. But, when the Soviet Union finished, there was a lot of unemployment and trash in the street."

"The main problem was that there was no work. For example, from 1974 to 1991, there was a beer factory in Kochkor and it shipped beer all over Naryn oblast and even to the town of Balykchi in Issyk Kul oblast. It made two types of beer, Jigylovski and Rijsky beer. The equipment that made the beer came from Czechoslovakia. But, when the Soviet Union stopped, the head of the factory died about the same time, the factory was closed and everything was sold off."

"Our economic problems were, for example, after the finish of the Soviet Union government workers did not receive salaries for several years. They just worked for free. Also, our pumps and well became broken and clogged. Our social problems were mainly in buying products. At one point, we even had a voucher system to purchase bread."

Question $1 b$ - During that time, what was your government doing about the problem?

"The government did not help to the people, rather they opened trade to China to provide cheaply made goods. Even now, the government still doesn't help much, but it does provide a pension for our work back in the Soviet times."

"They government did not even think of helping the people."

"Our government paid teachers their salary, students received food, and they repaired the water pumps."

"There were no problems during that time, life was good."

"The government gave loans to people so that they could buy cattle or private businesses. However, the interest rate was too high!"

"I do not know exactly, but people who worked hard during the Soviet Union were successful after it stopped." 
"At first, the government did not help the local people. Later, the government helped people who had children or government jobs."

"You know that our government is very poor, so they did not help people much... After CBT was organized, I began to wonder why the government was not doing the work that helped the people in Kochkor. I thought it was strange that an organization from another country had to come and help us and not our own government."

"Many organizations went bankrupt after the finish of the Soviet Union. Other organizations reduced the amount of work they produced so they would not have to pay as much to the workers. Some people would sell products that they would buy from Bishkek and sell them the village."

\section{Question 2 - Who helped make CBT?}

"I am not sure, I first learned about Altyn Kol. When I went to Altyn Kol's office, I learned about CBT because they share the same building. I needed money at the time, so I decided to also work with CBT."

"Helvetas, the Swiss agricultural cooperative, and AKUK, a local agricultural organization."

"I think it was 5 or 6 years ago, Swiss volunteers came to help grow potatoes and wheat. They saw that there were good places for tours and helped make CBT."

"One Swiss woman named Karen. Also, Anara Oruzbaieva... Also, 9 people from around Kyrgyzstan and Switzerland who once came to investigate our treks."

"The Swiss organization Helvetas, they sent people, for example can earn, Markus, Susan and Walter. But I don't know who from Kochkor helped."

"The members of Altyn Kol and Shepherd's Life went to seminars provided by Helvetas. One woman, Karen, taught these seminars for two years. They were about tourism and how to prepare Kyrgyz and Russian cuisine for tourists."

"CBT was made by the Swiss organization, Helvetas. First, they came to Kyrgyzstan and organized CBT in Kochkor; in 2000, these Swiss people came to Kochkor and made this organization for rural people."

"In 1996 two Swiss people came to Kochkor to help develop the agricultural system of Kochkor. They showed us new ways to grow potatoes and wheat. By 2000 they began to show us how to organize and run a tourism organization. We also had some volunteers from USAID and France who helped teach us about tourism. In 2003, we developed a fund and worked with our manager to help build a new office for an organization. During that time, we also opened an Internet café and the village. We work with international organizations and they provided us with computers." 
"First, there was Karen, who helped us for five years. Then it was Walter Schaleppe."

Stage 2 - Problem-setting

Question 5 - After new partners had been chosen, how did your community identify their problems?

"Our monthly sessions provide us with the opportunity to review our problems."

"Our first problems were not easy because of our lack of experience. AKUK and the aiyul ukmutu helped us in identifying our problems, and then the members would meet and decide what to do about these problems."

"People from Helvetas, like Anara or Demira Raeva, came to Kochkor and identified our problems for us. This was because we did not know about tourism."

"During our monthly sessions, the members discuss our problems. Each individual member provides their own opinions and then everyone votes on the issues."

"During our meetings, we would discuss problems as a group."

"During the same meetings, they would also discuss problems affecting the community. For example, economic problems or ecological problems."

"Our main office in Bishkek, has a special group to solve problems and to make seminars in Kochkor. They've come before to teach to members of CBT Kochkor about tourism. Our management and members also check CBT Kochkor for lack of service by our members to tourists."

"At meetings we discuss our problems and identify them."

Question $5 a$ - How did these problems relate to economic development in Kochkor village?

"There weren't any economic problems at all. But for the government, there was not enough money for factory and office workers."

"CBT had a lack of funds at first, Karen helped point out our economic problems."

“CBT doesn't help Kochkor's economy."

"At first, we had no office and then Helvetas financed our rent."

"In the beginning of CBT, the main economic problems that existed were assisted by Helvetas. However, any other economic problems were dealt with out of our own pocket." 
"During these meetings, mostly we discussed the fact that money was not available for our goals."

"In the first few years, they had the money or good office. Another problem was that they had no way to advertise and no Office Equipment. "“

"With CBT Kochkor we had problems like a lack of computers. One year we also had a fire in our office, and we did not have enough money for repairs."

Question $5 b$ - How did these problems relate to the preservation of the Kyrgyz culture?

"In the beginning of CBT, we would discuss during meetings about our culture. Everyone at those meetings agreed that it was important to show our culture to tourists. We wanted to be able to show our culture to visitors and then remember it. I feel that making these festivals are good for the health because we can play our national games which is good exercise and makes us happy."

"In Kyrgyzstan, the cultural problem was big because during the Soviet Union all cultural activity was discouraged. After the Soviet Union, most people didn't know about their own culture. So Helvetas organized culture seminars that were required for CBT members."

"For example, during the treks, I explain our traditions to the tourists. When I explain to them our customs, I remember them from before and don't forget them."

"The first members of CBT did not know a lot about Kyrgyz culture. Other Kyrgyz organizations came and trained on Kyrgyz culture and told us that we needed to share our culture with tourists so that we would not forget it."

"During our monthly sessions, we decided that if we show cultural presentations to tourists that visit Kochkor, that more tourists would come."

"The preservation of our culture was a very big problem. That was evident when people would come from other countries and ask questions about our traditions. Many people would not know how to answer them. This caused people in Kochkor to begin to think about their own culture and traditions. This was very important because at that time people were forgetting our culture, they would also be getting drunk in the streets. So, the people thought that we need to preserve the culture. For example, one tradition is our making of a felt carpets. Tourists would come and see the carpets being made and would ask questions. Not everyone could answer these questions, so we would teach the members about felt carpets and ornaments."

"We have sought to save Kyrgyz culture by providing festivals that would show our traditional customs and games, specifically games with our horses." 
Question 5c - How did these problems relate to preservation of Kochkor's ecology?

"In the beginning, we would care for our own land around our house. We would collect trash and burn it in our garden. But things like plastic bottles, we wouldn't burn them. Instead we would give them to people who could reuse them or sell them. We would also not throw away our animal manure, but make it into fire fuel. The smoke from this manure is useful for the health. It is good for the eyes and if you breathe it your liver is better."

"There was too much trash in the streets. We also had water supply problems. During Soviet Union, the government controlled land use for crops and cattle. After Soviet Union, there was no control of the land."

"For example, at the beginning of the season, a group of CBT members goes to Song-Kul Lake to clean up before the tourists come. But CBT does not help with the trash in Kochkor."

"When CBT was first made, they created an administrative group who would go to Song-Kul Lake and clean it. Now, after 5 years, they are also focusing on cleaning the trash in Kochkor."

"During CBT's beginning, we would keep our personal land clean and also encourage our neighbors to keep their areas clean too."

"Kochkor has too much wind. No real ecological problems, except perhaps too much trash. Oh, and we had an earthquake once."

"We had a lot of trash in this town, there was too much trash, the members of CBT decided to clear away the trash. So, they wrote some grants to hire people to clear away the trash."

"The main problem in Kochkor is the trash; we have a lot of trash here. Also, CBT made a project to work with Kochkor students that would train them how to take care of the ecology."

"Near a small village outside of Kochkor, called Ak Jar, there is a leather factory that is owned by the Chinese. It started in 1993 and brought with it a bad smell. It now poisons our river and any children who swim in its water gets blisters on their skin. Two organizations, ARIS and OSCE, have tried to stop it, but the local government won't do anything about it."

\section{Question 5d - How did these problems relate government?}

"The government was not helping."

"The government was not concerned about this."

"We would communicate with the government about cleaning the trash in Kochkor or provide dumpsters, but the government would not listen. So, CBT would clean parts of the village."

"The government did not help." 
"So, before we had a lot of unemployment, this was the government's responsibility to help and find jobs. We still have unemployment, but before we had even more. But, CBT, they work together to provide jobs to people who are willing to work with tourists."

"We have a local authority in Kochkor, the government thought the trash is a big problem in Kochkor. In 2008, the government began to clean trash in Kochkor. Each street now has its own sanitation manager. Before, we had a problem with financing sanitation technology. The Kochkor government won a grant to purchase a trash truck. Now the trash is taken to a dump near the mountains."

\section{$\underline{\text { Stage } 3 \text { - Direction-setting }}$}

Question 6 - After your community decided who the partners were and what the problems were, what did they do that grew the partnership?

"We would tell our friends and family that they should work with CBT, if they were interested they would go to the office."

"In the beginning, our manager looked for members. But most of our early members came from Shepherd's Life or word of mouth."

"When CBT opened, people came from the village and asked to work. But, at one point, we had a coordinator who did not work well for CBT. The members felt that she was responsible for a fire that destroyed our office. This fire cost a lot of money to repair."

"First, we would talk to friends and family and try to get them to work with us. Then, people began to learn about CBT and everyone wanted to work with us. During our meetings, we would review these people about their quality. We could not take everyone though."

"The people who worked in CBT would make advertisements in the local paper, the workers in CBT would also tell their family members that they should work with CBT, and people would come to the office and say they wanted to work with CBT. After CBT grew, the office coordinator would also go and look for new members."

"People from the jailoo would come and asked to work with us. We went and reviewed them to see if they could work with us."

"People would tell each other about CBT and they would try to work with them."

"We spend our profits correctly to grow CBT and exchanged information with other tourism groups. We also made sure we had a good coordinator who would make sure there was growth."

"The first members of CBT were very knowledgeable people. During the Soviet Union, they worked in the bank and with the regional government. Because of their experience they were able to grew CBT." 
"We are always looking for people who can give us new information. Sometimes we have volunteers come from other countries to help us. We had a Peace Corps volunteer once and a volunteer from France."

"The CBT members work hard, therefore our funds increased. We used this money to establish an office. We then decided on a manager and accountant. Also, an office in Bishkek was established. It increases business in Kochkor and in Kyrgyzstan."

"When CBT began to make money and make treks, they bought some computers and made advertisements about CBT services. They also wrote grants to buy equipment for guides, like tents."

"CBT Kochkor has opened new treks. We have also called journalists from Europe to make advertisements and brochures used in Europe in journals."

"CBT has tried to introduce more treks by using the history of the Silk Road."

Question $6 a$ - What were their goals?

"CBT's main goal is to improve the lives of the member's families."

"Our goals have been; to promote the people of Kochkor, to increase CBT's capacity, and to improve the quality of life of Kochkor."

"Our main goals are; increase the income of families, and to provide employment and a future for our families."

“To improve our economic system, our nature, and our culture."

Question $6 b$ - What rules did they create to guide further actions?

"Members must be punctual and responsible."

"Our most important rule is to be hospitable and friendly. We always restate this during every monthly meetings."

"Our rules are; keep houses clean, be hospitable, and maintain CBT economy."

"The members decided to learn more about our culture so that they could communicate to tourists about our culture. They also said that we must be open to other cultures and be hospitable."

"During a meeting we made one rule that we must show our traditional customs. As a group we confirmed this." 
Question 6c - How did they develop more partnerships in your community?

"We have worked with the aiyul ukmutu, we also pay our taxes."

"CBT Kochkor also works with Shepherd's Life, Tien-Shan Travel, Novinomad, and other CBT offices in Kyrgyzstan."

"I am not sure, but I believe that the head office in Bishkek and our coordinator try to create new partnerships."

"We have worked with the aiyul ukmutu and asked them to repair the bridge that goes to Saralasaz jailoo. We have also worked with the local hospital if any of our tourists become ill."

"CBT had the guides open new tours and treks. Other organizations in Bishkek did not have tours like these, and would send their tourists to us. All they had were drivers that would go straight to destinations by car, we had horse tours."

"There is a saying in Kyrgyz, friendship and hospitality is most important. Because of this saying, we communicate with other tour companies and share information with each other on how to do tourism. We do this with other companies and the other CBT offices."

Question 6d - What sort of groups did they make to confront their problems?

"We have made three groups, one for reviewing service quality, one for planning ecological actions, and one for planning cultural festivals."

"There are meetings for CBT members, there they make decisions to fix problems. For example, we had no conference hall. The members decided to build a new conference hall to help that problem."

"We have a member run group of advisors that try to fix our problems."

"We have three people who work as a group to resolve CBT's general problems."

"During meetings, we work on our problems such as service quality, accounts, and bills."

"CBT Kochkor has an ecological manager. She organizes the Song-Kol clean up. We also work with another organization that provides exhibitions of our traditional activities. For our economic problems, we have one group of three women in CBT that checks our accounts. But, for identifying our economic problems, our manager is responsible for identifying these problems."

"There is one special group to solve our problems, it has five people and they work with any social or financial problems we have. In this area are also a lot of orphans, CBT Kochkor sends them to Song-Kol Lake in the summer." 
"I know that we have three for four people in one of our groups that work towards our current issues, for example festivals and our new conference hall."

Question 7 - What did your community do to learn more about achieving their goals?

"We have sent some of our members to other countries for exchange programs and once we sought help from Peace Corps."

"At first, we watched to see how Shepherd's Life did their work and then copied what they did."

"At meetings, they talk about their goals."

"Karen, from Helvetas, taught us many things to solve our own problems as a group. This training was very useful."

"During our monthly sessions, we discuss our current issues."

"We learned what we needed in the Swiss seminars."

"For example, our management at CBT teaches the members and explains to them our cultural traditions so that they can teach them to tourists. Or for the Song-Kol clean-up, the head office in Bishkek annually organizes this festival. They would also come to Kochkor and find people from CBT to work at the festival."

"The members of CBT will go to schools to speak with the students, directors, headmasters to see which students can benefit from financial assistance."

Question $7 a$ - How did they acquire information to progress towards their goals?

The CBT members always share useful information with each other or sometimes we consult with the Bishkek office. If the problem is very big, we create a one year plan to focus on the problem.

Every day our manager goes to the internet and searches for different money to help our projects.

Every month during their meetings, the members present their problems such as, wanting to work in a different area on jailoo or needing money to repair their car.

Question $7 b$ - How did they explore possible alternatives to achieve their goals?

"Each day we get experience from working with CBT, but if someone does poorly in his or her work, they will be a member no more."

"We have worked with other organizations in the villages of Bokonbaiev, Tamchi, and Kemin to learn new ways to provide tourism services." 
"No, the management still does the same as before. However, sometimes management will visit other offices in Kyrgyzstan and learn how other managers do their work."

"During meetings we decided to provide national meals, but not everyone knew how to teach cooking. So a Kyrgyz person from Helvetas came in give a seminar on Kyrgyz national cuisine."

“CBT Kochkor's goals are to show to tourists Kyrgyz traditional customs and history, also our natural environment like our mountains and streams, and our meals and horse games so that they are saved for future generations."

Question 8 - After your community had decided how to complete their goals, how did they continue to improve CBT?

"Since 2004, we now own our office instead of renting. We are also now building our own conference hall for future meetings."

"During one early session, we decided to advertise CBT in local and international magazines and on television."

"We've held clean up festivals at Song-Kul lake and cooking seminars to help us learn more about Kyrgyz food."

"Over the years, we have made advertisements in local and international publications. We've also had good summer festivals that celebrate Kyrgyz culture. They've also instituted a certification program that motivated me to improve my house and my service to tourists."

"We have created the clean up festival at Song-Kul and the cultural festival at Saralasaz jailoo."

"A few years ago, we had a problem with our manager and she was replaced. One of our most experienced guides became the new manager; this has made many people happy."

"We have created a new conference hall, and are building a new well for people who live at Song-Kol Lake."

Stage 4 - Structuring

Question 8 - What roles were given to people?

"I am not sure, but now the members have contributed to the building of our new conference hall and provide meals for the construction workers."

"Jobs such as advertising organizer, festival organizer and crafts organizer were assigned to members." 
"Sometimes the guides need to find good horses for treks or bring building materials to the office. We have created three main groups for members to serve in; our ecological group, our service quality group, and our general group."

"We have management, an accountant, the ecological management group, the service quality group, two types of guides-English speaking and the non English-speaking guides."

Question 8c - Was a constitution made for CBT?

"I do not know about a constitution, but I have a list of rules about how to work with tourists. I also think we have list of rules in the office."

"I do not know."

"We do not have a constitution, but rather, we have a list of rules."

"We have a list of rules. I have a copy here somewhere."

"We do not have a constitution."

"We do not have a constitution, but we have a list of rules that is checked by the local government."

Question 8d - Was there any sort of system made that would examine your community's growth towards their goals?

"Yes, three or four local members check to see if management is doing its job."

"We have our general meeting, they check on our organization's goals."

"We have three commissions that are run by members that checks service quality and our economic status."

"Our management every month checks to see if CBT Kochkor is meeting its goals and then reports to the main office in Bishkek."

$\underline{\text { Stage } 5 \text { - Outcomes }}$

Question $9 b$ - What benefits were resulted from the partnership?

"I feel that the biggest benefit for us has been the relearning of Kyrgyz culture by the installation of yurts, making felt carpets, and our national games."

"CBT members can remodel their houses from the money they get from working." 
"Two or three years ago, our guest houses were not so good. Because of the money they have made, they can now repair their houses. Drivers can also now afford European cars instead of old Soviet cars."

"Every year CBT is growing because of tourism increasing. Our service providers then earn more and more money. They then use this money to improve their houses."

"In 2008, we had a great tourism season that contributed to a new fund to build a conference hall."

"CBT members have received individual results. I personally have received a good profit over the past two years."

"We have been able to own our office space instead of renting it. Also, now the coordinator has a salary and we can pay office workers a salary too."

"In 2006, we had a great increase to our income."

"When CBT makes big cultural celebrations, they sell many tickets and earn more money. From the tours, they also earn more money."

"In 2007, there were a lot of tourists into Kochkor, this was a great benefit. Last year was also a good year. Whenever tourists come, things get better."

"For me, I have been able to make more money and learn other languages. I've also been able to install internet in my house."

"During our tourism season, we have a greater income generation. From this we can remodel our houses. This gives us a better quality of life and improves our tourism service quality. Last year, people came from Talas and Osh to teach us about how to design our houses to be good for the ecology. It was good information and I remodeled my house to be green. I now have a green certificate from CBT."

"I enjoy showing Kyrgyzstan's culture to tourists. When I do this, I get to present and remember our culture."

Question 9d - What sort of impacts occurred from the partnership?

"Our local people are more respectful and hospitable. They have also learn more about other cultures. Before, people only know about jailoo, but after the tourists came, people began to learn more about the world. Before, Kochkor is a very poor place, but now Kochkor is a more developed place. This is because of the taxes we pay to our government, so the government has spent money on making more buildings."

"We have been motivated by an increase of family income. Also, the members have received advice on how to improve our homes. For example, more people have inside bathrooms now." 
"Because there was so much unemployment and many of the members only had a pension for income, working for CBT was a good way for making money. Also, the opportunity to exchange cultures was interesting."

"For them it is good, they make money and have a job. They make more money working for CBT than other jobs."

"We were motivated by the profits we made and that we could work with our friends."

"In the beginning, we saw a benefit to our income from working together. Once we saw that we would be making money we began to work harder together."

"There were many pensioners before CBT who had no work. When CBT came, they saw the opportunity to work and make money."

"I feel now that we saving our culture for future generations, in the past we lost so much."

"The preservation of our culture was a very big problem. That was evident when people would come from other countries and ask questions about our traditions. Many people would not know how to answer them. This caused people in Kochkor to begin to think about their own culture and traditions. This was very important because at that time people were forgetting our culture, they would also be getting drunk in the streets. So, the people thought that we need to preserve the culture. For example, one tradition is our making of a felt carpets. Tourists would come and see the carpets being made and would ask questions. Not everyone could answer these questions, so we would teach the members about felt carpets and ornaments."

"Our local people are more respectful and hospitable. They have also learn more about other cultures. Before, people only know about jailoo, but after the tourists came, people began to learn more about the world. Before, Kochkor is a very poor place, but now Kochkor is a more developed place. This is because of the taxes we pay to our government, so the government has spent money on making more buildings."

"We had one member... who wrote a grant to pay for garbage trucks to come and pick up trash on our streets. Before, we had to pay our own money. Everyone on the street would then pay. Before, during the Soviet Union, we had garbage disposal done by the government."

Question 9a - What programs were made to lighten the problems identified?

"We have created a savings fund that we use to promote CBT."

"In the beginning of CBT, we would discuss during meetings about our culture. Everyone at those meetings agreed that it was important to show our culture to tourists. We wanted to be able to show our culture to visitors and then remember it. I feel that making these festivals are good for the health because we can play our national games which is good exercise and makes us happy." 
"For the service providers, we have had our food training seminars and our cultural festivals."

"The members decided to learn more about our culture so that they could communicate to tourists about our culture. They also said that we must be open to other cultures and be hospitable. For the past two years at Song-Kul, we have had some celebrations to clean up the lake and show Kyrgyz traditions such as our horse games."

"We had a lot of trash in this town, there was too much trash, the members of CBT decided to clear away the trash. So, they wrote some grants to hire people to clear away the trash."

"We have a local authority in Kochkor, the government thought the trash is a big problem in Kochkor. In 2008, the government began to clean trash in Kochkor. Each street now has its own sanitation manager. Before, we had a problem with financing sanitation technology. The Kochkor government won a grant to purchase a trash truck. Now the trash is taken to a dump near the mountains." 


\section{Appendix G - Interview Analysis Matrix}

Scale
\begin{tabular}{|l|l|}
\hline No Answer & 0 \\
\hline Weak Answer & 1 \\
\hline Median Answer & 2 \\
\hline Strong Answer & 3 \\
\hline
\end{tabular}

Stage Scores
\begin{tabular}{|l|l|}
\hline Stage 1 - Antecedents & 0.76 \\
\hline Stage 2 - Problem-setting & 1.45 \\
\hline Stage 3 - Direction-setting & 1.50 \\
\hline Stage 4 - Structuring & 0.42 \\
\hline Stage 5 - Outcomes & 1.57 \\
\hline
\end{tabular}

Stage

Theme

Question \#

Participant 01

Participant 02

Participant 03

Participant 04

Participant 05

Participant 06

Participant 07

Participant 08

Participant 09

Participant 10

Participant 11

Participant 12

Participant 13

Participant 14

Participant 15

Question

Scores
1 Antecedents

\begin{tabular}{|c|c|c|c|c|c|c|c|c|c|}
\hline \multicolumn{5}{|c|}{ Crisis } & \multicolumn{3}{|c|}{ Leaders } & \multirow{2}{*}{$\begin{array}{c}\text { Networks } \\
\text { 2c }\end{array}$} & \multirow{2}{*}{$\begin{array}{c}\text { Broker } \\
2 d\end{array}$} \\
\hline 1 & $1 a$ & $1 b$ & $1 c$ & $1 d$ & 2 & $2 a$ & $2 b$ & & \\
\hline 2 & 0 & 0 & 0 & 2 & 0 & 0 & 0 & 0 & 0 \\
\hline 3 & 0 & 0 & 3 & 3 & 0 & 0 & 0 & 0 & 0 \\
\hline 3 & 0 & 0 & 0 & 3 & 3 & 3 & 3 & 2 & 2 \\
\hline 1 & 0 & 0 & 1 & 0 & 2 & 0 & 0 & 0 & 0 \\
\hline 1 & 0 & 0 & 0 & 0 & 1 & 0 & 0 & 0 & 1 \\
\hline 3 & 0 & 0 & 3 & 3 & 3 & 0 & 0 & 0 & 0 \\
\hline 3 & 0 & 0 & 0 & 3 & 2 & 0 & 0 & 0 & 2 \\
\hline 2 & 0 & 0 & 3 & 0 & 1 & 0 & 0 & 0 & 1 \\
\hline 2 & 0 & 0 & 3 & 2 & 2 & 2 & 0 & 0 & 2 \\
\hline 2 & 0 & 0 & 2 & 2 & 2 & 2 & 3 & 0 & 3 \\
\hline 2 & 0 & 0 & 0 & 3 & 0 & 0 & 0 & 0 & 0 \\
\hline 3 & 0 & 0 & 0 & 2 & 2 & 3 & 0 & 0 & 2 \\
\hline 3 & 0 & 0 & 0 & 0 & 0 & 0 & 0 & 0 & 0 \\
\hline 3 & 0 & 0 & 3 & 3 & 0 & 0 & 0 & 0 & 2 \\
\hline 3 & 0 & 0 & 3 & 0 & 2 & 0 & 0 & 0 & 0 \\
\hline
\end{tabular}

Antecedent Theme Scores

\begin{tabular}{|l|l|}
\hline Crisis & 1.11 \\
\hline Leaders & 0.80 \\
\hline Networks & 0.13 \\
\hline Broker & 1.00 \\
\hline
\end{tabular}


Stage

Question \#

Participant 01

Participant 02

Participant 03

Participant 04

Participant 05

Participant 06

Participant 07

Participant 08

Participant 09

Participant 10

Participant 11

Participant 12

Participant 13

Participant 14

Participant 15

Question

Scores

2

\begin{tabular}{c|c}
\hline $\begin{array}{c}\text { Recognize } \\
\text { inter- } \\
\text { dependence }\end{array}$ & $\begin{array}{c}\text { Consensus of } \\
\text { legitimate } \\
\text { stakeholders }\end{array}$
\end{tabular}

3

Problem-setting

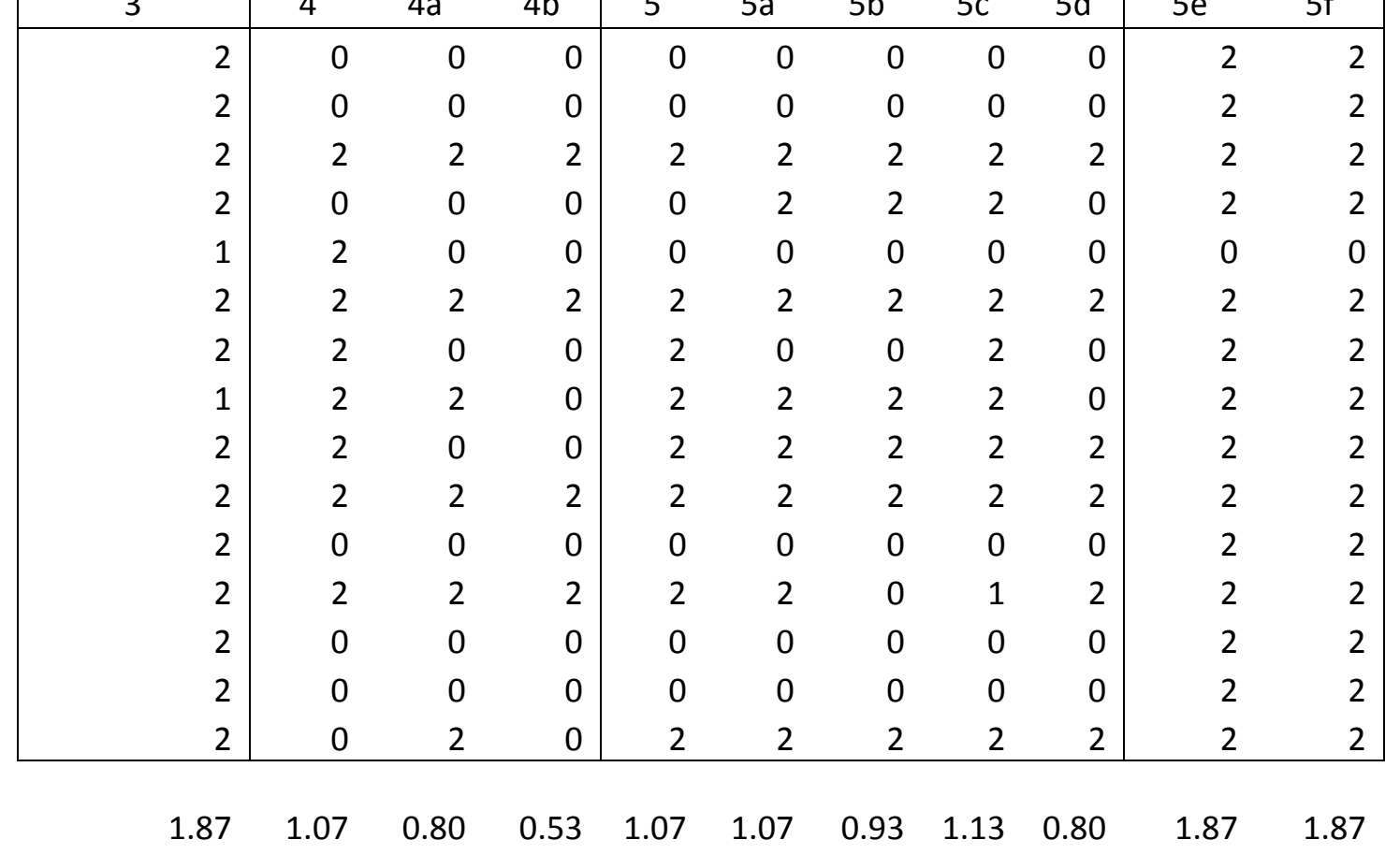

Problem-setting Theme Scores

\begin{tabular}{|l|l|}
\hline Recognize interdependence & 2.13 \\
\hline Consensus of legitimate stakeholders & 0.80 \\
\hline Common problem definition & 1.00 \\
\hline $\begin{array}{l}\text { Perceived benefits/costs to } \\
\text { stakeholders }\end{array}$ & 1.87 \\
\hline
\end{tabular}


Stage

Theme

Question \#

Participant 01

Participant 02

Participant 03

Participant 04

Participant 05

Participant 06

Participant 07

Participant 08

Participant 09

Participant 10

Participant 11

Participant 12

Participant 13

Participant 14

Participant 15

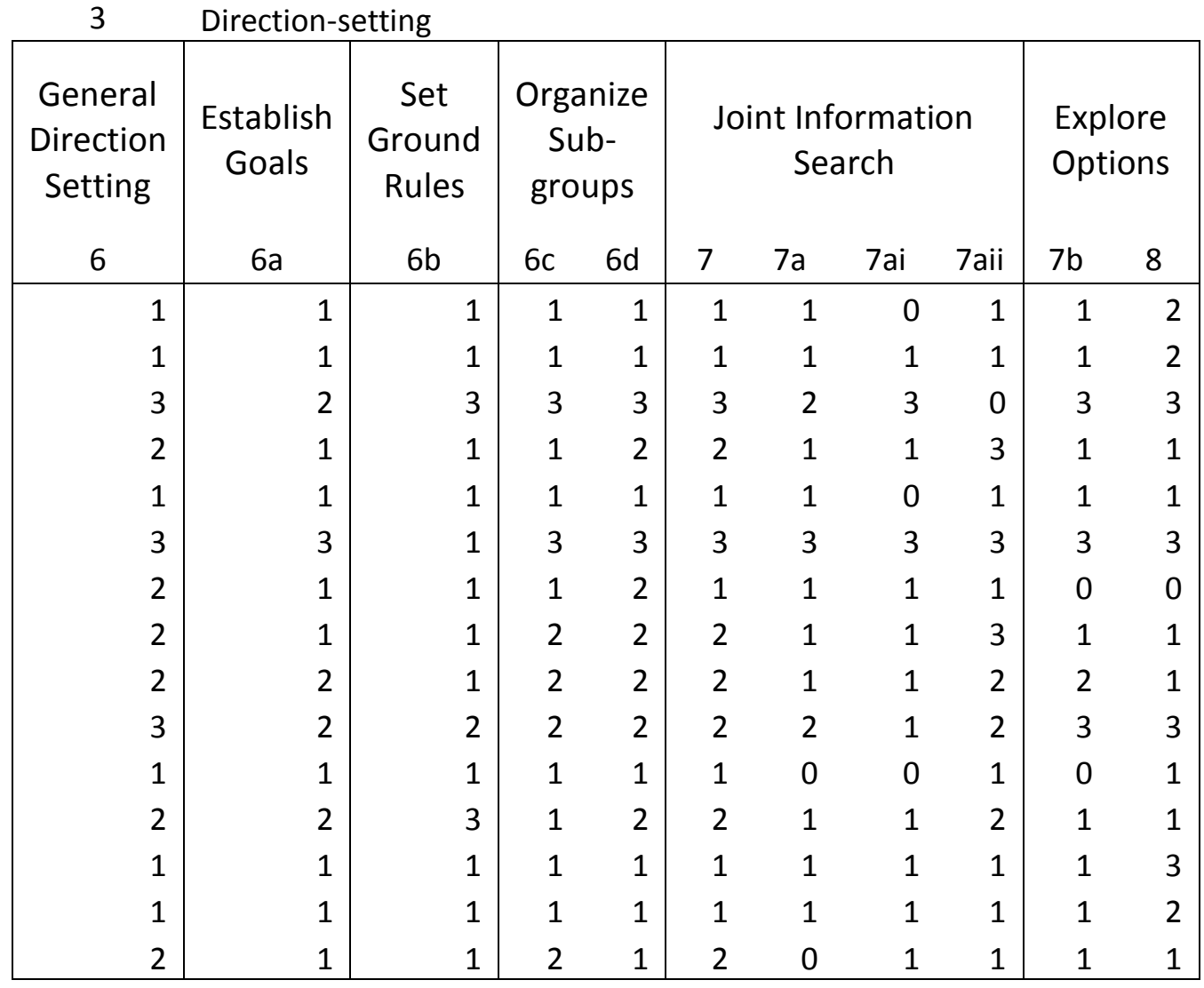

Direction-setting Theme Scores

\begin{tabular}{|l|l|}
\hline General Direction Setting & 1.80 \\
\hline Establish Goals & 1.40 \\
\hline Set Ground Rules & 1.33 \\
\hline Organize Sub-groups & 1.60 \\
\hline Joint Information Search & 1.35 \\
\hline Explore Options & 1.50 \\
\hline
\end{tabular}




\begin{tabular}{|c|c|c|c|c|c|}
\hline \multirow{3}{*}{$\begin{array}{l}\text { Stage } \\
\text { Theme } \\
\text { Question \# }\end{array}$} & \multicolumn{5}{|c|}{ Structuring } \\
\hline & \multicolumn{2}{|c|}{$\begin{array}{c}\text { Roles } \\
\text { assigned }\end{array}$} & \multirow{2}{*}{$\begin{array}{c}\text { Tasks } \\
\text { elaborated } \\
8 b \\
\end{array}$} & \multicolumn{2}{|c|}{$\begin{array}{c}\text { Monitoring and } \\
\text { control systems } \\
\text { designed }\end{array}$} \\
\hline & $8 a$ & 8ai & & $8 c$ & $8 d$ \\
\hline Participant 01 & 0 & 0 & 0 & 0 & 0 \\
\hline Participant 02 & 0 & 0 & 0 & 0 & 0 \\
\hline Participant 03 & 2 & 2 & 0 & 2 & 2 \\
\hline Participant 04 & 1 & 0 & 0 & 0 & 0 \\
\hline Participant 05 & 0 & 0 & 0 & 0 & 0 \\
\hline Participant 06 & 3 & 2 & 0 & 2 & 0 \\
\hline Participant 07 & 0 & 0 & 0 & 0 & 0 \\
\hline Participant 08 & 2 & 0 & 0 & 2 & 0 \\
\hline Participant 09 & 2 & 0 & 0 & 1 & 2 \\
\hline Participant 10 & 2 & 0 & 0 & 3 & 2 \\
\hline Participant 11 & 0 & 0 & 0 & 0 & 0 \\
\hline Participant 12 & 0 & 0 & 0 & 2 & 2 \\
\hline Participant 13 & 0 & 0 & 0 & 0 & 0 \\
\hline Participant 14 & 0 & 0 & 0 & 0 & 0 \\
\hline Participant 15 & 2 & 0 & 0 & 0 & 0 \\
\hline 2uestion & & & & & 2 \\
\hline
\end{tabular}

Structuring Theme Scores

\begin{tabular}{|l|l|}
\hline Roles assigned & 0.60 \\
\hline Tasks elaborated & 0.00 \\
\hline $\begin{array}{l}\text { Monitoring and control systems } \\
\text { designed }\end{array}$ & 0.67 \\
\hline
\end{tabular}


Stage

Theme

Question \#

Participant 01

Participant 02

Participant 03

Participant 04

Participant 05

Participant 06

Participant 07

Participant 08

Participant 09

Participant 10

Participant 11

Participant 12

Participant 13

Participant 14

Participant 15

Question

Scores

\begin{tabular}{|c|c|}
\hline & Outcomes \\
\hline Impacts & Programs \\
\hline 9 & $9 a$ \\
\hline 0 & \\
\hline 2 & \\
\hline 3 & \\
\hline 3 & \\
\hline 0 & \\
\hline 2 & \\
\hline 2 & \\
\hline 2 & \\
\hline 3 & \\
\hline 2 & \\
\hline 2 & \\
\hline 0 & \\
\hline 2 & \\
\hline 0 & 0 \\
\hline 2 & 1 \\
\hline 1.67 & 0.47 \\
\hline \multicolumn{2}{|l|}{ Scores } \\
\hline & 1.85 \\
\hline & 1.70 \\
\hline & 0.47 \\
\hline
\end{tabular}

Outcomes Theme Scores

\begin{tabular}{|l|l|}
\hline Impacts & 1.85 \\
\hline Benefits & 1.70 \\
\hline Programs & 0.47 \\
\hline
\end{tabular}

